NBER WORKING PAPER SERIES

\title{
JOB SEEKERS' PERCEPTIONS AND EMPLOYMENT PROSPECTS: HETEROGENEITY, DURATION DEPENDENCE AND BIAS
}

\author{
Andreas I. Mueller \\ Johannes Spinnewijn \\ Giorgio Topa \\ Working Paper 25294 \\ http://www.nber.org/papers/w25294 \\ NATIONAL BUREAU OF ECONOMIC RESEARCH \\ 1050 Massachusetts Avenue \\ Cambridge, MA 02138 \\ November 2018
}

\begin{abstract}
We thank Ned Augenblick, Raj Chetty, Stefano DellaVigna, Erik Eyster, Manolis Galenianos, Francois Gerard, Martin Hackman, Nathan Hendren, Greg Kaplan, Peter Kuhn, Atilla Lindner, Brendan Price, Matthew Rabin, Emmanuel Saez, Dan Silverman, Dmitry Taubinsky and Basit Zafar, and seminar participants at CalPoly, CEMFI, Harvard, LSE, NYFed, UC Berkeley, UC Davis, UCLA, UC Santa Barbara, UC San Diego, AEA Meetings San Diego, NBER Summer Institute, the T2M conference, TEC conference and EM3C conference for helpful comments and suggestions. We also thank Luis Armona, Jack Fisher, Nicole Gorton, Raymond Lim, Prakash Mishra, Anushka Mitra, Thomas Monk, Mathilde Muñoz, Will Parker, Ashesh Rambachan and Lauren Thomas for their excellent research assistance. Johannes Spinnewijn acknowledges financial support from ERC grant 716485. The views expressed here are our own and do not necessarily reflect those of the Federal Reserve Bank of New York, the Federal Reserve System, or the National Bureau of Economic Research.
\end{abstract}

NBER working papers are circulated for discussion and comment purposes. They have not been peerreviewed or been subject to the review by the NBER Board of Directors that accompanies official NBER publications.

(C) 2018 by Andreas I. Mueller, Johannes Spinnewijn, and Giorgio Topa. All rights reserved. Short sections of text, not to exceed two paragraphs, may be quoted without explicit permission provided that full credit, including (C) notice, is given to the source. 
Job Seekers' Perceptions and Employment Prospects: Heterogeneity, Duration Dependence and Bias

Andreas I. Mueller, Johannes Spinnewijn, and Giorgio Topa

NBER Working Paper No. 25294

November 2018, Revised May 2020

JEL No. E24,J6,J64

\begin{abstract}
This paper analyses job seekers' perceptions and their relationship to unemployment outcomes to study heterogeneity and duration dependence in both perceived and actual job finding. Using longitudinal data from two comprehensive surveys, we document that elicited beliefs are (1) strongly predictive of actual job finding, (2) subject to an optimistic bias that is larger for the long-term unemployed, and (3) not revised downward when job seekers remain unemployed. We exploit the joint observation of beliefs and ex-post realizations, to disentangle heterogeneity and duration dependence in true job finding rates. To this purpose, we estimate non-parametric bounds as well as a reduced-form statistical framework that allows for elicitation errors and systematic biases in beliefs. We find a substantial amount of heterogeneity in true job finding rates, accounting for most of the observed decline in job finding rates over the spell of unemployment. We also find that job seekers' beliefs systematically under-react to these differences in job finding rates. We show theoretically and quantify in a calibrated model of job search how these biased beliefs contribute to the slow exit out of unemployment and can explain more than 10 percent of the incidence of long-term unemployment.
\end{abstract}

Andreas I. Mueller

The University of Texas at Austin

Department of Economics

2225 Speedway

Austin, TX 78712

and NBER

andimueller@utexas.edu

Johannes Spinnewijn

Department of Economics

London School of Economics, Houghton Street

London, WC2A 2AE

J.Spinnewijn@1se.ac.uk
Giorgio Topa

Federal Reserve Bank of New York

Research \& Statistics Group

33 Liberty Street

New York, NY 10045

giorgio.topa@ny.frb.org 


\section{Introduction}

A critical challenge for unemployment policy is the high incidence of long-term unemployment. While long unemployment durations and a large share of long-term unemployed have been a common phenomenon in European countries (see Ljungqvist and Sargent [1998] and Machin and Manning [1999]), the Great Recession has imported this concern to the US as well (Kroft et al. [2016]). ${ }^{1}$ The consequences of job loss can be large, but especially so for people who get stuck in longs spells of unemployment (e.g., Jacobson et al. [1993], Kolsrud et al. [2018]). Moreover, the high incidence of long-term unemployment seems indicative of substantial frictions in the search and matching process (e.g., Clark and Summers [1979]), and can contribute to the persistence of employment shocks (e.g., Pissarides [1992]).

An ubiquitous empirical finding in the literature is the negative duration dependence of exit rates out of unemployment. As it is crucial for formulating policy responses, understanding why employment prospects are worse for the long-term unemployed has been the topic of a long literature. ${ }^{2}$ In theory, long-term unemployment may reduce a worker's chances to find a job (e.g., due to skill-depreciation or duration-based employer screening), but less employable workers also select into long-term unemployment. Empirically, separating the role of duration-dependent forces from heterogeneity across job seekers has been a challenge until today. Since the seminal work by Lancaster [1979] and Heckman and Singer [1984] among others, several studies have tried to estimate or calibrate the contribution of different forces to the negative duration dependence in exit rates out of unemployment. Direct evidence on the potential role of heterogeneity has been particularly limited. ${ }^{3}$

This paper takes a novel approach to address this question, using newly available data on unemployed job seekers' perceptions about their employment prospects together with actual labor market transitions. We present a conceptual framework that takes advantage of our ability to jointly observe job seekers' perceptions and actual job finding to identify heterogeneity in true job finding rates and separate dynamic selection from true duration dependence in explaining the observed decline in job finding. The key idea underlying identification in this framework is that the covariance between perceptions and actual job finding helps uncovering the extent of ex-ante heterogeneity in true job finding probabilities. The predictable variation in job finding provides a lower bound on the ex-ante heterogeneity in job finding. Beliefs can also be used in combination with a model that relates job seekers' elicited beliefs to their job finding probability to estimate the heterogeneity in the latter. This builds on recent work using risk elicitations to estimate heterogeneity in ex-ante risks in Hendren [2013, 2017].

Our analysis goes further in two important dimensions. Both are key to uncover the heterogeneity in job finding that contributes to the observed duration dependence and are relevant by themselves. First, in addition to idiosyncratic error in the beliefs (Hendren [2013]), we allow job seekers' beliefs to

\footnotetext{
${ }^{1}$ While the share of long-term unemployed workers (longer than six months) has been consistently above $50 \%$ in most European countries in recent decades, in the US this share rose from $20 \%$ to just below $50 \%$ in the aftermath of the Great Recession. In 2019, the share of LT unemployed was $50.4 \%$ and $20.3 \%$ in the EU and the US respectively (Eurostat; CPS).

${ }^{2}$ See Shimer and Werning [2006], Pavoni [2009] and Kolsrud et al. [2018] for the consequences for the design of the unemployment benefit profile. See Pavoni and Violante [2007], Spinnewijn [2013] and Wunsch [2013] for the consequences on the design of workfare, job search assistance and training programs.

${ }^{3}$ For a review of the relevant literature, see Machin and Manning [1999] who write: 'To conclude, it does not really seem possible in practice to identify separately the effect of heterogeneity from that of duration dependence without making some very strong assumptions about functional form which have no foundation in any economic theory.' See Kroft et al. [2013], Alvarez et al. [2016], Jarosch and Pilossoph [2018] and Farber et al. [2018] for recent examples in this literature.
} 
systematically over- or under-react to differences in job finding, either across job seekers or over the unemployment spell. This bias affects the covariance between perceptions and job finding and thus helps uncovering the heterogeneity in job finding from that covariance. We identify this bias by leveraging variation in job finding rates at different unemployment durations. Second, we allow for transitory differences in job seekers' job finding within a spell (e.g., temporary spells of reduced search, vacancy supply shocks), which do not contribute to the observed decline in job finding rates through dynamic selection. We show that we can separately identify permanent and transitory differences in job finding using the covariances between job finding and contemporaneous vs. lagged beliefs.

We turn to the data to estimate the relevant moments in our conceptual framework and document a number of novel facts about job seekers' perceptions. We use two distinct surveys, which elicited unemployed job seekers' beliefs about their chances of re-employment - which we thus refer to as the job finding probability. The first survey is the Survey of Consumer Expectations (SCE), which started in December 2012 and is run by the Federal Reserve Bank of New York. The survey has a rotating panel structure where a representative sample of about 1,300 household heads is interviewed every month for a period of up to 12 months (see Armantier et al. [2017] for details). The second survey is the Survey of Unemployed Workers in New Jersey, which surveyed a large sample of unemployment insurance recipients in NJ every week from October 2009 to March 2010 (see Krueger and Mueller [2011] for details). A crucial feature of our data is its longitudinal nature, which allows to compare reported perceptions to ex-post realizations as well as to analyze the evolution of perceptions over the spell of unemployment for the same individuals. Both surveys also elicited job seekers' beliefs about job finding at different horizons and/or in different ways, so we can study robustness to the elicitation method and use multiple measurements to reduce elicitation error (Morrison and Taubinsky [2019]).

The empirical analysis provides three main results. First, the perceived job finding probabilities significantly and strongly predict actual job finding at the individual level. This holds even when we control for a rich set of observable co-variates. In the SCE, the job finding probability is around .5 percentage points higher for an individual who reports his or her job finding probability to be 1 percentage point higher. Moreover, we find that the covariances of job finding with contemporaneous beliefs vs. with lagged beliefs are of similar size, suggestive of the persistence in job seekers' prospects. We use the empirical correlation between beliefs and job finding to inform our non-parametric bounds, which indicate substantial heterogeneity in job finding that can explain at least half of the observed decline in job finding.

Second, comparing the perceived and actual job finding across job seekers, we confirm in our data Spinnewijn's (2015) finding of an overall optimistic bias, but furthermore, we find that the bias rises strongly with unemployment duration. In the SCE, the elicited beliefs are in fact unbiased for job seekers at the start of the unemployment spell, but the observed decline in perceived job finding probabilities is only half of the observed decline in actual job finding rates. Hence, the long-term unemployed substantially over-estimate their probability of finding a job. We use the under-reaction in beliefs to inform our model of beliefs, and find that - combined with the high covariance between beliefs and job finding - it suggests that potentially all of the observed declined in job finding can be explained by dynamic selection.

Third, when using only within-person variation, we find that, if anything, job seekers report slightly 
higher job-finding probabilities the longer they are unemployed. This result is perhaps surprising, given the large empirical literature trying to identify the true duration dependence in job finding and often arguing that it is negative. It is consistent, however, with our reduced-form analysis that finds substantial heterogeneity in job finding, thus leaving limited scope for true negative duration dependence.

To jointly estimate the heterogeneity and dynamics of the true and perceived job finding rates, we propose a statistical model that allows us to infer the parameters of interest with exact equivalents of the moments in the data. Our model can allow for a differential response of beliefs to cross-sectional and longitudinal variation in job finding, using both changes in the means of perceived and true job finding and their covariances over the spell. We prove the semi-parametric identification of a stylized two-period version of the model and verify that the identification arguments hold up in the estimation of the fullyspecified dynamic model, showing how parameter estimates change with the empirical moments.

The estimates from our statistical model confirm the substantial heterogeneity in true job finding rates, accounting for almost all of the observed decline in job finding rates over the spell of unemployment (84.7 percent; s.e. 36.4 ). True duration dependence explains the remainder and thus plays a limited role, also in comparison to the importance it has been attributed in prior work. In line with the reducedform evidence, the pre-dominant role played by dynamic selection proves to be robust to alternative distributional and functional-form assumptions in the statistical model. The estimation also confirms the under-response of job seekers' beliefs to variation in job finding. Job seekers with a high underlying job finding rate tend to be over-pessimistic, whereas job seekers with a low job finding rate are overoptimistic. The latter remain unemployed longer, but they do not revise their beliefs downward. In the absence of significant duration dependence in true job finding, this explains why the long-term unemployed are over-optimistic. Our statistical framework is parsimoniously specified but fits the key moments in our data very well, whereas restricted versions of the model perform radically worse.

We finally study how the under-reaction in job seekers' perceptions itself can contribute to the observed decline in job finding and the incidence of long-term unemployment. To this purpose, we set up a job search model à la McCall [1970], introducing heterogeneity and duration dependence in job offer rates and allowing for biased beliefs. The key mechanism that we highlight in this structural model is that job seekers' behavior mitigates the mechanical effect of differences in job offer rates on job finding rates, but only when these differences are perceived as such. If perceptions under-respond to differences in job offer rates, either across job seekers or over the unemployment spell, the resulting differences in job finding rates will be amplified. The larger variation in job finding leads to a stronger decline in the observed job finding. To quantify the impact on the incidence of long-term unemployment, we calibrate the model with moments from our data and the statistical model. Correcting the biases in beliefs reduces the share of workers who are unemployed for longer than 6 months, by $2-3$ percentage points. Defining the incidence of long-term unemployment as the ratio of the LT vs. ST unemployment rate, we find that the biases in beliefs jointly explain $11-12 \%$ of this incidence.

Our paper aims to contribute to three different strands in the literature. As discussed before, we try to contribute to the large literature studying the different sources of duration dependence in job finding. We use a novel strategy to separate dynamic selection from true duration dependence, finding a predominant role played by dynamic selection. Recent resume audit studies (e.g., Kroft et al. [2013]) have documented large declines in callback rates over the unemployment the spell, suggesting the importance 
of true duration dependence instead. The evidence from audit studies themselves, however, is mixed (see Farber et al. [2018]) and the duration dependence in callback rates may not translate into duration dependence in job finding (e.g., Jarosch and Pilossoph [2018]). Alvarez et al. [2016] use data on multiple unemployment spells instead and find evidence for positive duration dependence. ${ }^{4}$ In general, direct evidence on the role of heterogeneity has been limited to the dynamic selection in longer unemployment spells based on observables, which tend to play a moderate role only (e.g., Kroft et al. [2016]).

Second, our analysis of the biases in beliefs relates to a strand in the behavioral labor economics literature trying to understand the role of information frictions and behavioral biases in the job search process. The new survey evidence confirms the optimistic bias in job seekers' beliefs (Spinnewijn [2015], Arni [2017], Conlon et al. [2018]) and the persistence in beliefs seems consistent with the lack of updating of reservation wages over the unemployment spell (Krueger and Mueller [2016], Drahs et al. [2018]). ${ }^{5}$ Adding to this evidence, our paper highlights the under-reaction in beliefs to differences in job finding, both across workers and over the unemployment spell, and shows the importance of the optimistic bias among the long-term unemployed in particular. The biases in beliefs add to other behavioral frictions distorting job search, like present bias (DellaVigna and Paserman [2005]), reference-dependence (DellaVigna et al. [2017]) and locus-of-control (Caliendo et al. [2015], Spinnewijn [2015]), and indicate the potential for information policies in particular. ${ }^{6}$

Third, our work relates to recent papers using survey elicitations to improve the estimation or calibration of structural models of job search. For example, Hall and Mueller [2018] use elicited reservation and offered wages in the New Jersey survey to identify different sources of wage dispersion in a search model. Conlon et al. [2018] relate expectations to realized wage offers in the SCE and focus on the updating of beliefs in response to wage offers to estimate a model of on- and off-the-job search with learning frictions. Similar to our numerical analysis, they then use the estimated structural model to assess the quantitative importance of these learning frictions. That job seekers' beliefs have predictive value has been documented elsewhere (Spinnewijn [2015], Arni et al. [2016]), but to our knowledge, it has never been used to bound the heterogeneity in job finding and its contribution to the observed decline in job finding. Elicited expectations are increasingly used in other applications, too, for example to study educational and occupational choices (e.g., Delavande and Zafar [2014], Arcidiacono et al. [2014], Wiswall and Zafar [2015]) or household finance (e.g., Fuster et al. [2018] and Crump et al. [2018]).

The paper proceeds as follows. Section 2 discusses the data. Section 3 sets up a conceptual framework and documents the basic facts in the data. Section 4 sets up the statistical model and estimates heterogeneity and duration dependence in perceived and actual job finding. Section 5 presents a behavioral model of job search, including numerical results on the impact of biases in beliefs. Section 6 concludes.

\footnotetext{
${ }^{4}$ See also Honoré [1993] who proves identification with multiple unemployment spells in the context of the mixed proportional hazard model. The comparative advantage of our approach is that it also captures heterogeneity that is specific to a given unemployment spell (e.g., savings, family structure, etc.).

${ }^{5}$ In a related experiment with uncertainty about job search ability, Falk et al. [2006] find limited updating in beliefs.

${ }^{6}$ See also the experimental evidence in Belot et al. [2020] who show how tailored information can change job seekers' scope of search and Altmann et al. [2018] who show how information treatments can improve the re-employment outcomes.
} 


\section{Data}

As briefly discussed in the introduction, our empirical analysis builds on two distinct surveys. The first survey is the Survey of Consumer Expectations (SCE), which is run by the New York Federal Reserve Bank and surveys a representative sample of about 1,300 household heads across the US. The sample is a rotating panel where each individual is surveyed every month for up to 12 months (see Armantier et al., 2013, for details). Our sample period stretches from December 2012 to June 2019 during which 948 job seekers have been surveyed while unemployed. The second survey is the Survey of Unemployed Workers in New Jersey, which was collected by Alan Krueger and Andreas Mueller and surveyed around 6,000 unemployed job seekers (see the appendix of Krueger and Mueller [2011] for details). In what follows, we refer to the survey as the Krueger-Mueller (KM) survey. The surveyed job seekers were unemployment insurance recipients in October 2009 and interviewed every week for 12 weeks until January 2010. The long-term unemployed were surveyed for an additional twelve weeks until March 2012.

Both surveys elicit the beliefs individuals hold when unemployed about their prospects to become employed again. In the SCE, unemployed job seekers report the probability they expect to be employed again both within the next 3 and 12 months. In the KM survey, job seekers report the probability that they expect to be re-employed within the next 4 weeks, as well as how many weeks they expect it will take before they are employed again. ${ }^{7}$ The beliefs are elicited up to 12 times (5 times) in the SCE (KM survey) for job seekers who remain unemployed. The KM survey is a weekly survey, but the belief questions were administered only every four weeks, starting about one month into the survey period. ${ }^{8}$

In addition to the elicited beliefs, both surveys contain information on the individuals' employment outcomes, and hence, we can link perceptions to actual outcomes for the same individuals. The SCE is superior to the KM survey in this respect because it suffers less from attrition and skipping. As reported by Armantier et al. [2017], out of those who completed one interview in the SCE, 74 percent completed two interviews. Attrition is much lower after the second interview and, in fact, 58 percent completed all 12 monthly interviews of the SCE panel. In addition, we find that nearly half of surveys where the respondent was unemployed were followed by three consecutive monthly interviews, which is the sub-sample that we use when comparing elicitations to employment outcomes over the next three months. Even if there was no attrition, this number would be at most 75 percent, since unemployed respondents who are rotating out of the panel survey do not have three monthly follow-up surveys (this affects anyone in interviews 10, 11 and 12). ${ }^{9}$ In the KM survey, out of those 2,384 individuals who completed the belief questions at least once, 60 percent completed the belief questions twice, but only 21 percent completed them more than twice. To a large extent, this drop-off in participation in the KM survey is simply due to the shorter horizon of the survey. However, we also find that the elicited belief about the probability of finding a job was negatively related to the number of follow-up

\footnotetext{
${ }^{7}$ Both are online surveys. The KM survey asked participants to slide a bar between 0 and 100, randomizing the initial position. The exact questions and response format is shown in Appendix A.

${ }^{8}$ Given that many individuals had already found a job after a month or left the survey for other reasons, and given the lower interview frequency of the belief questions, the sample of interest for our study is substantially smaller than the full weekly panel of the KM survey. Note also that for individuals who did not complete a weekly survey exactly four weeks after the last time the belief questions were administered, the belief questions were administered at the next interview.

${ }^{9}$ Respondents in the SCE who failed to complete three interviews consecutively are not invited back to the survey.
} 
Table 1: Descriptive Statistics for the Survey of Consumer Expectations (SCE) and the Krueger-Mueller (KM) Survey, and Comparions to the Current Population Survey (CPS)

\begin{tabular}{lcccc}
\hline & SCE & CPS & KM Survey & CPS NJ \\
(in \%) & $2012-19$ & $2012-19$ & $2009-10$ & $2009-10$ \\
\hline High-School Degree or Less & 44.5 & 49.0 & 32.5 & 46.6 \\
Some College Education & 32.4 & 29.8 & 37.4 & 24.6 \\
College Degree or More & 23.1 & 21.2 & 30.1 & 28.7 \\
Ages 20-34 & 25.4 & 47.6 & 38.1 & 39.4 \\
Ages 35-49 & 33.5 & 28.4 & 35.4 & 33.4 \\
Ages 50-65 & 41.1 & 24.0 & 26.5 & 27.2 \\
Female & 59.3 & 45.9 & 48.6 & 43.5 \\
Black & 19.1 & 22.2 & 24.4 & 21.4 \\
Hispanic & 12.5 & 20.1 & 27.5 & 22.1 \\
\hline Monthly job finding rate & & & & \\
... Full sample & 18.7 & 24.0 & 10.3 & 16.4 \\
.. Duration 0-6 months & 25.8 & 29.5 & 13.5 & 21.6 \\
.. Duration 7+ months & 12.7 & 13.4 & 9.2 & 10.0 \\
\hline \# of respondents & 948 & - & 2,384 & - \\
\# of respondents w/ at least 2 surveys & 534 & - & 1,422 & - \\
\# of survey responses & 2,597 & 211,129 & 4,803 & 2,818 \\
\hline
\end{tabular}

Notes: The SCE and KM survey are restricted to unemployed workers, ages 20-65, with interviews where the belief questions were administered. The samples for the CPS are restricted to unemployed workers, ages 20-65. In addition, the fourth column restricts the sample to the state of New Jersey. Survey weights are used for all statistics shown in the table. The monthly job finding rate in the SCE and CPS is the U-to-E transition rate between two consecutive monthly interviews. The monthly job finding rate in the KM survey is calculated as the fraction of unemployed workers who accepted a job or started working in the next four consecutive weekly interviews.

surveys completed. ${ }^{10}$ While the invitations and reminder emails explicitly stated that respondents are invited back to the survey regardless of their employment status, this suggests that the KM survey still exhibited some differential attrition by expected employment outcomes, introducing a potential bias when relating beliefs to employment outcomes later in the survey. For this reason, we focus mostly on the SCE when comparing beliefs to employment outcomes.

Table 1 compares some basic survey outcomes and demographics for the unemployed workers in the two surveys as well as the Current Population Survey (CPS). All samples are restricted to unemployed workers, ages 20-65. The sample of unemployed in the SCE is relatively small, which is due to the fact that - unlike the KM survey - the SCE samples the entire population and the sub-sample of unemployed is only a small fraction of it. Note that while the SCE is representative of the population of U.S. household heads, the CPS is representative of individuals, which can explain some of the observed differences, particularly in age. ${ }^{11}$ The KM survey's sample is representative of unemployment insurance

\footnotetext{
${ }^{10}$ We find that the elicited probability is 26 percent for those with four weekly surveys within the next four weeks, whereas it was 34 percent for those with less than four weekly survey within the next four weeks. For linking the employment outcomes to the elicited beliefs in the KM survey, we find that only about 17 percent of survey participants completed four consecutive weekly interviews following an interview where the 4-week belief question was elicited.

${ }^{11}$ Tables B1 and B2 show how sample characteristics change across the sub-samples used in the analysis.
} 
recipients in New Jersey, see Krueger and Mueller [2011] for details. The KM survey over-sampled longterm unemployed workers, but the survey includes survey weights, which adjust for both oversampling and non-response. The differences in the sampling universe also explain some of the differences in the characteristics of the unemployed between the SCE and the KM survey. The monthly job finding rate in the SCE is 18.7 percent compared to 10.3 percent in the KM survey, where the lower rate in the latter is likely due to the lower job finding rate in the immediate aftermath of the Great Recession, but may also be driven by differential attrition. In both datasets the job finding rates exhibit substantial negative duration dependence. In the SCE (KM) survey, monthly job finding rates of long-term unemployed workers are about one half (two thirds) of the job finding rates of the short-term unemployed. The job finding rate in the CPS is somewhat higher compared to the SCE, but the observed percent decline in job finding between the short- and long-term unemployed is similar across the two surveys. ${ }^{12}$

\section{Empirical Evidence}

This section presents the elicitations of job seekers' perceptions and how they relate to actual job finding. Our central objects of interest are the true and perceived job finding rate, which we denote by $T_{i, d}$ and $Z_{i, d}$ respectively, and how they differ across individuals $i$ and unemployment durations $d$. We first demonstrate conceptually how the relation between elicited beliefs and actual job finding can be used to analyze heterogeneity and duration dependence in both perceived and true job finding rates. The conceptual framework guides the reduced-form empirical evidence that we present in this section. We then add functional and distributional assumptions in the next section to estimate the full distribution of true and perceived job finding rates across job seekers and unemployment durations.

\subsection{Conceptual Framework}

An individual's job finding probability $T_{i, d}$ cannot be directly observed, nor is it possible to observe differences in job finding across individuals or how individual job finding evolves over the unemployment spell. We do, however, observe the realization $F_{i, d}$ of the job search of an unemployed individual at duration $d$, i.e., whether she finds a job $\left(F_{i, d}=1\right)$ or not $\left(F_{i, d}=0\right)$. We can also observe how the average job finding rate $E_{d}\left(T_{i, d}\right)=E_{d}\left(F_{i, d}\right)$ among the unemployed job seekers changes over the unemployment spell. This is typically found to be decreasing, as is the case in our data (see Table 1).

The observed duration dependence in job finding can be decomposed as follows: ${ }^{13}$

$$
E_{d}\left(T_{i, d}\right)-E_{d+1}\left(T_{i, d+1}\right)=E_{d}\left(T_{i, d}-T_{i, d+1}\right)+\frac{\operatorname{cov}_{d}\left(T_{i, d}, T_{i, d+1}\right)}{1-E_{d}\left(T_{i, d}\right)},
$$

where the subindex denotes the duration at which the job seekers are sampled to evaluate the corresponding moment. This decomposition clearly demonstrates how any negative duration dependence in job finding can be driven by true duration dependence in job finding, $E_{d}\left(T_{i, d}-T_{i, d+1}\right)>0$, or by the

\footnotetext{
${ }^{12}$ The comparison sample for the KM survey in the CPS includes both recipients and non-recipients, which likely explains their higher job finding rate. Krueger and Mueller [2011] show in administrative data that UI weekly exit hazard in the sample frame is $2.6 \%$ per week, or $10.0 \%$ per month, which is close to the $10.3 \%$ job finding rate in the survey.

${ }^{13}$ We provide the derivations underlying the equations in this section in Appendix C.
} 
dynamic selection of job seekers with worse re-employment prospects into prolonged unemployment, $\operatorname{cov}_{d}\left(T_{i, d}, T_{i, d+1}\right)>0$. The dynamic selection itself depends on how much heterogeneity there is in individuals' job finding and whether individuals' job finding probabilities are persistent,

$$
\operatorname{cov}_{d}\left(T_{i, d}, T_{i, d+1}\right)=\operatorname{var}_{d}\left(T_{i, d}\right)-\operatorname{cov}_{d}\left(T_{i, d}, T_{i, d}-T_{i, d+1}\right)
$$

When all heterogeneity in job finding probabilities is permanent, the contribution of dynamic selection to the observed decline in job finding is fully determined by the variance in job finding $\operatorname{var}_{d}\left(T_{i, d}\right)$. In the other extreme, where all heterogeneity in job finding probabilities is transitory, dynamic selection does not contribute to the observed decline in job finding.

The challenge is to separate the role of these forces empirically as individual job finding rates cannot be observed. Through surveys, however, we can elicit an individual's perceived job finding probability $Z_{i, d}$ and how it evolves over the unemployment spell. Importantly, when ex-ante elicitations are predictive of ex-post realizations, their relationship can be leveraged to learn about the ex-ante heterogeneity in true job finding itself. The elicited beliefs can also be compared to job seekers' average job finding to learn about biases in beliefs and their evolution over the unemployment spell.

Lower Bound on Heterogeneity If individuals had perfect information about their employment prospects, the heterogeneity in job finding chances would be fully captured by the variance in elicited beliefs. Beliefs, however, may be subject to bias and elicited with error. Still, the predictive value of individuals' elicitations can help uncovering the heterogeneity in true job finding probabilities. For binary risks the covariances of beliefs with ex-post job finding realizations and with ex-ante job finding probabilities simply coincide, $\operatorname{cov}_{d}\left(Z_{i, d}, F_{i, d}\right)=\operatorname{cov}_{d}\left(Z_{i, d}, T_{i, d}\right)$. So, when elicited beliefs are an unbiased - but potentially noisy - measure of job finding, the covariance between beliefs and ex-post job finding exactly identifies the variance in ex-ante job finding probabilities $\operatorname{var}_{d}\left(T_{i, d}\right)$ (see Hendren [2013]).

More generally, even when beliefs are biased, we can bound this variance using the Cauchy-Schwarz inequality (see Morrison and Taubinsky [2019]),

$$
\operatorname{var}_{d}\left(T_{i, d}\right) \geq \frac{\operatorname{cov}_{d}\left(Z_{i, d}, F_{i, d}\right)^{2}}{\operatorname{var}_{d}\left(Z_{i, d}\right)}
$$

For a given variance in elicitations, a larger covariance between elicitations and realizations indicates less noise in the elicited beliefs, and thus a larger variance in the job finding probabilities. When the elicited beliefs are subject to noise, we can further tighten this bound by using multiple elicitations in job seekers' beliefs, $Z_{i, d}^{k}$ (which are available in both surveys). Following a similar argument as Morrison and Taubinsky [2019], we find that the variance in job finding probabilities is bounded by

$$
\operatorname{var}_{d}\left(T_{i, d}\right) \geq \frac{\operatorname{cov}_{d}\left(Z_{i, d}^{1}, F_{i, d}\right) \operatorname{cov}_{d}\left(Z_{i, d}^{2}, F_{i, d}\right)}{\operatorname{cov}_{d}\left(Z_{i, d}^{1}, Z_{i, d}^{2}\right)}
$$

This bound relies on the elicitations not being negatively correlated, conditional on job finding chances, 
and their conditional expectation (and thus the bias) being the same. ${ }^{14}$

The bounds in (3) and (4) use only beliefs to predict the variation in job finding probabilities. More generally, from the variance decomposition, we know that any predictable variance, $\operatorname{var}_{d}\left(E_{d}\left(T_{i, d} \mid X_{i, d}\right)\right)$, provides a non-parametric lower bound on the variance in true job finding probabilities, $\operatorname{var}_{d}\left(T_{i, d}\right)$. While this holds for any set of observables, we find that job seekers' beliefs are particularly predictive.

Model of Beliefs While the non-parametric bounds are robust to biases in beliefs, we can go beyond partial identification by specifying how beliefs relate to observable variation in job finding. Consider the following model of beliefs where job seekers' elicited beliefs are an affine transformation of true job finding,

$$
Z_{i, d}=b_{0}+b_{1} T_{i, d}+\varepsilon_{i, d}
$$

with $\varepsilon_{i, d}$ capturing random error in the elicited beliefs $\left(E\left(\varepsilon_{i, d} \mid T_{i, d}\right)=0\right)$. The intercept $b_{0}$ captures a bias in perceptions that is common to all individuals. The slope parameter $b_{1}$ captures the extent to which the variation in job finding rates is perceived. The covariance between perceived and actual job finding scales the variance in true job finding rates with the slope parameter $b_{1}$,

$$
\operatorname{cov}_{d}\left(Z_{i, d}, F_{i, d}\right)=b_{1} \operatorname{var}_{d}\left(T_{i, d}\right)
$$

If job seekers' elicitations under-react to variation in job finding $\left(b_{1}<1\right)$, the covariance between perceived and actual job finding underestimates the variance in true job finding, and vice versa.

Now we can leverage the variation in job finding rates across durations to learn about the slope parameter. Intuitively, this parameter is revealed by the compression of the differences in $Z$ 's relative to the distribution of T's across durations. For the linear model, this becomes

$$
b_{1}=\frac{E_{d+1}\left(Z_{i, d+1}\right)-E_{d}\left(Z_{i, d}\right)}{E_{d+1}\left(T_{i, d+1}\right)-E_{d}\left(T_{i, d}\right)}
$$

E.g., with $b_{1}<1$, the low- $T_{i, d}$ types are more optimistic and thus over-optimism is predominant among those who fail to find a job and remain unemployed for longer. ${ }^{15}$

Note that our identification argument for $\operatorname{var}_{d}\left(T_{i, d}\right)$ continues to hold in the presence of non-classical measurement error with $E\left(\varepsilon_{i, d} \mid T_{i, d}\right)$ linear in $T_{i, d}$. While it changes the interpretation of $b_{1}$, capturing both biases and non-classical measurement error, it does not change any of the equations above. ${ }^{16} \mathrm{We}$ use the statistical model further below to probe the sensitivity of our results to the type of measurement

\footnotetext{
${ }^{14}$ Note that the lower bound in equation (3) can also be expressed as $\beta^{O L S} \operatorname{cov}_{d}\left(Z_{i, d}, F_{i, d}\right)$ where $\beta^{O L S}$ is the coefficient in the linear regression of $F_{i, d}$ on $Z_{i, d}$. Similarly, the lower bound in equation (4) can be expressed as $\beta^{I V} \operatorname{cov}_{d}\left(Z_{i, d}^{1}, F_{i, d}\right)$ where $\beta^{I V}$ is the coefficient in the linear regression of $F_{i, d}$ on $Z_{i, d}^{1}$, but where $Z_{i, d}^{1}$ is instrumented for by $Z_{i, d}^{2}$.

${ }^{15}$ In principle, we could use other observable variation in job finding rates to estimate how perceived and true job finding relate, for example between more and less educated job seekers. However, in that case we would need to assume that the average bias remains constant across workers with different education (or any other observable used). Using time spent unemployed to obtain variation in job finding rates gives the advantage that we can actually observe how job seekers' beliefs change over the spell, allowing us to relax the assumption that perceptions respond in the same way to variation in job finding across and within job seekers. We show this in the statistical model in Section 4.

${ }^{16}$ To be precise, the covariance between elicitations and job finding in (6) still pins down the variance of job finding probabilities, subject to the attenuation factor $b_{1}$, which is still identified by the compression of the differences in $Z$ 's relative to the differences in T's across durations in (7).
} 
error, and find that our results are generally robust.

Persistence in Job Finding The decomposition in equations (1) and (2) highlights that transitory heterogeneity in job finding does not contribute to dynamic selection. Only if differences in job finding probabilities are persistent, does the lower bound on heterogeneity translate to an upper bound on the role of true duration dependence. We can again use the relationship between actual job finding and elicited beliefs, but now using the lagged rather than contemporaneous beliefs, to shed light on the persistence in job finding probabilities. For the linear beliefs model, we have

$$
\operatorname{cov}_{d+1}\left(Z_{i, d}, F_{i, d+1}\right)=b_{1} \operatorname{cov}_{d+1}\left(T_{i, d}, T_{i, d+1}\right),
$$

which relates to the dynamic selection term in equation (1). When the heterogeneity in job finding can be represented by permanent differences and random transitory shocks, $T_{i, d}=T_{i}+\tau_{i, d}$, their respective role is fully captured by the difference in predictive value of lagged and contemporaneous beliefs. ${ }^{17}$

In what follows, we describe the elicited beliefs, how they relate to actual job finding, and how they change over the spell of unemployment. We use this evidence to gauge the importance of the different forces underlying the observed duration dependence in job finding, following the decomposition arguments above. We then develop these arguments in full in the context of a statistical model in Section 4. It is important again to note that our identification of the distribution of actual job finding does not rely on separating the role of biases vs. elicitation errors, nor does it depend on how job seekers' search strategy relates to the elicited beliefs. We do, however, take a stance on both issues when we study the impact of beliefs on search in Section 5 .

\subsection{Elicited Beliefs about Job Finding}

The two surveys ask unemployed job seekers to report their chances of finding a job that they will accept, which we refer to as the job finding probability (see Appendix A for the wording of the questions asked in both surveys). Figure 1 shows the histograms of these perceived job finding probabilities at the threemonth horizon in the SCE and the one-month horizon in the KM survey. ${ }^{18}$ For both surveys there is substantial dispersion over the entire range of potential probabilities. The perceived probabilities over the one-month horizon in the KM survey are more skewed to the left than the perceived probabilities over the three-month horizon in the SCE and the former are relatively high compared to the latter. While the elicitation horizon may be relevant, this comparison is difficult because it is across different samples. A common issue when eliciting probabilities is that subjects may bunch at round numbers. We do observe significant bunching for both measures, in particular at 50\%, as apparent in Figure $1 .{ }^{19}$

\footnotetext{
${ }^{17}$ In Appendix C, we show indeed that, in this case, $\operatorname{cov}_{d+1}\left(Z_{i, d+1}, F_{i, d+1}\right)-\operatorname{cov}_{d+1}\left(Z_{i, d}, F_{i, d+1}\right)=b_{1} \operatorname{var}_{d}\left(\tau_{i, d}\right)\left[1-\frac{\operatorname{var}_{d}\left(T_{i}\right)}{\left[1-E_{d}\left(T_{i, d}\right)\right]^{2}}\right]$.

${ }^{18}$ The question in the KM survey was for a 4-week period, but for simplicity we refer to it as a 1-month period.

${ }^{19}$ Manski [2004] discusses other surveys where respondents use the entire range of probabilities from 0 to 100 , as well as additional evidence that respondents are willing and able to provide meaningful probabilistic responses.
} 
Figure 1: Histogram of Elicitations of the 3-Month Job Finding Probability in the SCE (left panel) and the 1-Month Probability in the KM survey (right panel)
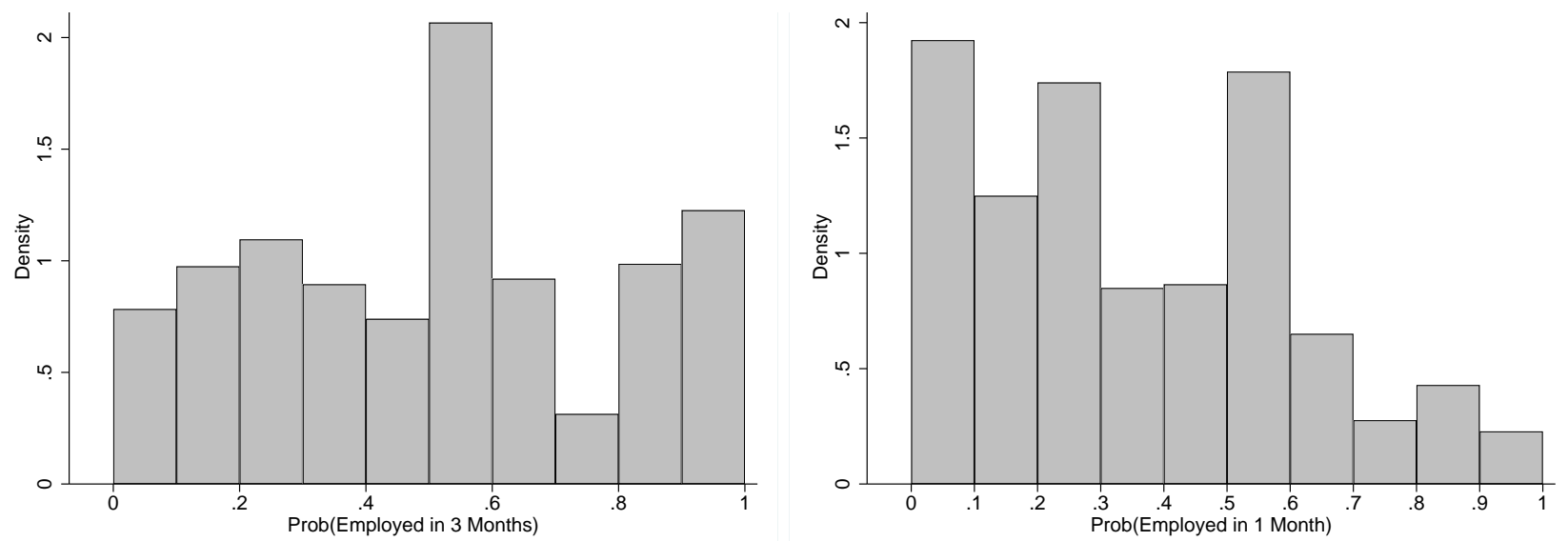

To assess the validity of our elicitations and the robustness to bunching, we compare the elicited beliefs about job finding at different horizons in the same sample of job seekers. In the SCE, job seekers report the perceived job finding probability at a three-month horizon as well as at a twelve-month horizon. We compare the distribution of the twelve-month job finding probabilities to the imputed job finding probability over twelve months based on the elicitation over a three-month horizon (see Appendix Figure D3). We find a high correlation of 0.76 between the two measures at the individual level. We also find that the distribution of the ratio of the two statistics has a mode of 1 (see Appendix Figure D4). This suggests that many survey respondents submit responses that are fully consistent with each other, at least if they believe that they live in a stationary world where the unemployment probability does not change over the spell of unemployment.

In the KM survey, job seekers report not only the perceived probability of finding employment, but also how many weeks they expect it will take to be employed again. The inverse of the expected unemployment duration equals the perceived job finding rate averaged over the remaining unemployment spell. Hence, the elicited average job finding rate and the job finding rate for next month should be related, again depending on whether an individual expects the job finding rate to change over the unemployment spell. ${ }^{20}$ Importantly, the alternative elicitation has the advantage that it avoids the sharp bunching at 0,50 and 100, but except for the difference in bunching, the distribution looks very similar to the distribution of the perceived job finding rates for the next month. The individual-level correlation between the two measures equals 0.65 (see Appendix Figure D3). ${ }^{21}$ The similarity between the different measures is also confirmed by Figure D4 in the Appendix, which plots the distribution of the ratio of the two measures, indicating that for most peoples the two measures indeed coincide.

\footnotetext{
${ }^{20}$ To be precise, given that the question was phrased in weeks, we impute the implied 1-month re-employment probability as $1-\left(1-\frac{1}{x}\right)^{4}$, where $x$ is the elicited remaining weeks unemployed.

${ }^{21}$ Note that throughout the paper we trim extreme outlier observations: In the KM survey, we eliminate 51 responses where the elicited and imputed probability are more than 75 percentage points apart and thus clearly inconsistent with each other. In the SCE, we eliminate 316 observations, where the 3-month probability is larger than the 12-month probability. We report robustness checks in the Appendix for not imposing these restrictions. If we do not impose this restriction, the correlation coefficient between the two measures remains high at 0.56 in the KM survey and 0.72 in the SCE.
} 
Figure 2: Averages of Actual Job Finding Probabilities, by Bins of Elicited Probabilities (SCE)

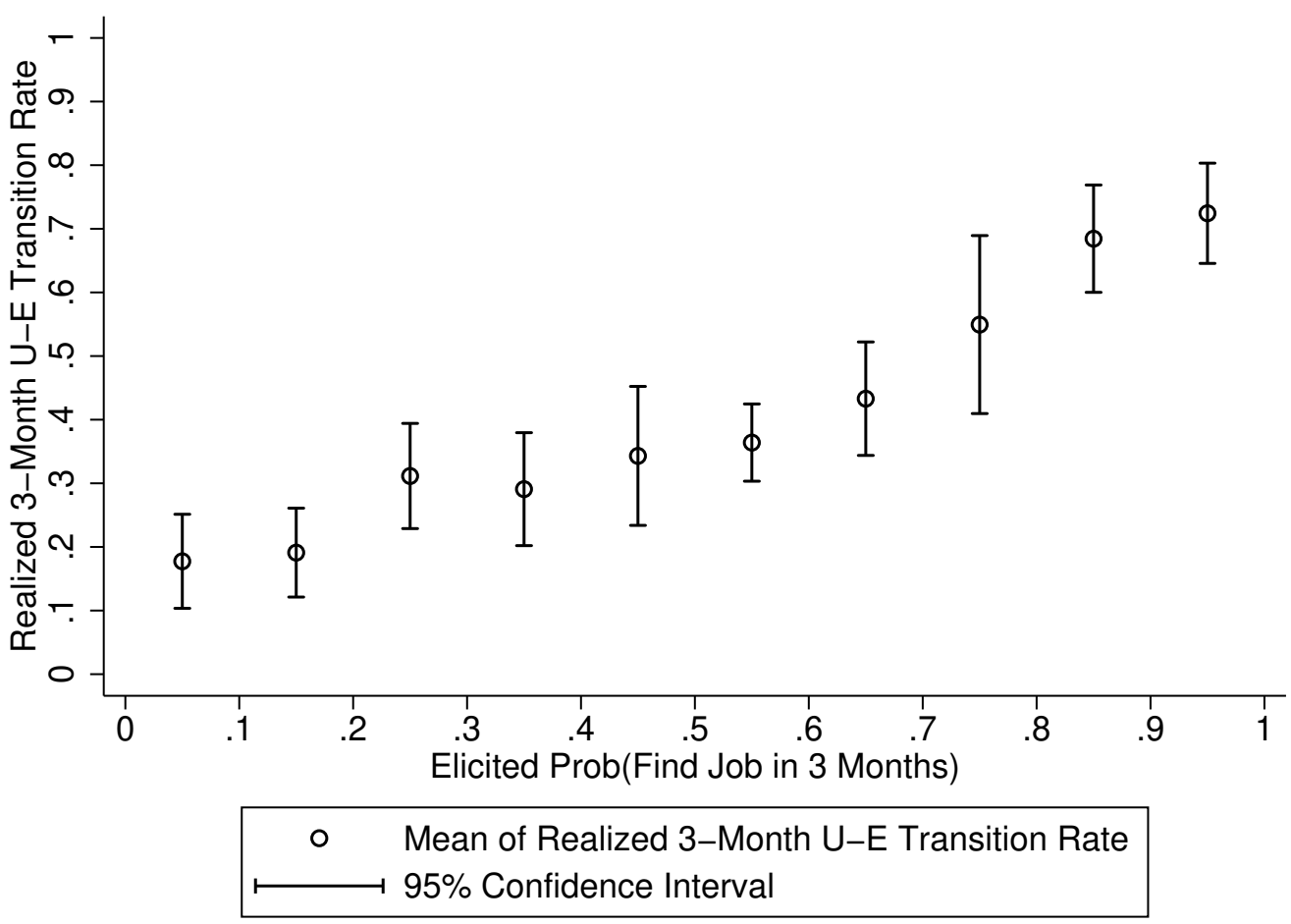

Overall, the similarity between the alternative elicitations is re-assuring. Our empirical analysis using the KM survey will focus on the elicited probability, but we will show that our results are similar for the expected duration measure and robust to the observed bunching at 0, 50 or 100 .

\subsection{Job Finding Beliefs and Outcomes}

We now study how job seekers' beliefs about job finding probabilities compare to actual job finding outcomes. $^{22}$

Predictive Power of Beliefs We can assess the predictive power of job seekers' beliefs by relating the elicited beliefs about job finding to actual job finding. Figure 2 shows the average job finding probability within the next three months by the perceived three-month job finding probability in the SCE. The positive gradient clearly reveals the strong predictive nature of the elicited beliefs - on average, people who report a higher job finding probability are more likely to find a job. Still, job seekers reporting the lowest probabilities tend to be too pessimistic (on average), while job seekers reporting higher probabilities tend to be too optimistic. The average job finding probability ranges from 18 percent to 72 percent for job seekers reporting probabilities in the first to the last decile.

Panel A of Table 2 reports the corresponding regression estimates, regressing a binary indicator for

\footnotetext{
${ }^{22}$ We focus here on the SCE's 3-month elicitation as it suffers less from attrition and gaps in survey completion, but we replicate all results in this Section for the KM survey in the Appendix. In the SCE, we restrict the sample to those interviews where we have 3 monthly consecutive follow-up interviews, to make sure that we do not miss any employment spells. Similarly, for the KM survey, we restrict the sample to those with four weekly consecutive interviews to avoid under-counting of job finding due to attrition and gaps in the weekly survey.
} 
Table 2: Linear Regressions of Realized Job Finding Rates on Elicitations (SCE)

\begin{tabular}{|c|c|c|c|c|}
\hline $\begin{array}{l}\text { Panel A. Dependent Variable: } \\
\text { 3-Month U-E Transition Rate }\end{array}$ & $(1)$ & $(2)$ & $(3)$ & $(4)$ \\
\hline Prob(Find Job in 3 Months) & $\begin{array}{c}0.586^{* * *} \\
(0.073)\end{array}$ & & $\begin{array}{c}0.464^{* * *} \\
(0.069)\end{array}$ & $\begin{array}{c}0.501^{* * *} \\
(0.092)\end{array}$ \\
\hline Prob(Find Job in 3 Months) x LT Unemployed & & & & $\begin{array}{c}-0.258^{*} \\
(0.142)\end{array}$ \\
\hline LT Unemployed & & & & $\begin{array}{l}-0.078 \\
(0.094)\end{array}$ \\
\hline Controls & & $\mathrm{x}$ & $\mathrm{x}$ & $\mathrm{x}$ \\
\hline Observations & 1,201 & 1,201 & 1,201 & 1,201 \\
\hline$R^{2}$ & 0.131 & 0.148 & 0.218 & 0.259 \\
\hline $\begin{array}{l}\text { Panel B. Dependent Variable: } \\
\text { 3-Month U-E Transition Rate }\end{array}$ & $(1)$ & $(2)$ & $(3)$ & $(4)$ \\
\hline Prob(Find Job in 3 Months) & $\begin{array}{l}0.346^{* *} \\
(0.136)\end{array}$ & & & \\
\hline 3-Month Lag of Prob(Find Job in 3 Months) & & & $\begin{array}{c}0.366^{* * *} \\
(0.105)\end{array}$ & $\begin{array}{c}0.301^{* * *} \\
(0.101)\end{array}$ \\
\hline Controls & & $\mathrm{x}$ & & $\mathrm{x}$ \\
\hline Observations & 474 & 474 & 474 & 474 \\
\hline$R^{2}$ & 0.063 & 0.123 & 0.063 & 0.159 \\
\hline
\end{tabular}

whether a job seeker has found a job within the next three months on the elicited probability. The results confirm the predictive nature of the elicited beliefs. On average, the job finding probability is 0.59 percentage points higher for an individual who reports his or her job finding probability to be 1 percentage point higher. The coefficient is only slightly lower when adding various controls, including gender, age, income, educational attainment, race and ethnicity, in column 3 of the table. This demonstrates that individuals' beliefs contain relevant information about future employment prospects above and beyond these demographic controls. The coefficient on the elicited job finding probability is high, but still significantly smaller than 1 . This attenuation could be driven both by random errors in perceptions or elicitations, which increase the variance in elicited beliefs, or by systematic biases in beliefs reflected by the parameter $b_{1}$ in the linear beliefs model.

In similar regressions carried out in the KM survey, we find a coefficient of 0.260 (s.e. 0.109) for the 1-month probability question (see Table D3 in the Appendix). The smaller coefficient in the KM survey compared to the SCE could be driven by the different horizon used for the elicitation. Indeed, we find a larger coefficient $(0.402$; s.e. 0.178$)$ when we run the same regression but with the inverse of the expected duration as the independent variable. Similar to the SCE, the perception questions retain significant predictive value when adding controls, and the predictive power is higher for the short-term 
unemployed with a coefficient of 0.382 for the 1-month probability and 0.513 for the inverse of the expected duration, compared to a coefficient of 0.501 in the SCE, as reported in column 4 of Table 2 .

Robustness We probe the robustness of our estimates by running different versions of the regression reported in column 1 of Table 2. Appendix Table D2 shows that our results are robust (1) to instrumenting the 3 -month eliciation with the 12-month elicitation (coefficient of 0.71), (2) to excluding answers equal to $50 \%$ (coefficient of 0.59 ), (3) to not trimming the sample for inconsistent answers between the 3- and 12-month elicitation (coefficient of 0.55), (4) to including only one unemployment spell for each person (coefficient of 0.62), (5) to including only the first observation for each person (coefficient of 0.44), (6) to including only those individuals who entered the SCE survey as employed and separate into unemployment during the survey period (coefficient of 0.65 ), (7) to controlling for cohort and time fixed effects (coefficient of 0.57), (8) to including only answers for those unemployed 3 months or less (coefficient of 0.57 ). In line with column 4 in Table 2, we also find that the coefficient declines with unemployment duration, with a value of 0.50 for those unemployed 4- 6 months and a value of 0.35 for those unemployed 7 months or more, though the coefficient remains highly statistically significant in all samples. Note also that we cannot reject the hypothesis of the equality of coefficients with the one in the baseline specification for all sub-samples except for the long-term unemployed. Overall, we find that our results are robust and confirm the substantial predictive power of reported beliefs for realized job finding. We also report the same robustness checks for the regression with controls, as in column 3 of Table 2. Again, the results for all robustness checks are similar to the baseline results.

Lower Bound on Heterogeneity The explanatory power of the beliefs in the SCE is large $\left(R^{2}=0.13\right)$ and almost the same as for all other observables together $\left(R^{2}=0.15\right) .{ }^{23}$ Moreover, the results in column 2 and 3 , where the $R^{2}$ increases from 0.15 to 0.22 when adding the elicited beliefs to the regression model with controls, confirm that the elicited beliefs have predictive power above and beyond observable characteristics. To formally assess the amount of heterogeneity in job finding, we calculate the non-parametric lower bounds on the variance in job finding probabilities derived in Section 3.1. The first row in Table 3 reports the lower-bound using the 3-month elicitation only, which is computed as $\frac{\operatorname{cov}\left(F_{i, d}, Z_{i, d}\right)^{2}}{\operatorname{var}\left(Z_{i, d}\right)}$ and equals 0.032 . This lower bound can be tightened by including the 12 -month elicitation in the SCE data as a second elicitation, $\frac{\operatorname{cov}\left(F_{i, d}, Z_{i, d}\right) \operatorname{cov}\left(F_{i, d}, Z_{i, d}^{12}\right)}{\operatorname{cov}\left(Z_{i, d}, Z_{i, d}^{12}\right)}$. This increases the lower bound to 0.038. ${ }^{24}$ As discussed, we can also tighten the bound further by including observable characteristics. The variance of the predicted job finding, using both beliefs and demographics (column

\footnotetext{
${ }^{23}$ Note that even if the perceived and actual job finding probabilities were to coincide, we would not expect an $R^{2}$ of 1 as we are not using the actual job finding probability but a dummy variable for the realization of the probability. The inherent randomness associated with the realization of the job finding probability thus implies an $R^{2}$ that is substantially lower than 1 even if beliefs were unbiased and measured without error. In the case where job seekers had perfect information about their types, the $R^{2}$ of the regression of actual job finding on beliefs would be equal to $\frac{\operatorname{var}\left(Z_{i, d}\right)}{E\left(Z_{i, d}\right)\left(1-E\left(Z_{i, d}\right)\right)}$ for large $N$. Using these moments from the SCE data, we obtain a value of 0.36 , suggesting that the $R^{2}$ of 0.13 for the actual job finding realizations is substantial and that the elicited job finding probabilities have substantial predictive power.

${ }^{24}$ As discussed, the lower bound argument requires the conditional expectations of the respective elicitations to be equal and the elicitations, conditional on job finding, not to be negatively correlated. Hence, we converted the elicited 12month probability $\left(\tilde{Z}_{i, d}^{12}\right)$ into a 3 -month probability $\left(Z_{i, d}^{12}\right)$, assuming the latter is constant over the spell of unemployment: $Z_{i, d}^{12}=1-\left(1-\tilde{Z}_{i, d}^{12}\right)^{\frac{1}{4}}$.
} 
Table 3: Non-parametric Lower Bounds for the Variance of 3-Month Job Finding Probabilities (SCE)

\begin{tabular}{lcc}
\hline Lower bound based on: & Value & S.e. \\
\hline$\ldots$ 3-month elicitations only & 0.032 & $(0.009)$ \\
$\ldots$ 3- and 12-month elicitations & 0.038 & $(0.010)$ \\
$\ldots$ controls only & 0.036 & $(0.009)$ \\
$\ldots$ controls and both elicitations & 0.054 & $(0.010)$ \\
\hline
\end{tabular}

Notes: Standard errors are bootstrapped with 2,000 replications.

3 in Table 2), equals 0.054. To interpret the magnitude of these variances, we compute how much the implied dynamic selection could contribute to the observed negative duration dependence in job finding (see equations (1) and (2)). The decline in the 3-month job finding rate between months $0-3$ and months 4-6 equals 17.0 percentage points. A variance in 3-month job finding of 0.032 could account for a decline in the job finding rate of 8.9 percentage points through selection, which is $52 \%$ of the observed decline of 17.0 percentage points. The higher variance of 0.054 could explain a decline of 15.1 percentage points through selection or $89 \%$ of the total observed decline. ${ }^{25}$

A first caveat with these calculations is that we use the full sample to compute the lower bounds in Table 3, while it is the variance in job finding conditional on unemployment duration that is relevant for determining the contribution of selection to the observed negative duration dependence in job finding. We fully address this in our statistical model in the next section that parametrizes the relevant heterogeneity and dynamics and uses the reduced-form empirical moments for estimation by simulating exact equivalents in the model. Our reduced-form evidence already indicates that beliefs become somewhat less predictive when controlling for unemployment duration, though it remains highly predictive for the short-term unemployed (see columns 4 in Table 2 for the SCE). Indeed, in the SCE, when residualizing the beliefs, taking out the variation across durations, the lower bound variance becomes smaller (0.03), but could still account for half of the decline in the observed job finding rate at the beginning of the unemployment spell. When restricting instead to the short-term unemployed (see Appendix Table D4), the lower bound variance becomes larger again (0.06) and could in fact account for all of the decline, leaving no role for true duration dependence. ${ }^{26}$

A second caveat is that some of the heterogeneity in job finding identified by our approach may be transitory and thus does not contribute to selection over the unemployment spell. To assess this further, we use the elicited beliefs in the SCE to infer the persistence in individual job finding rates, by restricting the sample to those who remained unemployed for at least 4 months and relating actual job finding to beliefs lagged by 3 months. The results in Panel B of Table 2 show that in this sample

\footnotetext{
${ }^{25}$ Appendix Table D5 reports the non-parametric bounds in the KM survey, which are substantially lower than in the SCE, but refer to the 1-month probability rather than to the 3 -month probability. The lower bound on the variance based on the 1-month elicitation in the KM survey can account for an observed decline in the monthly job finding rate of 0.45 percentage points per month, or 3.3 percent per month, when expressed as a percent of the job finding rate for the short-term unemployed. Computed over a period of 3 months, this is about two thirds of the relative decline estimated based on the 3-month elicitation in the SCE.

${ }^{26}$ As illustrated in Figure $5 \mathrm{a}$ in the statistical model, the variance of job finding probabilities is likely to be declining with unemployment duration, which is consistent with the observation in both datasets that the covariance between beliefs and job finding is lower for the long-term unemployed.
} 
the coefficient on the reported beliefs are generally smaller, but the reported beliefs retain a strong predictive power beyond the horizon of the 3-month question administered in the SCE. We find that for this sample of job seekers the relative difference in the covariance between the job finding and the contemporaneous and lagged beliefs, is only $11 \%$. This suggests that most of the variation in job seekers' job finding prospects, captured by the 3-month horizon question, is driven by persistent differences. ${ }^{27}$ Again, the statistical model in the next section is used to properly account for this issue.

Overall, our reduced-form results suggest that heterogeneity in job finding is important for explaining the observed duration dependence in job finding.

\subsection{Biases in Beliefs}

We now document how beliefs and actual job finding differ along the unemployment spell. In contrast with job seekers' true job finding, we can also study the within-individual change in their beliefs over the unemployment spell. As discussed above, it is possible to identify a lower bound on the heterogeneity in job finding from elicitations in beliefs without reference to potential biases in beliefs. However, if one wants to go beyond the lower bound and identify the level of the variance in job finding, one needs to identify the nature of these biases in the first place.

Average Bias by Duration While we cannot compare the actual and perceived job finding probabilities at the individual level, we can compare averages at the group level. Overall, the results indicate an average optimistic bias that is largely driven by the long-term unemployed. At the threemonth horizon in the SCE, we find an average optimistic bias ( $8 \mathrm{pp}$ ) indicating that job seekers perceive their chances to be 20 percent higher than they are. Figure 3 compares the averages in the SCE by unemployment duration. The figure confirms that the observed duration dependence in actual job finding rates is strongly negative. The perceived job finding rates are also decreasing, but at a slower rate. As a result, the bias is increasing with unemployment duration, resulting in a clear bias towards over-optimism for the long-term unemployed. In the KM survey, the overall bias is substantially larger in the KM survey, but we find similar results by duration of unemployment. ${ }^{28}$

Using the patterns of perceived and realized job finding, one can inform the model of beliefs in section 3.1. Based on equation (7), we compute an estimate of $b_{1}$ for two different duration intervals in the SCE. We find estimates of $b_{1}$ of 0.512 (0-3 vs. 4-6 months) and 0.556 (4-6 vs. 7+ months), suggesting that jobseekers' perceptions under-respond to their true job finding probability. Using an average of 0.534 of the two estimates and an estimate of 0.054 of the covariance between the 3 -month eliciation and realized job finding, $\operatorname{cov}\left(Z_{i, d}^{3}, F_{i, d}^{3}\right)$, we can leverage equation (6), to obtain an estimate for the variance in job finding probabilities of $\operatorname{var}\left(T_{i, d}\right)=0.101$. Benchmarking this as before, such variance

\footnotetext{
${ }^{27}$ Combining equations (6) and (9), one can solve for $\operatorname{var}(\tau)$ as a function of $b_{1}$ and data moments. Using our estimate of $b_{1}=0.534$ from further below and the values for the moments $\operatorname{cov}_{d+1}\left(Z_{i, d+1}, F_{i, d+1}\right)=0.0308, \operatorname{cov}_{d+1}\left(Z_{i, d}, F_{i, d+1}\right)=$ 0.0289 and $E_{d}\left(T_{i, d}\right)=0.491$, we get an estimate of $\operatorname{var}(\tau)=0.0045$, which corresponds to $8 \%$ of the total variance. The covariance moments are computed in the sample used for the regressions in Panel B of Table 2. Note that this derivation is done for a stylized model that ignores true duration dependence in job finding. Moreover, we compute again all moments over all durations, whereas the equations are exact only for a given duration $d$.

${ }^{28}$ Table D6 in the Appendix contains underlying numbers for both the SCE and the KM survey. Note that we restrict the sample for this comparison to interviews that were followed by 3 consecutive monthly interviews (SCE) or 4 consecutive weekly interviews (KM survey).
} 
Figure 3: Perceived vs. Realized Job Finding by Duration of Unemployment (SCE)

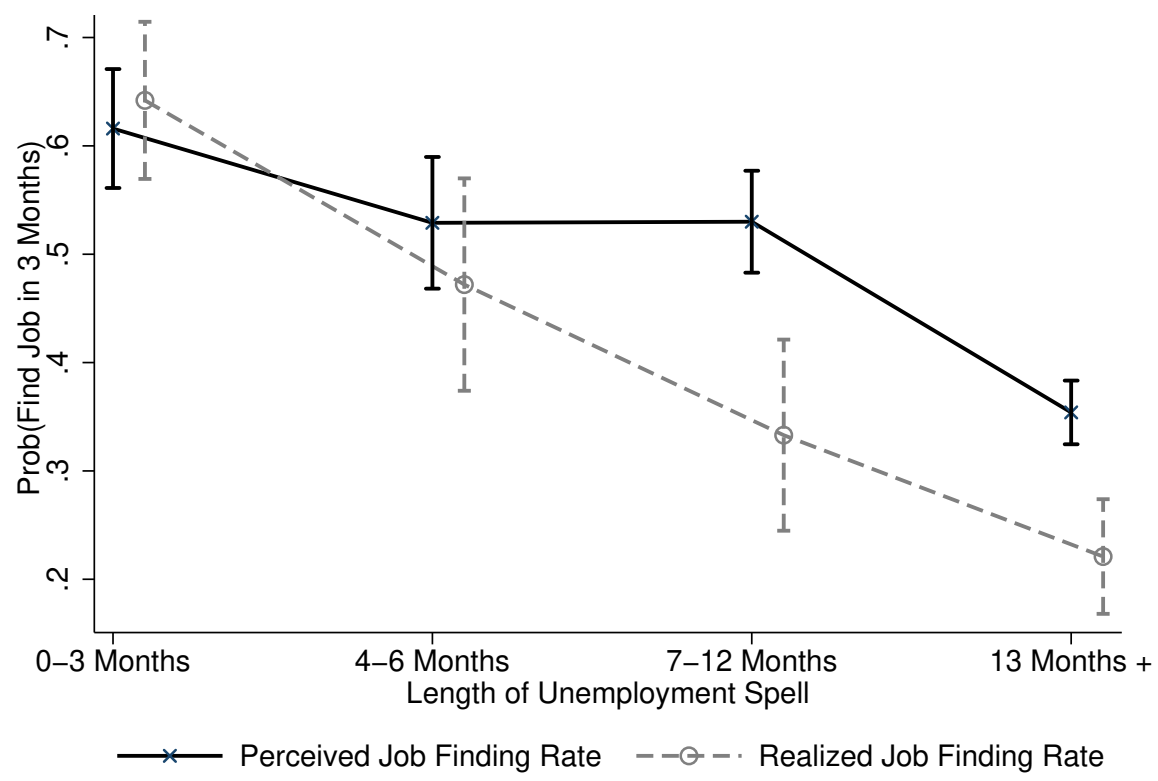

would account for a decline of 28 percentage points over the first three months of the unemployment spell through selection, which more than fully accounts for the observed decline. However, the relevant moments in the decomposition equation (1) condition on duration and account for the persistence in job finding, which reduces the contribution of dynamic selection to the decline in job finding. ${ }^{29}$

Job Finding Beliefs by Duration The panel dimension of the surveys provides a unique opportunity to assess the duration dependence in perceived job finding. Table 4 shows the results of linear regressions of the elicited beliefs on duration of unemployment, measured in months. The first column shows the results for the sample restricted to the first observation for each unemployment spell, the second and third column shows the results for the pooled cross-section of all observations available during an unemployment spell. The results of all three columns confirm the negative effect of unemployment duration on the elicited beliefs in the cross-section. However, it is again unclear whether these patterns are due to selection - those with high perceived probabilities find jobs faster and leave the sample - or due to changes in the beliefs at the individual level.

To adjust for selection, we exploit the repeated survey questions answered by the same job seekers over the unemployment spell. Column 4 in Table 4 includes in the regression spell or person fixed effects. Note that in the SCE, some individuals have multiple unemployment spells and thus we control for each spell separately, whereas in the KM survey we only observe one spell per person. ${ }^{30}$ In the SCE, the estimated effect of duration turns from negative to positive when including spell fixed effects with the job finding probability at the 3-month horizon increasing by $0.2(0.6)$ percentage points per month, though the coefficient is not statistically significantly different from zero. Panel B in Table 4 shows

\footnotetext{
${ }^{29}$ Using the residualized covariance, which takes out all variation across durations, we obtain an estimate for the variance of 0.067 (see Appendix Table D4). The implied decline in job finding is just above the observed decline (18.6 p.p.).

${ }^{30}$ Consistent with Elsby et al. [2015], we treat transitions from unemployment to out of the labor force and back to unemployment as part of the same unemployment spell.
} 
Table 4: Linear Regressions of Elicitations on Unemployment Duration (SCE and KM)

\begin{tabular}{lcccc}
\hline Panel A. SCE, Dependent Variable: & & & & \\
Elicited 3-Month Probability & $(1)$ & $(2)$ & $(3)$ & $(4)$ \\
\hline Unemployment Duration, in Months & $\begin{array}{c}-0.0057^{* * *} \\
(0.0007)\end{array}$ & $\begin{array}{c}-0.0050^{* * *} \\
(0.0007)\end{array}$ & $\begin{array}{c}-0.0043^{* * *} \\
(0.0006)\end{array}$ & $\begin{array}{c}0.0022 \\
(0.0064)\end{array}$ \\
\hline Demographic Controls & & & $\mathrm{x}$ & \\
Spell Fixed Effects & & & & $\mathrm{x}$ \\
Observations & 882 & 2,281 & 2,281 & 2,281 \\
$R^{2}$ & 0.110 & 0.090 & 0.155 & 0.824 \\
\hline Panel B. KM Survey, Dependent Variable: & $(1)$ & $(2)$ & & \\
Elicited 1-Month Probability & -0.0012 & -0.0020 & $-0.0025^{*}$ & $0.0216^{* *}$ \\
\hline Unemployment Duration, in Months & $(0.0020)$ & $(0.0021)$ & $(0.0014)$ & $(0.0077)$ \\
\hline Demographic Controls & & & $\mathrm{x}$ & \\
Individual Fixed Effects & & & & $\mathrm{x}$ \\
Observations & 2,278 & 4,435 & 4,318 & 4,435 \\
$R^{2}$ & 0.001 & 0.003 & 0.119 & 0.902 \\
\hline
\end{tabular}

Notes: Survey weights are used in all regressions. All samples are restricted to unemployed workers, ages 20-65. The demographic controls are the same as in Table 2. Column 1 shows the results for a sample that is for each individual restricted to the first observation in the survey; column 2 shows the results for the full sample; column 3 shows the results for the full sample with demographic controls; and column 4 shows the results for the full sample with spell or individual fixed effects. Robust standard errors are in parentheses and are clustered at the individual level except for column 4 in Panel A, where they are clustered at the spell level. Asteriks indicate statistical significance at the ${ }^{*} 0.1,{ }^{* *} 0.05$ and ${ }^{* * *} 0.01$ level.

that this pattern is much stronger for the KM survey, where an additional month spent unemployed significantly increases the perceived job finding probability by $2.2(0.8)$ percentage points per month. ${ }^{31}$

Figure 4 illustrates the difference between the observed (cross-sectional) duration dependence and the true (individual-level) duration dependence in the reported beliefs graphically. To increase power and control for potential cohort effects, the figure aggregates by time unemployed in survey rather than showing results by duration of unemployment. The left panel shows how the average of the perceived job finding probability is decreasing in time spent unemployed since the first interview observed in a given spell, conditional on still being unemployed. ${ }^{32}$ The right panel in Figure 4 shows the change in the perceived job finding probability within individual unemployment spells, again as a function of time spent unemployed since the first interview. The figures confirm the findings from the regression. In the cross-section, the perceived job finding probability is decreasing in time spent unemployed, but this decline disappears once we control for selection and look at the within-spell changes only. ${ }^{33}$ In the KM

\footnotetext{
${ }^{31}$ Note that in an environment where the 1-month horizon probability is increasing, the 3-month horizon probability may increase by less or more, depending on the initial level of the job finding probability.

${ }^{32}$ Figure D7 also shows results by unemployment duration for each cohort in the KM survey. There is no evidence of see-saw patterns or systematic cohort effects in beliefs, as there is for search effort in Krueger and Mueller [2011].

${ }^{33}$ In principle, the patterns of the within-spell changes could be driven by dynamic selection, since the observations later in the spell require the job seeker to be unemployed for longer. The relationship in column 4 of Table 4 , however, remains positive in both surveys even when we restrict the sample to those with relatively short spells of 6 months or less.
} 
Figure 4: Perceived Job Finding Probabilities by Time since First Interview (SCE and KM)

\section{A. SCE Survey}
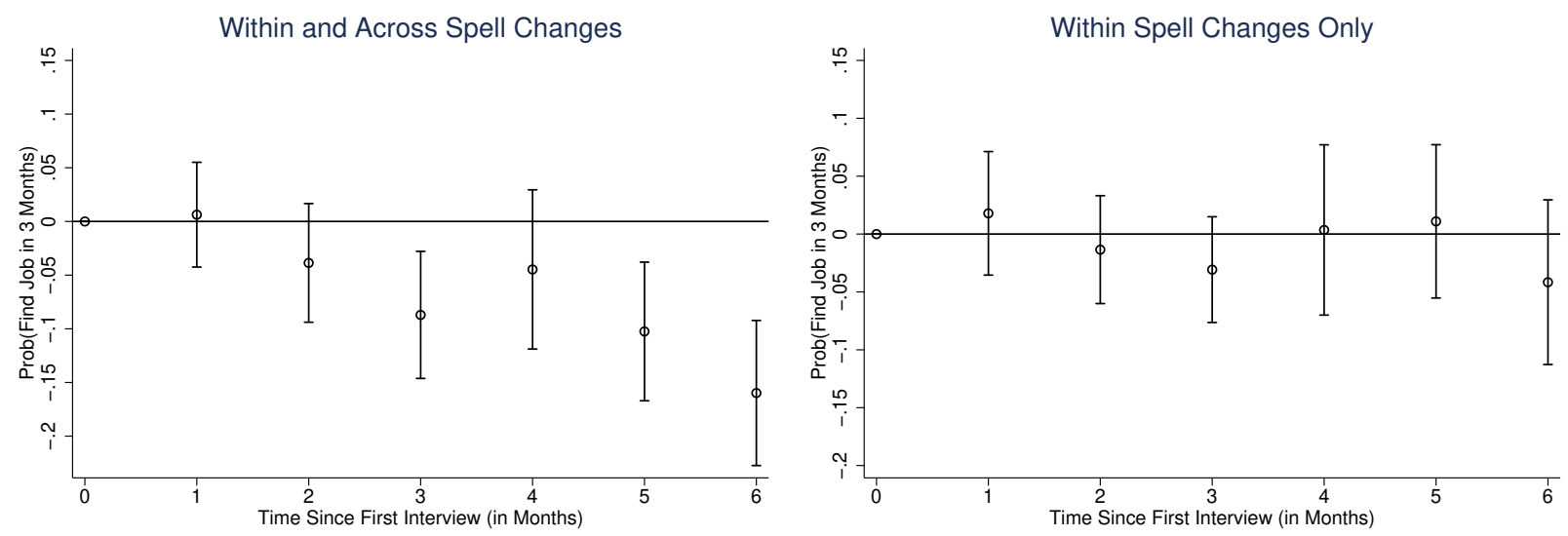

B. KM Survey
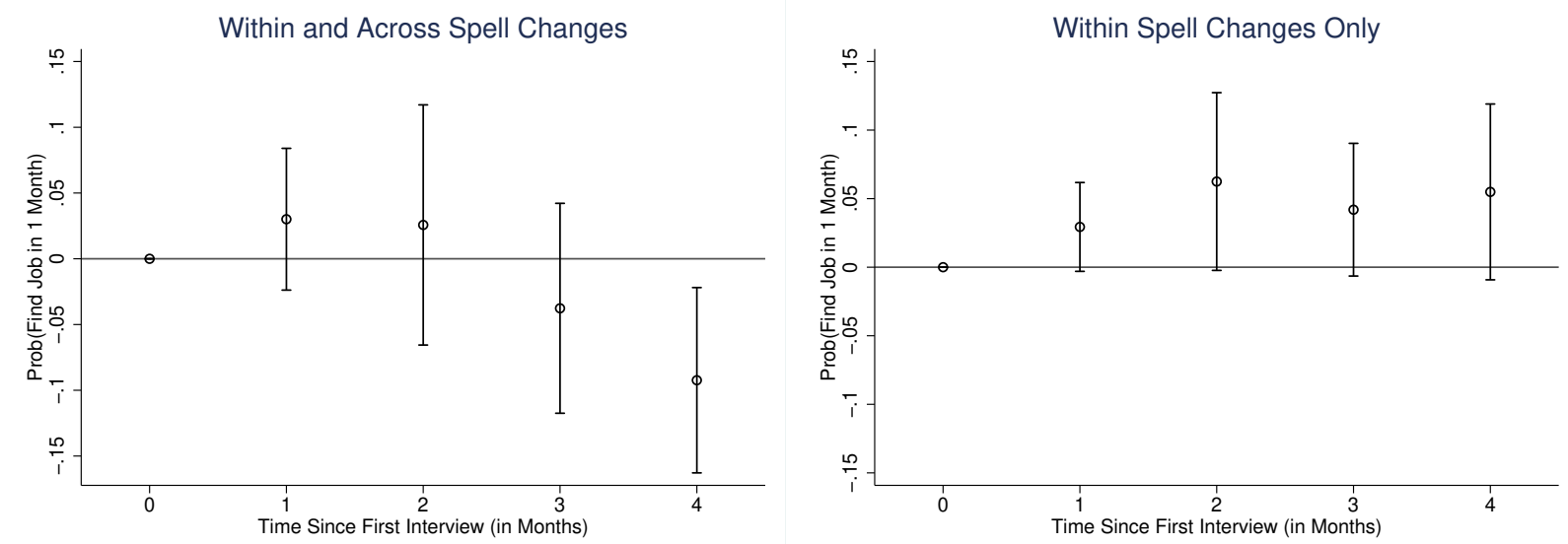

survey, job seekers even report higher job finding rates as they remain unemployed for longer.

Robustness We extensively probe the robustness of the finding that beliefs are not revised downward and also evaluate potential forces that may underlie the (weakly) increasing beliefs about job finding probabilities. We report here only a brief summary and refer to the Appendix D.3 for details. First, we find that the results in column 4 of Table 4 are similar for other measures of perceived job finding, such as expected remaining duration in the KM survey and the 12-month probability in the SCE survey. The results are also robust to excluding answers of 50 or 100 percent, or to excluding individuals who find a job within the next month. Moreover, we find that our results are robust to controlling for changes in aggregate labor market conditions or aggregate time fixed effects during our sample period. Finally, we find that our estimates are unlikely to be biased due to sample selection based on individuals dropping out of the labor force: In the SCE, those unemployment spells with a transition into out of the labor force do not exhibit any significant decline of beliefs over the spell of unemployment. Moreover, in the KM survey, the belief questions were administered independent of search effort and thus including those dropping out of the labor force. We conclude that our finding 
that beliefs are not revised downward is very robust.

Discussion Our analysis of job seekers' beliefs corroborates earlier evidence that job seekers' are too optimistic about their re-employment prospects (Spinnewijn [2015], Arni [2017], Conlon et al. [2018], Drahs et al. [2018]). Importantly, we find that the over-optimistic bias is particularly strong among long-term unemployed workers, implying that beliefs are under-responsive to differences in job finding, across job seekers and/or along the unemployment spell. As discussed, this under-reaction is important for inferring the heterogeneity and duration dependence in true job finding using job seekers' beliefs. We develop this insight further in Section 4. The under-reaction in beliefs is also important if it entails that job seekers do not adjust their search strategy to the specific employment prospects they face. We will study this issue further in Section $5 .{ }^{34}$

The empirical finding that job seekers, if anything, update their perceived job finding probability upward over the unemployment spell is surprising. However, our reduced-form evidence already suggests that there is limited scope for negative true duration dependence in the actual job finding probabilities. This suggests that various mechanisms underlying true duration dependence like human capital depreciation (see Acemoglu [1995] and Ljungqvist and Sargent [1998]), stock-flow sampling (see Coles and Smith [1998]) and employer-screening based on unemployment duration (see Lockwood [1991]) are empirically not important or, at least, not perceived as such. However, even with substantial variation in employment prospects across job seekers (rather than over the spell), we would expect that job seekers learn from the lack of success and update their beliefs downwards the longer they are unemployed. The lack of updating that we find thus remains surprising, but seems consistent with Krueger and Mueller [2016] who show - using data from the KM survey - that reservation wages are nearly constant over the spell. Their finding, however, is not sufficient to infer a lack of updating in beliefs about job finding, as other inputs into the probability of job finding such as search effort, the offer probability or the wage offer distribution may change over the unemployment spell, too. ${ }^{35}$

While we do not attempt to micro-found these biases, it is worth noting that a number of behavioral models can explain the observed optimistic biases in beliefs, why biases become more important or why there may be lack of learning over the spell. For example, regarding the dynamics, job seekers may be subject to the gambler's fallacy. This is an application of the law of small numbers with unsuccessful job seekers inferring from a series of bad draws (as their unemployment spell lasts) that the probability of a good draw increases (Rabin and Vayanos [2010]). ${ }^{36}$ Job seekers may also have motivated beliefs, managing their expectations to maintain a positive self-image or to get positive

\footnotetext{
${ }^{34}$ Providing direct evidence that biases in beliefs distort behavior is challenging. In Section 5 , we study this through the lens of a model that we calibrate to match true and perceived job finding in our data. In Appendix D.3.3, we discuss some further evidence on how perceptions correlate with reported search efforts and reservations wages.

${ }^{35}$ In fact, if job seekers learned about the wage offer distribution and revised their reservation wage downward as in Burdett and Vishwanath [1988], this type of learning would provide a reason for positive true duration dependence in job finding. However, the perceived wage offer probabilities and (expected) search effort may change as well. We study the relation between wage offer probability, reservation wages and job finding in a McCall model of job search in Section 5. Regarding search efforts, the evidence in Krueger and Mueller [2011], which documents patterns of search behavior in the KM survey, suggests a decline in search activity over the unemployment spell at the individual level, but two recent papers find that search activity is constant or even increasing, at least prior to the exhaustion of unemployment benefits (see Marinescu and Skandalis [2019] and DellaVigna et al. [2020]).

${ }^{36}$ Note that the same application of the law of small numbers may induce job seekers to become overly discouraged as they over-infer from a series of bad draws how employable they are (Rabin and Vayanos [2010]).
} 
value from optimistic expectation, potentially accounting for the implied distortions in their search behavior (e.g., Brunnermeier and Parker [2005] and Koszegi [2006]). The argument would be that lasting unemployment causes hardship and increases the demand for optimistic expectations. We cannot provide directs test of either theory, but the findings that the perceptions of long-term unemployed are more biased and less predictive can be consistent with these behavioral models. ${ }^{37}$ In a similar spirit, we provide further evidence in Appendix D.3.3 that the perceptions of unemployed individuals are not responsive to macro-economic indicators (while the perceptions of employed workers are).

\section{Statistical Framework}

This section describes a statistical model that allows us to use the reduced-form moments from our empirical analysis to jointly identify (1) the extent of heterogeneity in job finding rates, (2) the dynamics of job finding rates over the spell of unemployment and (3) the biases in perceived job finding rates as well as their evolution over the spell of unemployment. The model draws heavily on the conceptual framework developed in Section 3.1, but fully specifies the heterogeneity across job seekers and the dynamics over the unemployment spell, which allows to infer the parameters of interest with exact equivalents of the moments in the data.

\subsection{Model Setup}

We introduce notation $T_{i, d}^{x}$ to denote the probability of finding a job in the next $x$ months for individual $i$ with unemployment duration $d$. The monthly job finding probability equals $T_{i, d}=T_{i, d}^{1}$ and $T_{i, d}^{3}=$ $T_{i, d}+\left(1-T_{i, d}\right) T_{i, d+1}+\left(1-T_{i, d}\right)\left(1-T_{i, d+1}\right) T_{i, d+2}$ is the probability of finding a job in the next 3 months. $Z_{i, d}^{x}$ is the elicitation of the corresponding perceived probability. $F_{i, d}^{x}$ describes the actual job finding.

We assume that the monthly job finding rate of individual $i$ at duration $d$ satisfies

$$
T_{i, d}=(1-\theta)^{d}\left(T_{i}+\tau_{i, d}\right) \in[0,1]
$$

where $\theta$ is a scalar that determines the depreciation in job finding over the spell of unemployment (or appreciation when negative), $T_{i}$ is the persistent component of the job finding rate that is common across durations and $\tau_{i, d}$ is a transitory change in job finding rate at duration $d$ with $E\left(\tau_{i, d} \mid T_{i, d}\right)=0$. $T_{i}$ and $\tau_{i, d}$ are distributed according to some distributions $g_{T}$ and $g_{\tau}$ respectively.

We continue to impose the same linear structure on the relationship between job finding rates and elicited beliefs at the 3 -month horizon:

$$
Z_{i, d}^{3}=b_{0}+b_{1} T_{i, d}^{3}+\varepsilon_{i, d} \in[0,1]
$$

As stated before, we cannot separate the role of biases in perceptions vs. elicitations underlying the bias parameters and error terms. The variable $\varepsilon_{i, d}$ captures random error in the elicited perceptions, which can be driven by either noise in the beliefs themselves or by noise in the elicitation of the beliefs.

\footnotetext{
${ }^{37}$ This finding is also supported by the recent experimental evidence in Altmann et al. [2018] showing the differential impact of information on workers by predicted time spent unemployed.
} 
In our baseline model, we assume that the conditional mean of the error term is independent of $T_{i, d}^{3}$, $E\left(\varepsilon_{i, d} \mid T_{i, d}^{3}\right)=0$, but non-classical measurement could still be captured through the slope parameter $b_{1}$. While this separation is not needed to identify the heterogeneity in job finding, we do gauge the robustness of our estimates to different distributional assumptions on the error term, including the mean-independence assumption.

\subsection{Identification}

A key advantage of the statistical model is that the parameters of interest are estimated using exact equivalents of the moments in data. To be more precise, in the conceptual framework, we derived relationships between data moments and parameters for a given duration $d$, but due to limited sample size, it is not possible to compute these moments in our data for each month of the unemployment spell. Instead, the data moments are computed over intervals of duration (or the entire unemployment spell) and thus subject to selection and duration dependence within these intervals. The statistical model develops an account of the data that fully addresses these issues in an internally consistent manner.

For the identification of the parameters in the statistical model, we build on the identification arguments presented in Section 4 and develop them formally in a stylized two-period version in Appendix Section E.3. To further validate the identification arguments in the full model, we show how the estimated parameters change with the values of the targeted moments and how the model's fit changes when restricting the key features of the model, in particular regarding the heterogeneity and duration dependence of both actual and perceived job finding rates. We also show extensively how the model estimates are robust to different functional forms, distributional assumptions and incidental parameters.

As discussed in Section 3, we face two interdependent identification challenges. The first is to disentangle the heterogeneity and true duration dependence in job finding rates that underlies the observed duration dependence. The second is to identify how beliefs change with variation in job finding rates. Given our assumptions on the geometric depreciation and the permanent vs. transitory shocks, we can rewrite the earlier decomposition of the observed job finding in equation (1) as

$$
\frac{E_{d+1}\left(T_{i, d+1}\right)}{E_{d}\left(T_{i, d}\right)}=(1-\theta)\left[1-\frac{\operatorname{var}_{d}\left(T_{i}\right)}{E_{d}\left(T_{i, d}\right)\left(1-E_{d}\left(T_{i, d}\right)\right)}\right] \text {, }
$$

where the subindex again denotes the duration at which the job seekers are sampled to evaluate the corresponding moment. The evolution of the observed job finding depends on the depreciation in job finding and the variance in the persistent component only.

In the absence of transitory shocks and biases in beliefs, we could simply identify the relevant variance in job finding through the covariance between perceived and actual job finding, and equation (12) would give the depreciation of job finding. In the presence of transitory shocks, the covariance between perceived and actual job finding is no longer sufficient. As discussed before in Section 3.1, transitory shocks generate more contemporaneous covariance of elicitations and job finding rates, but do not generate more covariance between elicitations and the job finding one period ahead. Hence, we can separately identify the variance in transitory shocks through the difference in covariances, since the contemporaneous covariance depends on both persistent and temporary components of $T_{i, d}$, whereas the 
one period ahead covariance only depends on the persistent component. We develop this identification argument formally in Appendix Section E.3 and show that the ahead covariance is a monotone function of the dispersion in transitory shocks. ${ }^{38}$

Finally, the presence of systematic biases in beliefs also changes the covariance between perceived and actual job finding relative to the variance in true job finding. If job seekers under-react to variation in job finding $\left(b_{1}<1\right)$, the covariance between perceived and actual job finding underestimates the variance in true job finding. As already discussed in Section 3.1, we identify this potential compression by leveraging the variation in job finding rates across durations.

By jointly exploiting the elicited beliefs and the structure on the relationship between elicited beliefs and job finding embedded in a dynamic framework, the statistical model goes beyond earlier work identifying the role of heterogeneity through the dynamic selection on observables only. Other prior work has tried instead to use indirect evidence on true duration dependence in job finding (e.g., Kroft et al. [2013]) or to infer heterogeneity in multiple-spell data. Compared to the approach that uses data on multiple unemployment spells as a source of identification (see, e.g., Honoré [1993] and Alvarez et al. [2016]), our approach is made possible by the availability of elicitations and realizations for the same individual in the same unemployment spell and thus does not rely on multiple spells for the same individual. ${ }^{39}$ As mentioned before, our identification strategy abstracts from search decisions underlying the job finding rates and how they are affected by job seekers' beliefs, which we study in Section 5 .

\subsection{Distributional and Functional Form Assumptions}

We propose to parametrize our model relatively parsimoniously. Baseline job finding rates, $T_{i}$, follow the Beta distribution with shape parameters $\alpha$ and $\beta$. The Beta distribution is defined over the interval $[0,1]$ and is quite flexible in terms of its shape. ${ }^{40}$ The transitory component of the job finding rate, $\tau_{i, d}$, follows a uniform distribution subject to the bounds $\left[-T_{i}, \frac{1}{(1-\theta)^{d}}-T_{i}\right]$, and with masspoint(s) at the bounds of this interval such that $E\left(\tau_{i, d} \mid T_{i}\right)=0$ for all $T_{i}{ }^{41}$ Random error in perceptions or elicitations, $\varepsilon_{i, d}$, follows a uniform distribution on the interval $\left[-\sigma_{\varepsilon}, \sigma_{\varepsilon}\right]$ subject to the bounds $\left[-b_{0}-b_{1} \hat{T}_{i, d}^{3}, 1-b_{0}-b_{1} T_{i, d}^{3}\right]$, and with masspoint(s) at the bounds of this interval such that $E\left(\varepsilon_{i, d} \mid T_{i, d}^{3}\right)=0$ for all $T_{i, d}^{3}{ }^{42}$ As discussed

\footnotetext{
${ }^{38}$ In particular, Appendix Section E.3 starts with a formal proof of identification, showing that in a two-period version of the statistical model, where $\sigma_{\tau}=0$, all other parameters are an explicit function of moments with an empirical counterpart in the data. We then develop the identification arguments in a two-period model with $\sigma_{\tau}>0$. While we cannot solve explicitly the model for these parameters, we complement the argument by showing that a monotone relationship exists between $\sigma_{\tau}$ and the one period ahead covariance. We then also prove the identification of an extra longitudinal belief parameter $\hat{\theta} \neq \theta$ discussed in Section 4.5.

${ }^{39}$ Relying on multiple unemployment spells may skew the estimation results since a sample of individuals with multiple (frequent) spells may not be entirely representative of the population. In addition, identification through multiple unemployment spells only identifies the extent of heterogeneity that is fixed between unemployment spells, which may be years apart, whereas our approach also identifies the heterogeneity that is fixed within a spell but varies across spells (e.g., changes in marital status, savings or unemployment insurance eligibility may affect the job finding probability).

${ }^{40}$ Note that for our exercise here it is important that there is a continuum of job finding probabilities or at least a large number. Assuming two types for the job finding probabilities and estimating their relative mass is not an attractive option, because our observed elicitations are reported on the interval between 0 and 1. A model with only two underlying job finding rates thus would not perform well in matching the distribution of these elicitations.

${ }^{41}$ More precisely, $\tau \mid T_{i}$ follows a uniform distribution on the interval $\left[\max \left(-\sigma_{\tau},-T_{i}\right), \min \left(\sigma_{\tau}, \frac{1}{(1-\theta)^{d}}-T_{i}\right)\right]$, with a masspoint at the bound of this interval if a bound is binding, such that $E\left(\tau_{i, d} \mid T_{i}\right)=0$ for all $T_{i}$.

${ }^{42}$ More precisely, $\varepsilon \mid \hat{T}_{i, d}^{3}$ follows a uniform distribution on the interval $\left[\max \left(-\sigma_{\varepsilon},-b_{0}-b_{1} T_{i, d}^{3}\right), \min \left(\sigma_{\varepsilon}, 1-b_{0}-b_{1} T_{i, d}^{3}\right)\right]$, with a masspoint at the bound of this interval if a bound is binding, such that $E\left(\varepsilon_{i, d} \mid T_{i, d}^{3}\right)=0$ for all $T_{i, d}^{3}$.
} 
before, the identification of heterogeneity does not rely on particular distribution functions for $T_{i}, \tau_{i, d}$ and $\varepsilon_{i, d}$, and we test the sensitivity of our results to alternative distributional assumptions. Finally, job finding rates depreciate at a geometric rate over the unemployment spell in our baseline specification, with $\theta_{d}=(1-\theta)^{d}$. In an alternative specification, we assume a piece-wise linear specification for the depreciation where $\theta_{d}=1-d \theta$ if $d \leq 12$ and $\theta_{d}=1-12 \theta$ otherwise.

\subsection{Targeted Moments and Estimated Parameters}

In our data, we observe the means of realized and perceived job finding rates at different durations, as well as their covariance and the variance in perceived job finding rates. As already noted above, we focus on the moments from the SCE data, because due to attrition we have less confidence in the moments in the KM data that relate to the co-variance of perceptions and actual job finding. In the estimation of our model, we target the following moments in the SCE data:

1. The mean of the 3-month job finding rate at durations $0-3$ months, 4-6 months and $7+$ months: $m_{F_{03}}=0.642, m_{F_{46}}=0.472$ and $m_{F_{7+}}=0.256 .{ }^{43}$

2. The mean of elicitations of the percent chance of finding a job in the next 3 months at durations 0-3 months, 4-6 months and 7+ months: $m_{Z_{03}}=0.616, m_{Z_{46}}=0.529$ and $m_{Z_{7+}}=0.409$.

3. The variance of elicitations of the percent chance of finding a job in the next 3 months: $s_{Z}^{2}=0.093$.

4. The covariance of the 3 -month job finding rate and elicitations: $c_{F, Z}=0.054$.

5. The covariance of the 3 -month job finding rate (3-month ahead) and elicitations: $c_{F_{+3}, Z}=0.025$.

6. The monthly change in 3-month elicitations as measured by the coefficient on duration in the regressions of perceived job finding rates on unemployment duration, controlling for individual fixed effects: $m_{d Z}=0.008{ }^{44}$

This implies that we have a total of 10 moments that we try to match. With two parameter distributions, there are 7 parameters to estimate $\left(\alpha, \beta, \sigma_{\tau}, \theta, b_{0}, b_{1}, \sigma_{\varepsilon}\right)$ and thus the model is overidentified. Following our earlier discussion, the parameters $\alpha$ and $\beta$ and $\theta$ are mainly identified through the mean of job finding rates at durations 0-3, 4-6 and 7 and higher, and the covariance of elicitations and job finding rates, whereas the parameter $\sigma_{\tau}$ is mainly identified through the differences in the covariances $c_{Z_{d}, F_{d}}$ and $c_{Z_{d}, F_{d+3}}$. The parameters $b_{0}$ and $b_{1}$ are mainly identified through the mean of the deviations of elicitations from actual job finding rates at durations 0-3, 4-6 and 7 and higher. While $b_{0}$ is mainly identified by the average bias between elicitations and job finding, $b_{1}$ is identified by the gradient of this bias by duration. ${ }^{45}$ The parameter $\sigma_{\varepsilon}$ is identified through the variance of elicitations.

\footnotetext{
${ }^{43}$ Note that we assume that the maximum duration for each job seeker is two years, but we relax this assumptions in a set of robustness checks, where we allow for a maximum duration of up to five years.

${ }^{44}$ Note that this is slightly higher than the value reported earlier in the paper, because the sample here is restricted to the sample where we have at least 3 consecutive interviews.

${ }^{45}$ Note that the gradient of the perceived job finding depends on the covariance of elicitations and job finding rates, determining the dynamic selection, and on the mean of monthly innovations in elicitations, determining the true-duration dependence in beliefs. As shown in Appendix Section E.3, in a stylized two-period model, the mean of monthly innovations provides no additional identifying variation.
} 
Table 5: Estimation Results

\begin{tabular}{clcr}
\hline A. Parameter Estimates & & \\
\hline Parameter/Moment & Explanation & Estimate & (S.e.) \\
\hline$E\left(T_{i}\right)$ & Mean of distribution of permanent component, $T_{i}$ & 0.403 & $(0.057)$ \\
$\operatorname{Var}\left(T_{i}\right)$ & Variance of distribution of permanent component, $T_{i}$ & 0.045 & $(0.022)$ \\
$\sigma_{\tau}$ & Dispersion in transitory component of job finding rate, $\tau_{i, d}$ & 0.334 & $(0.213)$ \\
$\theta$ & Depreciation in job finding & 0.017 & $(0.047)$ \\
$b_{0}$ & Intercept bias & 0.265 & $(0.045)$ \\
$b_{1}$ & Slope bias & 0.550 & $(0.101)$ \\
$\sigma_{\varepsilon}$ & Dispersion in elicitation errors, $\varepsilon_{i, d}$ & 0.453 & $(0.020)$ \\
\hline
\end{tabular}

\section{B. Additional Moments}

\begin{tabular}{clcr}
\hline Moment & Explanation & Estimate & $($ S.e. $)$ \\
\hline $\operatorname{Var}_{0}\left(T_{i, 0}^{3}\right)$ & Variance in 3-month job finding rates at $d=0$ & 0.076 & $(0.014)$ \\
$\operatorname{Var}_{0}\left(T_{i}^{3}\right)$ & Variance in permanent component of $T_{i, 0}^{3}$ at $d=0$ & 0.057 & $(0.023)$ \\
$\operatorname{Var}_{0}\left(Z_{i, 0}^{3}\right)$ & Variance in 3-month elicitations at $d=0$ & 0.081 & $(0.005)$ \\
\hline $\mathrm{TD}$ & 12-month decline in job finding rates (total) & 0.459 & $(0.061)$ \\
$\mathrm{LD}$ & 12-month decline in job finding rates (longitudinal) & 0.070 & $(0.171)$ \\
$1-\frac{L D}{T D}$ & Share explained by selection (in \%) & 84.71 & $(36.37)$ \\
\hline
\end{tabular}

Notes: The total decline (TD) in 3-month job finding is defined as $E_{0}\left(T_{i, 0}^{3}\right)-E_{12}\left(T_{i, 12}^{3}\right)$. The longitudinal decline (LD) in 3-month job finding is defined as $E_{0}\left(T_{i, 0}^{3}-T_{i, 12}^{3}\right)$.

\subsection{Estimation and Results}

We use the method of simulated moments to estimate the model parameters and minimize the sum of squares of the deviation of the empirical moments from the moments simulated from the model. We use the inverse of the bootstrapped covariance matrix of the empirical moments as weighting matrix, where the bootstrapped variances were computed with 2,000 repetitions. Standard errors were obtained by estimating the model on 200 bootstrap samples and taking the standard deviation of estimates across the 200 samples. As shown in the Appendix Table E1, our model matches the 10 moments very well, even though it is over-identified. There is almost no discernible difference for the monthly innovations and the variance and co-variance moments, which all carry a large weight in the estimation. The weighted sum of squared residuals is 0.47 . Table 5 shows the parameter estimates and selected moments of interest. The estimation delivers two important sets of results, which confirm the reduced-form findings.

Heterogeneity vs. Depreciation The estimation reveals substantial heterogeneity in the job finding rates and confirms that the negative duration dependence in job finding rates is predominantly driven through dynamic selection. Figure 5a shows that the model estimates imply a large dispersion of persistent types, $T_{i}$, at the start of the unemployment spells. The estimated Beta distribution is unimodal and slightly skewed to the left. As the high- $T_{i}$ types find jobs, the distribution of the persistent component $T_{i}$ among survivors becomes more skewed to the left with a substantially lower average overall. These changes are more extreme one year into the unemployment spell. Figure 5b 
Figure 5: Heterogeneity and Duration Dependence in the Estimated Model

(a) Distribution of $T_{i}$ among Survivors

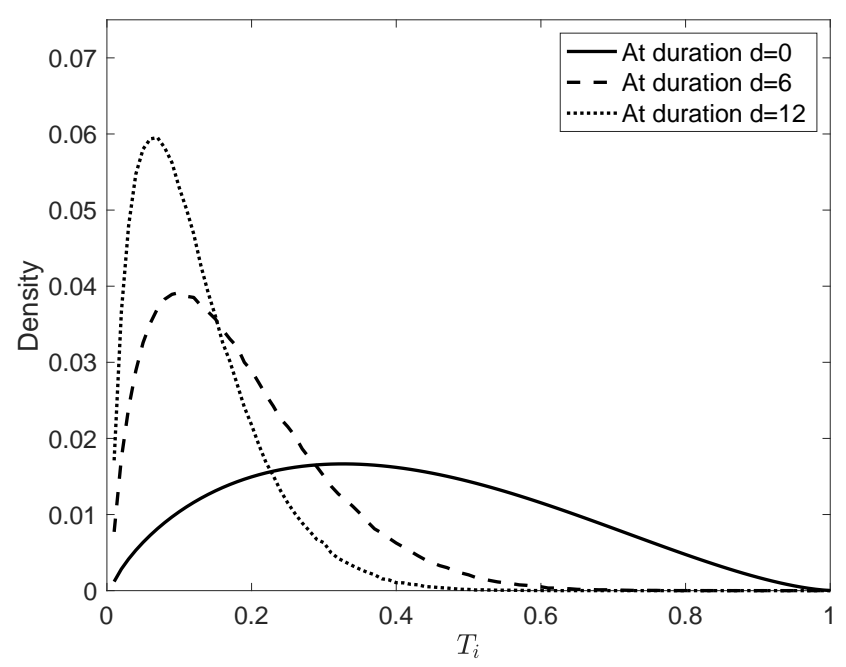

(b) Duration Dependence in Job Finding

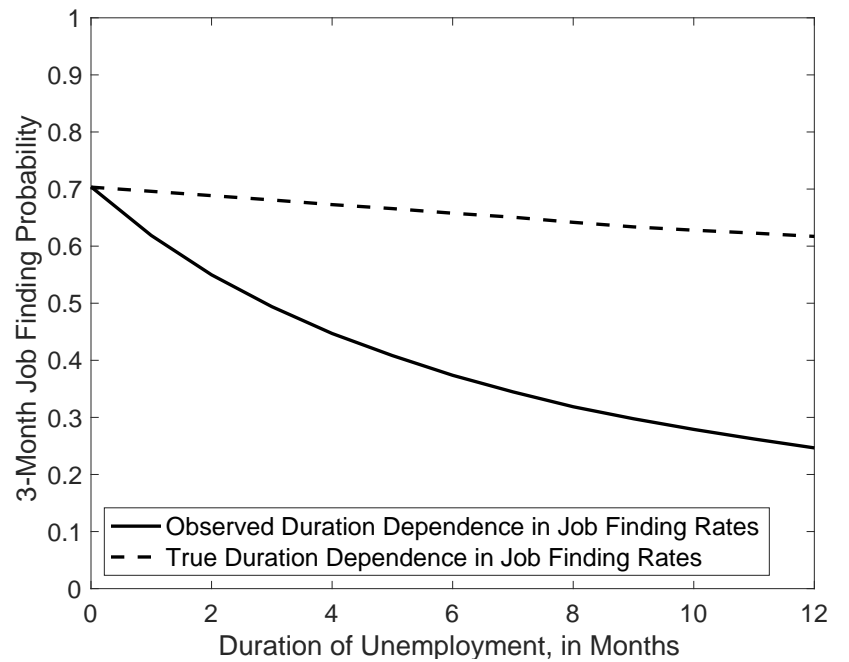

shows that the large amount of heterogeneity in job finding rates accounts for most of the observed duration dependence in job finding rates. The figure compares simulations of the baseline model (solid line), with a model where all heterogeneity is eliminated and the only source of duration dependence in job finding rates is $\theta \neq 0$ (dashed line). Our model attributes $84.7 \%$ (s.e. $36.4 \%$ ) of the decline in 3 -month job finding rates, which is from 0.70 to 0.24 over the first year of unemployment, to selection. ${ }^{46}$ The remainder - a decline of only 7 percentage points - is due to the depreciation of the job finding probability over the spell of unemployment. This corresponds to a modest monthly depreciation rate of 1.7 percent for the 1-month job finding rate.

To assess the amount of heterogeneity predicted by our model, we can compare it to our reducedform estimates in Section 3. The variance of 3-month job finding probabilities in our model for all durations is 0.102 , which exactly coincides with our earlier calculation using reduced-form estimates for $\operatorname{cov}\left(Z_{i, d}^{3}, F_{i, d}^{3}\right) / b_{1}$. The importance of adding structure on the beliefs can be gauged by comparing this value to our non-parametric lower bound estimates in Section 3.3. We found that the non-parametric lower bound on the variance in job finding using the 3-month elicitation alone was 0.032 . This corresponds to 31 percent of the estimated variance in 3-month job finding probabilities in our model. We tightened this bound further by including both the 3-month and the 12-month elicitation as well as the observables used before to obtain a variance of predicted values of 0.054 , which now corresponds to 53 percent of the estimated variance. The total variance of 3-month job finding probabilities in our model is somewhat larger than the variance of 0.076 that is reported in Table 5, where we restrict the sample to newly unemployed workers. Finally, a significant share of this variation (25\%) is driven by transitory shocks, which do not contribute to dynamic selection. Overall, the differences in job finding are thus

\footnotetext{
${ }^{46}$ We note that this relative role is relatively imprecisely estimated, but this is not too surprising, given its residual nature and thus dependence on all other parameters in the estimation. Nevertheless, we strongly reject the case that attributes all of the observed duration dependence to depreciation at the individual level.
} 
estimated to be highly persistent, but somewhat less than suggested by the reduced-form evidence. ${ }^{47}$

Biases in Beliefs The estimation also confirms the importance of biases in beliefs. Perceptions substantially under-react to the variation in job finding across workers. On average, workers who face a 10 percent higher job finding probability on average perceive their chances as only 5.50 percent higher (s.e. 1.01). The slope bias is thus large and significant. Since the average wedge between actual and perceived job finding is small, low- $T_{i}$ types are estimated to be over-optimistic and conversely high- $T_{i}$ types are over-pessimistic. Our baseline model does not allow for the variation in job finding rates to be perceived differently across and within job seekers. This implies that job seekers perceive only about half of the 7 percentage point decline of job finding over the first 12 months of their spell.

We probe the robustness of our results to the latter assumption, and extend our model to allow for beliefs to be perceived differently across and within job seekers. Specifically, we assume a linear model for the elicitations of the perceived 3-month job finding rate:

$$
Z_{i, d}^{3}=b_{0}+b_{1} \hat{T}_{i, d}^{3}+\varepsilon_{i, d} \in[0,1]
$$

where we define the variable $\hat{T}_{i, d}$, in analogy to equation (10) above,

$$
\hat{T}_{i, d}=(1-\hat{\theta})^{d}\left(T_{i}+\tau_{i, d}\right) \in[0,1] .
$$

The variable $\hat{T}_{i, d}^{3}$ captures the duration dependence in perceptions through the parameter $\hat{\theta} .^{48}$ This dynamic parameter depends on the perceived depreciation, but also any learning from unsuccessful job search and is expressed at the monthly frequency so that it directly corresponds to the parameter that controls the true duration dependence, $\theta$. For example, while $b_{1}<1$ implies that perceptions underreact to variation in job finding across individuals, $\hat{\theta}<\theta$ implies that perceptions change even less with variation in job finding over the spell.

We can identify any additional duration dependence in beliefs that is separate from duration dependence in job finding (i.e., $\hat{\theta} \neq \theta$ ) using the variances of perceived job finding and the covariances of actual and perceived job finding over the spell of unemployment. Intuitively, more depreciation in perceived job finding (higher $\hat{\theta}$ ) implies a lower variance of perceived job finding and a lower covariance between actual and perceived job finding at higher durations of unemployment. We again develop this identification argument formally in Appendix Section E. $3{ }^{49}$

We add the variance of perceived job finding and the covariance with actual job finding at different duration intervals as additional moments to estimate the new parameter $\hat{\theta}$. Column 14 of Appendix Table E4 shows the estimation results, which are very similar to the baseline model. The slope coefficient is almost identical $\left(b_{1}=0.52\right)$ and the duration dependence parameter $\theta$ is 0.022 , which is small and

\footnotetext{
${ }^{47}$ This is higher than in our back-of-the-envelope calculation in footnote 3.3 , which did not condition on a given duration $d$ and ignored any potential true duration dependence in job finding.

${ }^{48}$ Note that $\hat{T}_{i, d}^{3}=\hat{T}_{i, d}+\left(1-\hat{T}_{i, d}\right) \hat{T}_{i, d+1}+\left(1-\hat{T}_{i, d}\right)\left(1-\hat{T}_{i, d+1}\right) \hat{T}_{i, d+2}$.

${ }^{49}$ Appendix Section E.3 starts with a formal proof of identification, showing that in a two-period version of the statistical model, where $\sigma_{\tau}=0$ and $\hat{\theta} \neq \theta$, all parameters are an explicit function of moments with an empirical counterpart in the data. We then develop the identification arguments in the full model. While we can no longer solve explicitly for these parameters, we show that a monotone relationship exists between $\hat{\theta}$ and both the variance of perceived job finding for the long-term unemployed as well as the covariance with actual job finding for the long-term unemployed.
} 
very close to the 0.017 in the baseline model. The corresponding beliefs parameter $\hat{\theta}$ is slightly larger at 0.037 , but note that the change in perceptions over the unemployment spell depends on both the parameter $\hat{\theta}$ as well as $b_{1}$. More precisely, while $\hat{\theta}$ is slightly larger than $\theta$ and thus $\hat{T}_{i, d}^{3}$ declines more over the spell than $T_{i, d}^{3}$, to get to the change in $Z_{i, d}^{3}$, the change in $\hat{T}_{i, d}^{3}$ is multiplied by $b_{1}=0.52$. As shown in Table E4, the extended model predicts a decline of actual job finding at the individual level of 8.9 percentage points over the first 12 months of the unemployment spell, whereas the decline in perceived job finding equals 8.2 percentage points. The fact that the perceived and actual job finding decline at similar and modest rates over the spell, indicates that there is limited scope for learning from remaining unemployed. ${ }^{50}$ We note that the fact that perceptions decline slightly at the individual level is still consistent with our positive within-spell estimates in the empirical section because of the presence of mean reversion in transitory job finding. We also note, not surprisingly, that the fit of the restricted model in column 15 where $\hat{\theta}=\theta$ is close to the fit of the unrestricted version in column 14 .

\subsection{Robustness}

We study the robustness of our results when using alternative specifications, alternative moments, and alternative functional forms and distributions.

We have aimed to parametrize our model as parsimoniously as possible. To illustrate this, we estimate a number of versions of the model where we restrict parameter choices as reported in Table 6 (see also the Appendix Table E2, which reports all the estimated parameters). Regarding the actual job finding rates, we first estimate a version of the model where we do not allow for any depreciation in job finding rates, $\theta=0$ (column 2). Unsurprisingly, this model version fits the data nearly as well as the baseline. In contrast, when we estimate a version of the model where we do not allow for any heterogeneity in $T_{i, d}$, the model fits the data very poorly (column 3 ). The two versions jointly underline the relative importance of heterogeneity relative to true duration dependence to explain the empirical moments. We also estimate a version of the model, where we set only $\sigma_{\tau}=0$, i.e., we do not allow for any transitory changes in job finding. As shown in column (4) of Appendix Table E2, this specification has difficulty in matching both $c_{Z_{d}, F_{d}}$ and $c_{Z_{d}, F_{d+3}}$. The version without transitory shocks implies a much larger extent of heterogeneity in $T_{i}$ and, as a result, an appreciation of the job finding rates over the unemployment spell $(\theta<0)$. Given our estimation procedure leveraging elicitations to learn about heterogeneity in types, it proves to be important to allow for transitory heterogeneity.

Regarding the perceived job finding rates, we estimate a version of the model where we do not allow for any under-response to differences in job finding (column 5 with $b_{1}=1$ ). The fit gets substantially worse, indicating the importance of allowing for the slope bias. Very similar results are obtained when adding also the restriction that the intercept bias equals zero (column 6 in Table E2 with $b_{0}=0$ ).

We also assess the estimated heterogeneity in our statistical model using the variation in job finding that is not predictable based on observable characteristics. To this purpose, we estimate the model on a set of moments obtained from the residuals of regressions of the 3-month belief question and of the

\footnotetext{
${ }^{50}$ This is also illustrated in Appendix Figure E2, which shows the difference in actual and perceived job finding by duration of unemployment in the estimated extended model. It shows that at the individual level, there is almost no change in the bias by duration of unemployment. The figure also implies that the optimistic bias of the long term unemployed is almost entirely driven by the dynamic selection of over-optimistic individuals into long-term unemployment.
} 
Table 6: Selected Moments and Model Fit for Restricted Versions of the Model

\begin{tabular}{lcccccc}
\hline & $(1)$ & $(2)$ & $(3)$ & $(4)$ & $(5)$ & $\begin{array}{c}(6) \\
\text { Moments }\end{array}$ \\
& Baseline & $\theta=0$ & $\begin{array}{c}\text { No heterog. } \\
\text { in } T_{i, d}\end{array}$ & $\begin{array}{c}\sigma_{\tau}=0 \\
b_{1}=1\end{array}$ & $\begin{array}{c}b_{0}=0 \\
b_{1}=1\end{array}$ \\
\hline $\operatorname{Var}_{0}\left(T_{i, 0}^{3}\right)$ & 0.076 & 0.079 & 0.000 & 0.085 & 0.051 & 0.047 \\
$\operatorname{Var}_{0}\left(T_{i}^{3}\right)$ & 0.057 & 0.065 & 0.000 & 0.085 & 0.040 & 0.033 \\
$\mathrm{LD}$ & 0.070 & 0.000 & 0.430 & -0.116 & 0.054 & 0.071 \\
$1-L D / T D($ in $\%)$ & 84.71 & 100.00 & 0.000 & 125.67 & 82.20 & 77.53 \\
\hline Weighted SSR & 0.470 & 0.695 & 49.198 & 2.514 & 12.251 & 21.613 \\
\hline
\end{tabular}

Notes: TD stands for total decline in 3-month job finding, whereas LD stands for longitudinal decline in 3-month job finding over the first 12 months of the unemployment spell. See Table 5 for details.

3-month job finding rate on demographic controls (the same set of controls as used for the regressions reported in Table 2). The estimation results are similar to the baseline, with the role played by true duration dependence being close to zero. ${ }^{51}$ Of course, the extent of heterogeneity is smaller, as the effects of observables are parsed out from all moments. We also obtain a comparable estimate for $b_{1}$ (0.559), which suggests that the relationship between observed heterogeneity in job finding and beliefs is similar as the relationship between unobserved heterogeneity in job finding and beliefs.

We finally probe the robustness of our findings to alternative assumptions about functional form and distributions as well as extensions of the model, as reported in Appendix Tables E3 and E4. Without discussing these estimates in detail, the table shows that the parameter estimates are very stable across all of the results reported in the table. In particular, our results are robust to assuming that $T_{i}$ follows the Gamma distribution, and to assuming that $\varepsilon$ follows a truncated normal distribution, which no longer satisfies mean-independence of the error term. Our results are also robust to assuming piecewise linear duration dependence instead of geometric depreciation and extending the horizon of the model to 5 years. We also find that our results are robust to fully persistent elicitation errors (i.e., $\varepsilon_{i, d}=\varepsilon_{i}$ ) and bunching at $0,0.5$ and 1 of the elicited beliefs. Furthermore, we report the results for a model, where a share $\alpha$ of individuals has random elicitations $\left(Z_{i, d}^{3}=b_{0}+\varepsilon\right)$ and a share $1-\alpha$ correctly perceives their job finding prospects $\left(Z_{i, d}^{3}=T_{i, d}^{3}\right)$. The model results are very similar to our baseline, and the value of $1-\alpha$ is close to the value of $b_{1}$, suggesting that $b_{1}$ in our baseline may instead capture the share of individuals who perceive their job finding prospects correctly. Finally, our results are very similar when excluding individuals with recall expectations when generating the data moments, when restricting the set of moments by using only $0-6$ and $7+$ months for the time intervals and dropping the mean of monthly innovations, so that the model is exactly identified, or when using the inverse of the bootstrapped variances as weights instead of the full variance-covariance matrix.

\section{$5 \quad$ Structural Model of Job Search with Biased Beliefs}

In the statistical model we have estimated the heterogeneity and duration dependence in perceived and true job finding, but we have abstracted from the underlying behavior of job seekers and how it

\footnotetext{
${ }^{51}$ The estimation results and targeted moments are shown in Tables E4 and E5 in the Appendix.
} 
depends on their beliefs. Using our estimates from the statistical model, in this section, we calibrate a McCall type model, which explicitly relates workers' job search to their perceived and true job finding prospects. We use the calibrated model to quantify the impact of biases in beliefs on unemployment duration and the incidence of long-term unemployment. We refer to Appendix F for further details on the model and its calibration.

\subsection{Model}

We consider a stylized version of McCall's search model in which agents decide how to set their reservation wage. We allow for heterogeneity and duration dependence in both the true and perceived arrival rates of wage offers, denoted by $\lambda_{i, d}$ and $\hat{\lambda}_{i, d}$ respectively. ${ }^{52}$ Wage offers are drawn from a known distribution $w \sim F\left(\mu_{w}, \sigma_{w}^{2}\right)$. The perceived value of unemployment for agent $i$ at duration $d$ equals

$$
\left.U_{i, d}=u\left(b_{u}\right)+\frac{1}{1+\delta} \max _{R}\left\{U_{i, d+1}+\hat{\lambda}_{i, d} \int_{R}\left[V_{i}(w)-U_{i, d+1}\right)\right] d F(w)\right\}
$$

where $\delta$ is the discount rate, $u\left(b_{u}\right)$ is the per-period utility flow when unemployed and $V_{i}(w)$ is the value of being employed at wage $w .^{53} \mathrm{~A}$ job seeker sets her reservation wage $R_{i, d}$ to maximize her perceived continuation value at any time of the unemployment spell. At this reservation wage, the agent is indifferent between accepting a job and remaining unemployed, $U_{i, d}=V\left(R_{i, d}\right)$. The resulting actual and perceived job finding rate for agent $i$ at time $t$ equal

$$
T_{i, d}=\lambda_{i, d}\left(1-F\left(R_{i, d}\right)\right) \text { and } Z_{i, d}=\hat{\lambda}_{i, d}\left(1-F\left(R_{i, d}\right)\right)
$$

respectively, corresponding to the actual and perceived job finding rates in our statistical model.

We assume two types of job seekers: a high type $h$ and a low type $l$, with $\lambda^{h}>\lambda^{l}$, and $\phi$ denoting the share of job seekers with a high arrival rate. For both types of job seekers, the arrival rate depreciates at geometric rate $\theta$. As in the statistical model, we allow for three types of biases in job seekers' beliefs, but now applied to the arrival rates. First, job seekers may be subject to a uniform bias $B_{0}$. That is, any type's arrival rate is perceived as $\hat{\lambda}^{j}=\lambda^{j}+B_{0}$. Second, job seekers misperceive their employability type with probability $1-B_{1}$. That is, $\operatorname{Prob}\left(\hat{\lambda}_{i, 0}=\hat{\lambda}^{j} \mid \lambda_{i, 0}=\lambda^{j}\right)=B_{1}$. This is a parsimonious way to capture that job seekers' beliefs under-react to their differences in risk. Finally, job seekers perceive a depreciation rate of their arrival rates of $B_{\theta} \theta \cdot{ }^{54}$

\footnotetext{
${ }^{52}$ In order to provide tractable characterizations of the impact on job finding and on duration dependence, all the action in terms of heterogeneity, dynamics and biases is introduced through the arrival rates. As we assume that the wage offer distribution is known, optimal search behavior is represented by a simple reservation price rule (see Rothschild [1974] and Bikhchandani and Sharma [1996]) and this is not affected by the dynamics we introduce in the perceived arrival rate. We abstract away from other potential biases. See Dubra [2004] and Conlon et al. [2018] for models with varying priors regarding the wage offer distribution and learning based on the received wage offers. See Spinnewijn [2015] for a model of search efforts with biased beliefs, distinguishing between baseline beliefs - regarding the baseline probability of job finding - and control beliefs - regarding the increase in the job finding probability when searching more.

${ }^{53}$ The value of employment follows a similar structure, given an arrival rate of offers, $\lambda_{e}$, and accounting for an exogenous job separation rate, $\sigma$. For our analytical derivations, we set $\lambda_{e}=\sigma=0$, but we relax this in the numerical analysis.

${ }^{54}$ The arrival rate of worker $i$ of type $j$ after $d$ periods of unemployment equals $\lambda_{i, d}=(1-\theta)^{d} \lambda^{j}$, while the perceived arrival rate equals $\hat{\lambda}_{i, d}=\left(1-B_{\theta} \theta\right)^{d} \lambda^{j}+B_{0}$ with probability $B_{1}$ and $\hat{\lambda}_{i, d}=\left(1-B_{\theta} \theta\right)^{d} \lambda^{-j}+B_{0}$ otherwise. Note that our model ignores additional random errors in the beliefs, which we cannot credibly separate from noise in the elicitations.
} 
Biased Beliefs The setup allows us to illustrate a key behavioral mechanism in the presence of biased beliefs. When a job seeker's employment prospects change, she adapts her job search strategy to mitigate the impact on her employment chances. This response, however, only comes into play when the change in employment prospects is perceived. In our model, when the arrival rate of offers increases for a job seeker, this mechanically increases the job finding rate. However, the job seeker becomes more selective and increases her reservation wage (and thus decreases the job finding rate), but only to the extent that the increase in the arrival rate is perceived. The mechanical and behavioral effect thus work in opposite directions: $:^{55}$

$$
d T=\underbrace{[1-F(R)] d \lambda}_{\text {Mechanical Effect }}-\underbrace{\left[\lambda f(R) \frac{\partial R}{\partial \hat{\lambda}}\right] d \hat{\lambda}}_{\text {Behavioral Effect }} .
$$

For constant arrival rates, we show that the pass-through elasticity of the arrival rate to the job finding rate simplifies to

$$
\varepsilon_{i}^{T, \lambda}=1-\frac{d \hat{\lambda}_{i}}{d \lambda_{i}} \kappa_{i}
$$

for $\kappa_{i}=\frac{T_{i}}{1+\delta} \frac{f\left(R_{i}\right)}{1-F\left(R_{i}\right)} E\left(\frac{u(w)-u\left(R_{i}\right)}{u^{\prime}\left(R_{i}\right)} \mid w \geq R_{i}\right) \geq 0$. Importantly, the mitigating behavioral effect is proportional to $d \hat{\lambda}_{i} / d \lambda_{i}$, highlighting the impact biased beliefs have on actual unemployment outcomes. For the same true arrival rates, job seekers who are more optimistic about their employment prospects take actions that cause them to exit unemployment more slowly.

Heterogeneity vs. Duration-Dependence The wedge between the true and perceived arrival rates, either across agents or over the unemployment spell, changes the observed duration dependence in job finding rates. Giving the mitigating impact of job seekers' behavior, any difference across job seekers' or over the unemployment spell that is not perceived leads to larger differences in actual job finding. This implies stronger negative duration dependence in job finding and thus a higher incidence of long-term unemployment. In our model, we can state:

Proposition 1. Starting from a stationary, single-agent model $\left(\theta=0, \lambda^{h}=\lambda^{l}=\bar{\lambda}\right)$ and assuming $\kappa<\min \left\{1 / B_{1}, \lambda_{0} / B_{\theta}\right\}$ :

i. A mean-preserving spread in the true arrival rates $\left(\lambda^{h}>\lambda^{l}\right.$ for $\left.\phi=1 / 2\right)$ introduces negative duration dependence in the job finding, $\frac{E_{1}\left(T_{i, 1}\right)}{E_{0}\left(T_{i, 0}\right)}<1$, and at a higher rate when $B_{1}<1$.

\footnotetext{
${ }^{55}$ While we introduce variation in job finding through the arrival rates, it is important to note that the mechanical and behavioral effect would continue to have opposite signs when changing the mean of the wage offer distribution instead, like in Conlon et al. [2018]. A more favorable wage offer distribution increases job finding for a given reservation wage, but workers would increase their reservation wage if this is perceived. See Dubra [2004] for general conditions under which optimistic job seekers remain unemployed for longer. The mechanical and behavioral effect have also opposite signs in a model with endogenous search, like in Spinnewijn [2015], when varying the baseline probability of finding employment, keeping the returns to search fixed. The two effects would have the same sign, however, when varying the returns to search instead; job seekers with higher returns to search find jobs at a higher rate and search more if they perceive the higher returns. In contrast with the other three sources of heterogeneity, this final source of heterogeneity would give rise to a positive correlation between job finding and the optimistic bias, which is opposite to what we find in the data.
} 
ii. Geometric depreciation in the true arrival rates $(\theta>0)$ introduces negative duration dependence in the job finding rates, $\frac{E_{d+1}\left(T_{i, d+1}\right)}{E_{d}\left(T_{i, d}\right)}<1$, and at a higher rate when $B_{\theta}<1$.

See Appendix F.1.1 for the proof. First, when arrival rates are heterogeneous across job seekers, those with lower resulting job finding rates are more likely to remain unemployed. Following equations (1) and (2), the dynamic selection is stronger the larger the variance in job finding rates. We can approximate this variance at the start of the spell for limited heterogeneity $\left(\lambda_{i}=\bar{\lambda}+d \lambda_{i}\right)$ by

$$
\begin{aligned}
\operatorname{var}_{d}(T) & \cong \operatorname{var}_{d}\left([1-F(R)] d \lambda-\bar{\lambda} f(R) \frac{\partial R}{\partial \hat{\lambda}} d \hat{\lambda}\right) \\
& \propto\left[1+\kappa^{2}-2 \kappa\left(2 B_{1}-1\right)\right] \operatorname{var}_{d}(d \lambda)
\end{aligned}
$$

The approximation shows that the variance in job finding rates is increasing in the heterogeneity in true arrival rates, but less so the more this heterogeneity is perceived. ${ }^{56}$

Second, the evolution of job finding rates over the spell depends on how the arrival rates evolves and how the reservation wage responds,

$$
\frac{E_{d+1}\left(T_{i, d+1}\right)}{E_{d}\left(T_{i, d}\right)}=\frac{E_{d}\left(\lambda_{d+1}\left[1-F\left(R_{d+1}\right)\right]\right)}{E_{d}\left(\lambda_{d}\left[1-F\left(R_{d}\right)\right]\right)} .
$$

Any depreciation of the arrival rates translates mechanically into negative duration dependence in the job finding rates. However, when job seekers perceive the depreciation in arrival rates, they will adjust their reservation wages and thus the acceptance rates. Starting from a stationary setting, the effect on the relative job finding rate equals

$$
\frac{d\left[\frac{E_{d+1}\left(T_{i, d+1}\right)}{E_{d}\left(T_{i, d}\right)}\right]}{d \theta} \cong B_{\theta} \times \frac{\kappa}{\lambda_{0}}-1,
$$

where the behavioral effect is again scaled by the perception of the depreciation $B_{\theta}$. As the perceived depreciation lowers the arrival rates more later in the spell, it induces workers to lower the reservation wage more later in the spell, translating into a larger increase in the acceptance rate later on. This behavioral response thus works in the opposite direction as the mechanical effect.

In sum, both heterogeneity and true duration dependence cause the observed duration dependence in job finding rates to be magnified when the respective force is under-estimated. Making job seekers' beliefs more accurate would thus reduce duration dependence and the incidence of long-term unemployment.

\subsection{Numerical Analysis}

We calibrate our structural model with heterogeneity and duration dependence in the actual and perceived arrival rates, targeting a subset of moments from our empirical and statistical analysis. ${ }^{57}$ Ap-

\footnotetext{
${ }^{56}$ The argument regarding the variance holds at any duration $d$, but its impact on duration dependence is normalized by $E_{d}\left(T_{i, d}\right)\left(1-E_{d}\left(T_{i, d}\right)\right)$. Hence, changes in the average job finding rate $E_{d}\left(T_{i, d}\right)$ can lead to offsetting effects for $d>0$, while the job finding rate at $d=0$ remains constant for a mean-preserving spread.

${ }^{57}$ While in theory it is possible, to perform the same estimation exercise in the structural model as in the reduced form statistical model, fitting our cross-sectional data moments requires a large number of types, which is computationally
} 
pendix Tables F1 and F2 show the targeted moments and calibrated parameters. As in the statistical model, the targeted moments include the empirical true and perceived job finding rates for the short, medium and long-term unemployed. But rather than targeting the covariances between true and perceived job finding rates, we directly target the true duration dependence in job finding as estimated in the statistical model. In particular, we target the ratio of the sample average of job finding when long-term unemployed ( $>6$ months) vs. the sample average of job finding when short-term unemployed ( $\leq 6$ months). This ratio is estimated to be 0.90 in the statistical model. We gauge the sensitivity of our results to setting this target ratio at 0.75 , which is below any estimate from the statistical model.

The estimated parameters minimize the sum of squared differences between data moments and simulated moments from the model. We closely match our targeted moments and obtain plausible values for standard labor market statistics. We provide details on the calibration in Appendix F.2.

Comparative Statics We use the calibrated model to illustrate the opposing mechanical and behavioral effects on job finding (see Appendix Figure F1). Starting from our baseline model, decreasing the arrival rate of job offers by 10 percent increases the unemployment duration by 10 percent in the absence of behavioral responses, but this increase is mitigated to only 6.8 percent when the worse employment prospects are accurately perceived. In line with Proposition 1, we also find that a 10 percent increase in the spread of arrival rates increases the share of unemployed workers who are unemployed for longer than 6 months by 28 percent. A 10 percent increase in the correlation between the actual and perceived arrival rates, however, reduces that share of LT unemployed by 3.7 percent. Similarly, increasing the depreciation rate from its baseline level to the high level, corresponding to our two calibration models respectively, the share of LT unemployed increases by 16 percent, but the impact would be mitigated to an increase of 13 percent if the change in depreciation were perceived as such.

Counterfactual Analysis We also use the calibrated model to quantify the impact of eliminating the biases in beliefs on job seekers' employment and the incidence of long-term unemployment in particular (see Appendix Table F3). While eliminating all three biases jointly $\left(B_{0}=0, B_{1}=B_{\theta}=1\right)$ lowers the average unemployment duration slightly, the impact on the share of LT unemployed is significant as it decreases by 8.2 percent $(2.4 \mathrm{pp})$. Interestingly, the results are qualitatively similar for the calibrated model with a high depreciation rate. While the effect on the average unemployment duration is slightly larger, the effect on the share of LT unemployed is basically the same at 8.9 percent. The model's prediction that biased beliefs contribute substantially to the high incidence of LT unemployment seems robust to the relative importance of heterogeneity vs. depreciation in the true arrival rates. This is not too surprising as job seekers' perceptions under-react to the overall variation in job finding in both calibrations. In line with Proposition 1, both under-reacting to the cross-sectional and to the longitudinal variation increases the incidence of LT unemployment. ${ }^{58}$ Expressed as the ratio of the LT vs. ST unemployment rate, we conclude that $11-12$ percent of the high incidence of LT unemployment

challenging, given that we need to solve the decision problem for each type.

${ }^{58}$ The probability that high (low) types perceive themselves as high (low) types equals $B_{1}=0.84$ in the baseline model. The cross-sectional bias becomes smaller $\left(B_{1}=0.89\right)$ in the model with high depreciation. However, with no perceived depreciation in both models $\left(B_{\theta}=0\right)$, the under-estimation of the depreciation is more pronounced in the latter. 
in our model is explained by biased beliefs. We view this as a clear lower bound as we focus only on systematic biases in beliefs but ignore random errors in perceptions as an additional source of bias.

\section{Conclusion}

This paper analyzes job seekers' perceptions about their employment prospects and how these perceptions relate to employment outcomes. We have offered three sets of results:

We have documented empirically (1) that reported beliefs have strong predictive power for actual job finding, (2) that job seekers are over-optimistic in their beliefs, particularly the long-term unemployed, and (3) that job seekers do not revise their beliefs downward when remaining unemployed.

We have then developed a novel framework, where we show how the relation between beliefs and ex-post realizations can be used to disentangle heterogeneity and duration dependence in true job finding rates. Using this framework, we find that the reported beliefs reveal a substantial amount of heterogeneity in true job finding rates, accounting for most of the observed decline in job finding rates over the spell of unemployment. Moreover, we find that job seekers' beliefs are systemically biased and under-respond to differences in job finding rates across job seekers. Job seekers with low job finding are over-optimistic and select into long-term unemployment without adjusting their beliefs downward.

We have also shown in a model of job search how biases in beliefs contribute to the slow exit out of unemployment and the incidence of long-term unemployment. Unemployed workers with worse employment prospects are over-optimistic, setting their reservation wage too high and not sufficiently adjusting it as the unemployment spell progresses. Calibrating this model, we find that this mechanism significantly increases the incidence of long-term unemployment.

Our analysis demonstrates the broader value of having data on both expectations and realizations for the same individuals over time. In our context, the data allow us to learn about job seeker's true employment prospects, providing us with a novel identification strategy to separate dynamic selection and true duration dependence, with well-known implications with regard to a broad range of labor market policies. Further, the data allow us to learn about biases in the perceived employment prospects and to study their interplay with behavior in determining unemployment outcomes. We believe this opens up an important area of research with again wide-ranging policy implications. Our findings for

example raise the question of whether biases in beliefs amplify the rise of long-term unemployment in recessions. If unemployed workers fail to adjust their beliefs about their employment prospects in response to developments in the aggregate labor market, the lack of a behavioral response is likely to lead to greater unemployment levels than would otherwise be the case. 


\section{References}

Acemoglu, Daron, "Public Policy in a Model of Long-term Unemployment," Economica, 1995, 62 (246), $161-178$.

Altmann, Steffen, Armin Falk, Simon Jäger, and Florian Zimmermann, "Learning about job search: A field experiment with job seekers in Germany," Journal of Public Economics, 2018, 164, 33 - 49.

Alvarez, Fernando E., Katarina Borovickova, and Robert Shimer, "Decomposing Duration Dependence in a Stopping Time Model," April 2016. NBER Working Paper No. 22188.

Arcidiacono, Peter, V. Joseph Hotz, Arnaud Maurel, and Teresa Romano, "Recovering Ex Ante Returns and Preferences for Occupations using Subjective Expectations Data," Working Paper 20626, National Bureau of Economic Research October 2014.

Armantier, Olivier, Giorgio Topa, Wilbert van der Klaauw, and Basit Zafar, "An Overview of the Survey of Consumer Expectations," Economic Policy Review, 2017, 23 (2), 51-72.

Arni, Patrick, "What's in the Blackbox? The Effect of Labor Market Policy on Job Search Behavior, Beliefs and Non-cognitive Skills. A Field Experiment," 2017. IZA Discussion Paper 9617.

_ , Marco Caliendo, Robert Mahlstedt, and Steffen Kunn, "Predicting the Risk of Longterm Unemployment: What Can We Learn from Personality Traits, Beliefs and other Behavioral Variables?," 2016. Mimeo.

Belot, Michèle, Philipp Kircher, and Paul Muller, "Providing Advice to Jobseekers at Low Cost: An Experimental Study on Online Advice," 2020. Forthcoming in the Review of Economics Studies.

Bikhchandani, Sushil and Sunil Sharma, "Optimal search with learning," Journal of Economic Dynamics and Control, 1996, 20 (1), 333 - 359.

Brunnermeier, Markus K. and Jonathan A. Parker, "Optimal Expectations," American Economic Review, 2005, 95 (4), 1092-1118.

Burdett, Kenneth and Tara Vishwanath, "Declining Reservation Wages and Learning," The Review of Economic Studies, 1988, 55 (4), 655-665.

Caliendo, Marco, Deborah A. Cobb-Clark, and Arne Uhlendorff, "Locus of Control and Job Search Strategies," The Review of Economics and Statistics, 2015, 97 (1), 88-103.

Clark, Kim B. and Lawrence H. Summers, "Labor Market Dynamics and Unemployemnt: A Reconsideration," Brookings Papers on Economic Activity, 1979, 10 (1), 13-72.

Coles, Melvyn G and Eric Smith, "Marketplaces and Matching," International Economic Review, February $1998,39(1), 239-254$.

Conlon, John J., Laura Pilossoph, Matthew Wiswall, and Basit Zafar, "Labor Market Search With Imperfect Information and Learning," NBER Working Papers 24988, National Bureau of Economic Research, Inc September 2018.

Crump, Richard, Stefano Eusepi, Giorgio Topa, and Andrea Tambalotti, "Subjective Intertemporal Substitution," 2018. Mimeo.

Delavande, Adeline and Basit Zafar, "University choice: the role of expected earnings, non-pecuniary 
outcomes, and financial constraints," Staff Reports 683, Federal Reserve Bank of New York August 2014.

DellaVigna, Stefano and M. Daniele Paserman, "Job Search and Impatience," Journal of Labor Economics, 2005, 23 (3), 527-588.

_ , Attila Lindner, Balázs Reizer, and Johannes F. Schmieder, "Reference-Dependent Job Search: Evidence from Hungary*," The Quarterly Journal of Economics, 2017, 132 (4), 1969-2018.

_ , Joerg Heining, Johannes F. Schmieder, and Simon Trenkle, "Evidence on Job Search Models from a Survey of Unemployed Workers in Germany," March 2020. Mimeo.

Drahs, Sascha, Luke Haywood, and Amelie Schiprowski, "Job Search with Subjective Wage Expectations," 2018. Mimeo.

Dubra, Juan, "Optimism and overconfidence in search," Review of Economic Dynamics, 2004, 7 (1), $198-218$.

Elsby, Michael W.L., Bart Hobijn, and Aysegul Sahin, "On the importance of the participation margin for labor market fluctuations," Journal of Monetary Economics, 2015, 72, 64-82.

Faberman, R. Jason, Andreas I. Mueller, Aysegul Sahin, and Giorgio Topa, "Job Search Behavior among the Employed and Non-Employed," August 2017. NBER Working Paper No. 23731.

Falk, Armin, David B. Huffman, and Uwe Sunde, "Self-Confidence and Search," IZA Discussion Papers 2525, Institute for the Study of Labor (IZA) December 2006.

Farber, Henry S, Chris M Herbst, Dan Silverman, and Till von Wachter, "Whom Do Employers Want? The Role of Recent Employment and Unemployment Status and Age," Working Paper 24605, National Bureau of Economic Research May 2018.

Feldstein, Martin and James Poterba, "Unemployment insurance and reservation wages," Journal of Public Economics, 1984, 23 (1-2), 141-167.

Fishe, Raymond P. H., "Unemployment Insurance and the Reservation Wage of the Unemployed," The Review of Economics and Statistics, 1982, 64 (1), 12-17.

Fuster, Andreas, Greg Kaplan, and Basit Zafar, "What would you do with \$500? Spending responses to gains, losses, news, and loans," Staff Reports 843, Federal Reserve Bank of New York March 2018.

Hall, Robert E. and Andreas I. Mueller, "Wage Dispersion and Search Behavior: The Importance of Non-Wage Job Values," Journal of Political Economy, August 2018, 4, 1594-1637.

Heckman, James J. and B. Singer, "The Identifiability of the Proportional Hazard Model," The Review of Economic Studies, 1984, 51 (2), 231.

Hendren, Nathaniel, "Private information and insurance rejections," Econometrica, 2013, 81 (5), 17131762.

_ , "Knowledge of Future Job Loss and Implications for Unemployment Insurance," American Economic Review, 2017, 107 (7), 1778-1823.

Honoré, Bo E., "Identification Results for Duration Models with Multiple Spells," Review of Economic Studies, 1993, 60 (1), 241-246. 
Hornstein, Andreas, Per Krusell, and Giovanni L. Violante, "Frictional Wage Dispersion in Search Models: A Quantitative Assessment," American Economic Review, December 2011, 101 (7), 287398.

Jacobson, Louis S., Robert J. LaLonde, and Daniel G. Sullivan, "Earnings Losses of Displaced Workers," The American Economic Review, 1993, 83 (4), 685-709.

Jaeger, Simon, Benjamin Schoefer, Samuel Young, and Josef Zweimuller, "Wages and the Value of Nonemployment," 2020. Forthcoming in the Quarterly Journal of Economics.

Jarosch, Gregor and Laura Pilossoph, "Statistical Discrimination and Duration Dependence in the Job Finding Rate," The Review of Economic Studies, 2018, 86 (4), 1631-1665.

Kolsrud, Jonas, Camille Landais, Peter Nilsson, and Johannes Spinnewijn, "The Optimal Timing of UI Benefits: Theory and Evidence from Sweden," American Economic Review, 2018, 108 (4-5), 985-1033.

Koszegi, Botond, "Ego Utility, Overconfidence, and Task Choice," Journal of the European Economic Association, 2006, 4 (4), 673-707.

Kroft, Kory, Fabian Lange, and Matthew J. Notowidigdo, "Duration Dependence and Labor Market Conditions: Theory and Evidence from a Field Experiment," Quarterly Journal of Economics, 2013, $128(3), 1123-1167$.

_ , _ , _, and Lawrence F. Katz, "Long-Term Unemployment and the Great Recession: The Role of Composition, Duration Dependence and Non-Participation," Journal of Labor Economics, 2016, 34, S7-S54.

Krueger, Alan B. and Andreas I. Mueller, "Job Search, Emotional Well-Being, and Job Finding in a Period of Mass Unemployment: Evidence from High-Frequency Longitudinal Data," Brookings Papers on Economic Activity, Spring 2011, 1 (1), 1-70.

- and _, "A Contribution to the Empirics of Reservation Wages," American Economic Journal: Economic Policy, February 2016, 8 (1), 142-179.

Lancaster, Tony, "Econometric Methods for the Duration of Unemployment," Econometrica, 1979, 47 (4), 939-56.

Ljungqvist, Lars and Thomas J. Sargent, "The European Unemployment Dilemma," Journal of Political Economy, June 1998, 106 (3), 514-550.

Lockwood, Ben, "Information Externalities in the Labour Market and the Duration of Unemployment," Review of Economic Studies, 1991, 58 (4), 733-753.

Machin, Stephen and Alan Manning, "The Causes and Consequences of Longterm Unemployment in Europe," in Orley C. Ashenfelter and David Card, eds., Handbook of Labor Economics, Vol. 3, Part C of Handbook of Labor Economics, Elsevier, 1999, pp. 3085 - 3139.

Manski, Charles F., "Measuring Expectations," Econometrica, September 2004, 72 (5), 1329-1376.

Marinescu, Ioana and Daphne Skandalis, "Unemployment Insurance and Job Search Behavior," November 2019. Mimeo.

McCall, J. J., "Economics of Information and Job Search," The Quarterly Journal of Economics, 1970, $84(1), 113-126$. 
Morrison, William and Dmitry Taubinsky, "Rules of Thumb and Attention Elasticities: Evidence from Under- and Overreaction to Taxes," 2019. Mimeo.

Pavoni, Nicola, "Optimal Unemployment Insurance, With Human Capital Depreciation, and Duration Dependence," International Economic Review, 2009, 50 (2), 323-362.

- and G. L. Violante, "Optimal Welfare-to-Work Programs," The Review of Economic Studies, 2007, 74 (1), 283-318.

Pissarides, C., "Loss of Skill during Unemployment and the Persistence of Employment Shocks," The Quarterly Journal of Economics, 1992, 10\%, 1371-1391.

Rabin, Matthew and Dimitri Vayanos, "The Gambler's and Hot-Hand Fallacies: Theory and Applications," Review of Economic Studies, 2010, 77 (2), 730-778.

Rothschild, Michael, "Searching for the Lowest Price When the Distribution of Prices Is Unknown," Journal of Political Economy, 1974, 82 (4), 689-711.

Schmieder, Johannes F. and Till von Wachter, "The Effects of Unemployment Insurance Benefits: New Evidence and Interpretation," Annual Review of Economics, 2016, 8 (1), 547-581.

Shimer, Robert and Ivan Werning, "On the Optimal Timing of Benefits with Heterogeneous Workers and Human Capital Depreciation," NBER Working Papers 12230, National Bureau of Economic Research, Inc May 2006.

Spinnewijn, Johannes, "Training and search during unemployment," Journal of Public Economics, 2013 , $99,49-65$.

_ , "Unemployed but Optimistic: Optimal Insurance Design with Biased Beliefs," Journal of the European Economic Association, 2015, 13 (1), 130-167.

Wiswall, Matthew and Basit Zafar, "Determinants of College Major Choice: Identification using an Information Experiment," The Review of Economic Studies, 2015, 82 (2), 791-824.

Wunsch, Conny, "Optimal Use of Labor Market Policies: The Role of Job Search Assistance," The Review of Economics and Statistics, 2013, 95 (3), 1030-1045. 


\section{Online Appendix (Not for Publication)}

\section{A Survey Questions}

\section{A.1 Survey of Consumer Expectations}

Question about 12-Month Job Finding Prospect

What do you think is the percent chance that within the coming 12 months, you will find a job that you will accept, considering the pay and type of work?

\section{[Ruler \& box]}

\section{Question about 3-Month Job Finding Prospect}

And looking at the more immediate future, what do you think is the percent chance that within the coming 3 months, you will find a job that you will accept, considering the pay and type of work?

\section{[Ruler \& box]}

\section{A.2 Krueger-Mueller Survey}

Question about 1-Month Job Finding Prospect

What do you think is the percent chance that you will be employed again within the next 4 weeks?

Please move the red button on the bar below to select the percent chance, where 0\% means 'absolutely no chance' and $100 \%$ means 'absolutely certain'.

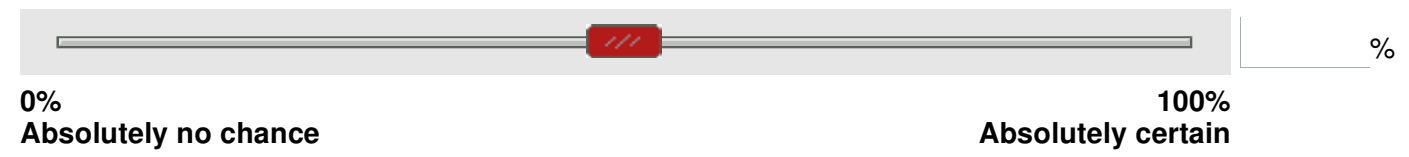

[NB: Initial position on bar is randomized.]

\section{Question about Expected Duration}

How many weeks do you estimate it will actually take before you will be employed again? 


\section{B Descriptive Statistics and Sample Comparisons}

This appendix provides additional descriptive statistics for both surveys, for the main samples used in the analysis and a series of sub-samples. Table B1 shows statistics for the SCE, while Table B2 shows statistics for the KM survey. In both tables, column 1 shows the full sample of unemployed, column 2 shows the main sample used in the longitudinal analysis and column 3 shows the main sample used for the analysis of predictive power of beliefs. The samples statistics are very similar across the different main samples, except for the sample in column 3 for the KM survey, which is substantially smaller and somewhat selected. Columns 4 and 5, shows descriptive statistics for the short- and the long-term unemployed. The long-term unemployed in both surveys are older and more female, though little differences exist by education. Finally, columns 6 and 7 show descriptive statistics separately by number of surveys completed. In the SCE, attrition appears to be non-random with respect to education, though survey weights adjust for this. Reassuringly, the monthly job finding rate is similar across the two samples. In the KM survey, attrition also appears non-random, but again survey weights adjust for this. Moreover, the sample in column 7 with two surveys or more, which is the variation we use for the longitudinal analysis in the KM data, is similar to the full weekly panel, which is representative of the UI population in New Jersey over the survey period. 
Table B1: Sample Comparison in the SCE

\begin{tabular}{|c|c|c|c|c|c|c|c|c|}
\hline \multirow[b]{2}{*}{ (in \%) } & \multirow{2}{*}{$\begin{array}{c}\text { Full } \\
\text { sample }\end{array}$} & \multicolumn{3}{|c|}{$\begin{array}{l}\text { Unemployed: } \\
\text { Main samples }\end{array}$} & \multicolumn{4}{|c|}{$\begin{array}{c}\text { Unemployed: } \\
\text { Sub-samples of sample (2) }\end{array}$} \\
\hline & & (1) & $(2)$ & $(3)$ & $(4)$ & (5) & (6) & $(7)$ \\
\hline High-School Degree or Less & 34.9 & 44.5 & 42.1 & 43.7 & 42.1 & 42.0 & 46.6 & 39.4 \\
\hline Some College Education & 31.4 & 32.4 & 32.6 & 30.3 & 30.3 & 34.5 & 35.9 & 30.6 \\
\hline College Degree or More & 33.7 & 23.1 & 25.4 & 26.0 & 27.6 & 23.5 & 17.5 & 29.9 \\
\hline Ages 20-34 & 23.1 & 25.4 & 23.8 & 21.2 & 29.4 & 19.1 & 29.9 & 20.3 \\
\hline Ages $35-49$ & 34.0 & 33.5 & 34.4 & 33.1 & 34.5 & 34.4 & 32.8 & 35.4 \\
\hline Ages $50-65$ & 42.9 & 41.1 & 41.7 & 45.7 & 36.1 & 46.5 & 37.4 & 44.2 \\
\hline Female & 51.3 & 59.3 & 58.0 & 55.3 & 53.3 & 62.0 & 60.6 & 56.6 \\
\hline Black & 11.1 & 19.1 & 18.2 & 14.3 & 17.9 & 18.5 & 19.9 & 17.2 \\
\hline Hispanic & 9.6 & 12.5 & 12.2 & 11.0 & 13.2 & 11.4 & 11.3 & 12.8 \\
\hline Monthly job finding rate & - & 18.7 & 18.2 & 17.3 & 24.2 & 13.2 & 18.9 & 18.0 \\
\hline \# respondents & 12,200 & 948 & 882 & 494 & 513 & 479 & 395 & 487 \\
\hline$\#$ respondents $\mathrm{w} />1$ survey & 10,147 & 534 & 477 & 278 & 260 & 239 & 166 & 311 \\
\hline \# survey responses & 84,174 & 2,597 & 2,281 & 1,201 & 1,070 & 1,211 & 756 & 1,525 \\
\hline
\end{tabular}

Notes: All samples are restricted to ages 20-65. Survey weights are used to compute the descriptive statistics. The table shows descriptive statistics for the full sample in the SCE, including those employed and out of the labor force, as well as statistics for (1) all unemployed, (2) all unemployed where the sample was trimmed from observations with inconsistent elicitations between the 3-month and the 12-month probability, and (3) the same sample as in (2) but in addition limited to interviews with at least 3 consecutive monthly follow-up interviews (used to measure 3-month job finding). Sample (2) is the baseline sample in our paper and sample (3) is used for the analysis of the predictive power of beliefs in Section 3.3. Sub-sample (4) consists of unemployed workers of durations 0-6 months and sub-sample (5) of unemployed workers of duration of 7 or more months. Sub-sample (6) consists of those in the main sample (2) with less than 9 interviews over the 12 months of the SCE and sub-sample (7) consists of those in the main sample (2) with at least 9 interviews over the 12 months of the SCE. 
Table B2: Sample Comparison in the KM Survey

\begin{tabular}{|c|c|c|c|c|c|c|c|c|}
\hline \multirow[b]{2}{*}{ (in \%) } & \multirow{2}{*}{$\begin{array}{c}\text { Weekly } \\
\text { panel }\end{array}$} & \multicolumn{3}{|c|}{$\begin{array}{l}\text { Monthly panel: } \\
\text { Main samples }\end{array}$} & \multicolumn{4}{|c|}{$\begin{array}{c}\text { Monthly panel: } \\
\text { Sub-samples of (2) }\end{array}$} \\
\hline & & $(1)$ & $(2)$ & $(3)$ & $(4)$ & $(5)$ & $(6)$ & $(7)$ \\
\hline High-School Degree or Less & 32.6 & 32.5 & 32.4 & 30.2 & 32.8 & 32.3 & 39.6 & 29.3 \\
\hline Some College Education & 38.0 & 37.4 & 37.4 & 36.7 & 37.0 & 37.5 & 38.0 & 37.1 \\
\hline College Degree or More & 29.5 & 30.1 & 30.2 & 33.0 & 30.2 & 30.2 & 22.4 & 33.7 \\
\hline Ages 20-34 & 35.3 & 38.1 & 38.7 & 21.7 & 44.9 & 35.7 & 55.1 & 31.4 \\
\hline Ages $35-49$ & 36.5 & 35.4 & 34.8 & 31.8 & 35.8 & 34.3 & 31.8 & 36.2 \\
\hline Ages 50-65 & 28.2 & 26.5 & 26.5 & 46.4 & 19.3 & 30.0 & 13.1 & 32.4 \\
\hline Female & 48.1 & 48.6 & 47.3 & 42.7 & 46.2 & 47.8 & 50.2 & 46.0 \\
\hline Black & 22.8 & 24.4 & 24.1 & 15.2 & 23.0 & 24.6 & 30.7 & 21.1 \\
\hline Hispanic & 23.6 & 27.5 & 27.8 & 16.9 & 33.7 & 24.9 & 31.8 & 26.0 \\
\hline Monthly job finding rate & 11.1 & 10.3 & 10.5 & 10.5 & 13.5 & 9.5 & - & 9.2 \\
\hline \# respondents & 4,939 & 2,384 & 2,278 & 552 & 397 & 1,884 & 744 & 1,534 \\
\hline \# respondents $\mathrm{w} />1$ survey & 3,835 & 1,422 & 1,296 & 121 & 175 & 1,118 & 0 & 1,296 \\
\hline \# survey responses & 27,021 & 4,803 & 4,435 & 734 & 572 & 3,863 & 744 & 3,691 \\
\hline
\end{tabular}

Notes: All samples are restricted to unemployed workers, ages 20-65. Survey weights are used to compute the descriptive statistics. The table shows descriptive statistics for the full weekly panel of the KM survey, as well as statistics for (1) the full monthly panel with elicitations about job finding, (2) the same sample as in (1) but trimmed for observations with inconsistencies between the elicitation of the 1-month probability and the expected remaining duration, and (3) the same sample as in (2) but in addition limited to interviews with at least 4 consecutive weekly follow-up interviews (used to measure 1-month job finding). Sample (2) is the baseline sample in our paper and sample (3) is used for the analysis of the predictive power of beliefs. Sub-sample (4) consists of unemployed workers of durations 0-6 months and sub-sample (5) of unemployed workers of duration of 7 or more months. Sub-sample (6) consists of those in the main sample (2) with only 1 interview in the monthly panel and sub-sample (2) consists of those with more than 1 interview in the monthly panel. 


\section{Theoretical Derivations in Conceptual Framework}

This appendix provides the derivations underlying the characterizations in Section 3.1.

Decomposition of Duration Dependence We first establish the following result linking the expectations at different durations:

$$
E_{d+1}\left(X_{i, \delta}\right)=E_{d}\left(X_{i, \delta}\right)-\frac{\operatorname{cov}_{d}\left(X_{i, \delta}, T_{i, d}\right)}{1-E_{d}\left(T_{i, d}\right)}
$$

To obtain this expression, we note first that

$$
\begin{aligned}
E_{d}\left(T_{i, d}\right) & =\int \frac{S_{i, d}}{S_{d}} T_{i, d} d i=\int \frac{S_{i, d}}{S_{d}}\left(\frac{S_{i, d}-S_{i, d+1}}{S_{i, d}}\right) d i \\
& =\int \frac{S_{i, d}-S_{i, d+1}}{S_{d}} d i=1-\frac{S_{d+1}}{S_{d}} .
\end{aligned}
$$

where $S_{i, d}$ refers to the survival rate to duration $d$ for individuals of type $i$. We can then re-write

$$
\begin{aligned}
E_{d+1}\left(X_{i, \delta}\right) & =\int \frac{S_{i, d+1}}{S_{d+1}} X_{i, \delta} d i=\frac{S_{d}}{S_{d+1}} \int \frac{S_{i, d}\left(1-T_{i, d}\right)}{S_{d}} X_{i, \delta} d i \\
& =\frac{1}{1-E_{d}\left(T_{i, d}\right)}\left\{\int \frac{S_{i, d}}{S_{d}} X_{i, \delta} d i-\int \frac{S_{i, d}}{S_{d}} T_{i, d} X_{i, \delta} d i\right\} \\
& =\frac{1}{1-E_{d}\left(T_{i, d}\right)}\left\{\begin{array}{c}
\int \frac{S_{i, d}}{S_{d}} X_{i, \delta} d i-\left[\int \frac{S_{i, d}}{S_{d}} T_{i, d} d i\right]\left[\int \frac{S_{i, d}}{S_{d}} X_{i, \delta} d i\right] \\
-\left[\int \frac{S_{i, d}}{S_{d}} T_{i, d} X_{i, \delta} d i-\left[\int \frac{S_{i, d}}{S_{d}} T_{i, d} d i\right]\left[\int \frac{S_{i, d}}{S_{d}} X_{i, \delta} d i\right]\right]
\end{array}\right\} \\
& =\frac{1}{1-E_{d}\left(T_{i, d}\right)}\left\{E_{d}\left(X_{i, \delta}\right)\left(1-E_{d}\left(T_{i, d}\right)\right)-\operatorname{cov}_{d}\left(T_{i, d}, X_{i, \delta}\right)\right\}, \\
& =E_{d}\left(X_{i, \delta}\right)-\frac{\operatorname{cov}_{d}\left(T_{i, d}, X_{i, \delta}\right)}{1-E_{d}\left(T_{i, d}\right)}
\end{aligned}
$$

which proves the earlier statement.

The decomposition of the observed duration dependence immediately follows from applying equation (20) to the average job finding. That is,

$$
E_{d}\left(T_{i, d}\right)-E_{d+1}\left(T_{i, d+1}\right)=E_{d}\left(T_{i, d}-T_{i, d+1}\right)+\frac{\operatorname{cov}_{d}\left(T_{i, d}, T_{i, d+1}\right)}{1-E_{d}\left(T_{i, d}\right)}
$$

where

$$
\begin{aligned}
\operatorname{cov}_{d}\left(T_{i, d}, T_{i, d+1}\right) & =\operatorname{cov}_{d}\left(T_{i, d}, T_{i, d}+\left(T_{i, d+1}-T_{i, d}\right)\right) \\
& =\operatorname{var}_{d}\left(T_{i, d}\right)-\operatorname{cov}_{d}\left(T_{i, d}, T_{i, d}-T_{i, d+1}\right)
\end{aligned}
$$


Lower Bound on Heterogeneity We first note that

$$
\begin{aligned}
\operatorname{cov}_{d}\left(Z_{i, d}, F_{i, d}\right) & =E_{d}\left(Z_{i, d} F_{i, d}\right)-E_{d}\left(Z_{i, d}\right) E_{d}\left(F_{i, d}\right) \\
& =E_{d}\left(E_{d}\left(Z_{i, d} F_{i, d} \mid T_{i, d}\right)\right)-E_{d}\left(Z_{i, d}\right) E_{d}\left(T_{i, d}\right) \\
& =E_{d}\left(E_{d}\left(Z_{i, d} \times 1 \mid T_{i, d}\right) \operatorname{Pr}\left(F_{i, d}=1 \mid T_{i, d}\right)+E_{d}\left(Z_{i, d} \times 0 \mid T_{i, d}\right) \operatorname{Pr}\left(F_{i, d}=0 \mid T_{i, d}\right)\right)-E_{d}\left(Z_{i, d}\right) E_{d}\left(T_{i, d}\right) \\
& =E_{d}\left(E_{d}\left(Z_{i, d} T_{i, d} \mid T_{i, d}\right)\right)-E_{d}\left(Z_{i, d}\right) E_{d}\left(T_{i, d}\right) \\
& =E_{d}\left(Z_{i, d} T_{i, d}\right)-E_{d}\left(Z_{i, d}\right) E_{d}\left(T_{i, d}\right) \\
& =\operatorname{cov}_{d}\left(Z_{i, d}, T_{i, d}\right)
\end{aligned}
$$

Now we can use the Cauchy-Schwarz inequality,

$$
\begin{aligned}
\operatorname{var}_{d}\left(T_{i, d}\right) \operatorname{var}_{d}\left(Z_{i, d}\right) & \geq \operatorname{cov}_{d}\left(Z_{i, d}, T_{i, d}\right)^{2} \\
& =\operatorname{cov}_{d}\left(Z_{i, d}, F_{i, d}\right)^{2}
\end{aligned}
$$

Hence, we have derived the first lower-bound on the variance in job finding rates,

$$
\operatorname{var}_{d}\left(T_{i, d}\right) \geq \frac{\operatorname{cov}_{d}\left(Z_{i, d}, F_{i, d}\right)^{2}}{\operatorname{var}_{d}\left(Z_{i, d}\right)}
$$

We next use Proposition 3 in Morrison and Taubinsky [2019] to derive a second lower-bound using two measurements of the beliefs, $Z_{i, d}^{1}$ and $Z_{i, d}^{2}$, which requires that both are independently distributed conditional on $T_{i, d}$ (i.e., $\left.Z_{i, d}^{1} \perp Z_{i, d}^{2} \mid T_{i, d}\right)$ and have the same conditional expectation (i.e., $E\left(Z_{i, d}^{j} \mid T_{i, d}\right)=$ $\left.\left.\alpha\left(T_{i, d}\right)\right)\right)$. Following the proof in Morrison and Taubinsky [2019], we first note that

$$
\begin{aligned}
\operatorname{cov}_{d}\left(Z_{i, d}^{1}, Z_{i, d}^{2}\right) & =E_{d}\left(Z_{i, d}^{1} Z_{i, d}^{2}\right)-E_{d}\left(Z_{i, d}^{1}\right) E_{d}\left(Z_{i, d}^{2}\right) \\
& =E_{d}\left(E_{d}\left(Z_{i, d}^{1} Z_{i, d}^{2} \mid T_{i, d}\right)\right)-E_{d}\left(\alpha\left(T_{i, d}\right)\right) E_{d}\left(\alpha\left(T_{i, d}\right)\right) \\
& =E_{d}\left(\alpha\left(T_{i, d}\right)^{2}\right)-E_{d}\left(\alpha\left(T_{i, d}\right)\right)^{2} \\
& =\operatorname{var}_{d}\left(\alpha\left(T_{i, d}\right)\right) \text { and } \\
\operatorname{cov}_{d}\left(F_{i, d}, Z_{i, d}^{j}\right) & =\operatorname{cov}_{d}\left(T_{i, d}, \alpha\left(T_{i, d}\right)\right)
\end{aligned}
$$

So we can combine these expressions with the Cauchy-Schwarz inequality,

$$
\operatorname{var}_{d}\left(T_{i, d}\right) \operatorname{var}_{d}\left(\alpha\left(T_{i, d}\right)\right) \geq \operatorname{cov}_{d}\left(T_{i, d}, \alpha\left(T_{i, d}\right)\right)^{2}
$$

to derive the lower bound

$$
\operatorname{var}_{d}\left(T_{i, d}\right) \geq \frac{\operatorname{cov}_{d}\left(F_{i, d}, Z_{i, d}^{1}\right) \operatorname{cov}_{d}\left(F_{i, d}, Z_{i, d}^{2}\right)}{\operatorname{cov}_{d}\left(Z_{i, d}^{1}, Z_{i, d}^{2}\right)} .
$$

Note that if the two measurements are positively correlated, conditional on $T_{i, d}$, the lower bound argument continues to hold, since then $\operatorname{cov}_{d}\left(Z_{i, d}^{1}, Z_{i, d}^{2}\right) \geq \operatorname{var}\left(\alpha\left(T_{i, d}\right)\right)$. 
Linear Beliefs Model For the linear beliefs model, we have

$$
E_{d}\left(Z_{i, d}\right)=b_{0}+b_{1} E_{d}\left(T_{i, d}\right) \text { for any } d \text {. }
$$

Hence, it trivially follows that

$$
b_{1}=\frac{E_{d+1}\left(Z_{i, d+1}\right)-E_{d}\left(Z_{i, d}\right)}{E_{d+1}\left(T_{i, d+1}\right)-E_{d}\left(T_{i, d}\right)} .
$$

The variance in job finding is thus identified by

$$
\operatorname{var}_{d}\left(T_{i, d}\right)=\frac{1}{b_{1}} \times \operatorname{cov}_{d}\left(F_{i, d}, Z_{i, d}\right)=\frac{E_{d+1}\left(T_{i, d+1}\right)-E_{d}\left(T_{i, d}\right)}{E_{d+1}\left(Z_{i, d+1}\right)-E_{d}\left(Z_{i, d}\right)} \times \operatorname{cov}_{d}\left(F_{i, d}, Z_{i, d}\right)
$$

We also note that with two elicitations $Z_{i, d}^{1}$ and $Z_{i, d}^{2}$ that are both some linear transformation of $T_{i, d}$

$$
Z_{i, d}^{j}=b_{0}^{j}+b_{1}^{j} T_{i, d}+\varepsilon_{i, d}^{j},
$$

our earlier lower bound becomes tight,

$$
\operatorname{var}_{d}\left(T_{i, d}\right)=\frac{\operatorname{cov}_{d}\left(F_{i, d}, Z_{i, d}^{1}\right) \operatorname{cov}_{d}\left(F_{i, d}, Z_{i, d}^{2}\right)}{\operatorname{cov}_{d}\left(Z_{i, d}^{1}, Z_{i, d}^{2}\right)} .
$$

But this is only the case when the error terms are independently distributed. The covariance ratio becomes a lower bound when the error terms are positively correlated.

Persistence in Job Finding For the linear beliefs model, it naturally follows that

$$
\operatorname{cov}_{d+1}\left(F_{i, d+1}, Z_{i, d}\right)=b_{1} \operatorname{cov}_{d+1}\left(T_{i, d+1}, T_{i, d}\right) .
$$

This term relates to the dynamic selection term contributing to the duration dependence in job finding, but is backward-looking rather than forward-looking. We characterize this relationship in case the job finding probability consists of a permanent term and a random transitory term, independently drawn every period,

$$
T_{i, d}=T_{i}+\tau_{i, d}
$$

Here, the forward-looking covariance simplifies to the variance in the persistent component,

$$
\operatorname{cov}_{d}\left(T_{i, d+1}, T_{i, d}\right)=\operatorname{var}_{d}\left(T_{i}\right)
$$


The backward-looking covariance can be re-expressed as

$$
\begin{aligned}
\operatorname{cov}_{d+1}\left(T_{i, d+1}, T_{i, d}\right)= & \operatorname{cov}_{d+1}\left(T_{i}+\tau_{i, d+1}, T_{i}+\tau_{i, d}\right) \\
= & E_{d+1}\left(\left(T_{i}+\tau_{i, d+1}\right)\left(T_{i}+\tau_{i, d}\right)\right)-E_{d+1}\left(T_{i}+\tau_{i, d+1}\right) E_{d+1}\left(T_{i}+\tau_{i, d}\right) \\
= & E_{d+1}\left[E_{d+1}\left(\left(T_{i}+\tau_{i, d+1}\right)\left(T_{i}+\tau_{i, d}\right) \mid T_{i}\right)\right] \\
& -E_{d+1}\left[E_{d+1}\left(T_{i}+\tau_{i, d+1} \mid T_{i}\right)\right] E_{d+1}\left[E_{d+1}\left(T_{i}+\tau_{i, d} \mid T_{i}\right)\right] \\
= & E_{d+1}\left(T_{i}^{2}+T_{i} \tau_{i, d}\right)-E_{d+1}\left(T_{i}\right) E_{d+1}\left(T_{i}+\tau_{i, d}\right) \\
= & \operatorname{var}_{d+1}\left(T_{i}\right)+\operatorname{cov}_{d+1}\left(T_{i}, \tau_{i, d}\right)
\end{aligned}
$$

Here, we can apply the characterization of the conditional expectation in (20) to re-express

$$
\begin{aligned}
\operatorname{cov}_{d+1}\left(T_{i}, \tau_{i, d}\right) & =E_{d+1}\left(T_{i} \tau_{i, d}\right)-E_{d+1}\left(T_{i}\right) E_{d+1}\left(\tau_{i, d}\right) \\
& =E_{d}\left(T_{i} \tau_{i, d}\right)-\frac{\operatorname{cov}_{d}\left(T_{i} \tau_{i, d}, T_{i, d}\right)}{1-E_{d}\left(T_{i, d}\right)}-E_{d+1}\left(T_{i}\right)\left[E_{d}\left(\tau_{i, d}\right)-\frac{\operatorname{cov}_{d}\left(\tau_{i, d}, T_{i, d}\right)}{1-E_{d}\left(T_{i, d}\right)}\right] \\
& =-\frac{E_{d}\left(T_{i} \tau_{i, d}^{2}\right)}{1-E_{d}\left(T_{i, d}\right)}+E_{d+1}\left(T_{i}\right) \frac{\operatorname{var}_{d}\left(\tau_{i, d}\right)}{1-E_{d}\left(T_{i, d}\right)} \\
& =-\frac{1}{1-E_{d}\left(T_{i, d}\right)}\left[E_{d}\left(T_{i} \tau_{i, d}^{2}\right)-E_{d}\left(T_{i}\right) E\left(\tau_{i, d}^{2}\right)-\left(E_{d+1}\left(T_{i}\right)-E_{d}\left(T_{i}\right)\right) \operatorname{var}_{d}\left(\tau_{i, d}\right)\right] \\
& =-\frac{1}{1-E_{d}\left(T_{i, d}\right)}\left[\operatorname{cov}\left(T_{i}, \tau_{i, d}^{2}\right)-\left(E_{d+1}\left(T_{i}\right)-E_{d}\left(T_{i}\right)\right) \operatorname{var}_{d}\left(\tau_{i, d}\right)\right] \\
& =\frac{E_{d+1}\left(T_{i}\right)-E_{d}\left(T_{i}\right)}{1-E_{d}\left(T_{i, d}\right)} \operatorname{var}_{d}\left(\tau_{i, d}\right) \\
& =-\frac{\operatorname{var}_{d}\left(T_{i}\right) \operatorname{var}_{d}\left(\tau_{i, d}\right)}{\left[1-E_{d}\left(T_{i, d}\right)\right]^{2}}
\end{aligned}
$$

where we have used

$$
\begin{aligned}
\operatorname{cov}_{d}\left(T_{i} \tau_{i, d}, T_{i}+\tau_{i, d}\right) & =E_{d}\left(T_{i}^{2} \tau_{i, d}\right)+E_{d}\left(T_{i} \tau_{i, d}^{2}\right)-E_{d}\left(T_{i} \tau_{i, d}\right) E_{d}\left(T_{i}\right)-E_{d}\left(T_{i} \tau_{i, d}\right) E_{d}\left(\tau_{i, d}\right) \\
& =E_{d}\left(T_{i} \tau_{i, d}^{2}\right), \\
E_{d+1}\left(T_{i}\right)-E_{d}\left(T_{i}\right) & =-\frac{\operatorname{cov}_{d}\left(T_{i}, T_{i}\right)}{1-E_{d}\left(T_{i, d}\right)} \text { and } \\
\operatorname{cov}\left(T_{i}, \tau_{i, d}^{2}\right) & =E_{d}\left(T_{i} \tau_{i, d}^{2}\right)-E_{d}\left(T_{i}\right) E\left(\tau_{i, d}^{2}\right)=0 .
\end{aligned}
$$

Hence, we have

$$
\operatorname{cov}_{d+1}\left(T_{i, d+1}, T_{i, d}\right)=\operatorname{var}_{d+1}\left(T_{i}\right)-\frac{\operatorname{var}_{d}\left(T_{i}\right) \operatorname{var}_{d}\left(\tau_{i, d}\right)}{\left[1-E_{d}\left(T_{i, d}\right)\right]^{2}}
$$

while instead

$$
\operatorname{cov}_{d+1}\left(T_{i, d+1}, T_{i, d+1}\right)=\operatorname{var}_{d+1}\left(T_{i}\right)+\operatorname{var}_{d+1}\left(\tau_{i, d+1}\right)=\operatorname{var}_{d+1}\left(T_{i}\right)+\operatorname{var}_{d}\left(\tau_{i, d}\right)
$$


Putting the two expressions together, we obtain

$$
\operatorname{cov}_{d+1}\left(T_{i, d+1}, T_{i, d+1}\right)-\operatorname{cov}_{d+1}\left(T_{i, d+1}, T_{i, d}\right)=\operatorname{var}_{d}\left(\tau_{i, d}\right)\left[1-\frac{\operatorname{var}_{d}\left(T_{i}\right)}{\left[1-E_{d}\left(T_{i, d}\right)\right]^{2}}\right],
$$

which shows that the difference in the contemporaneous covariance and lagged covariance is increasing in the variance in transitory shocks, but decreasing in the variance in the permanent shocks. Combined with

$$
\operatorname{cov}_{d}\left(T_{i, d}, T_{i, d}\right)=\operatorname{var}_{d}\left(T_{i}\right)+\operatorname{var}_{d}\left(\tau_{i, d}\right)
$$

and, for the linear beliefs model,

$$
\begin{aligned}
\operatorname{cov}_{d+1}\left(F_{i, d+1}, Z_{i, d}\right) & =b_{1} \operatorname{cov}_{d+1}\left(T_{i, d+1}, T_{i, d}\right) \\
\operatorname{cov}_{d+1}\left(F_{i, d+1}, Z_{i, d+1}\right) & =b_{1} \operatorname{cov}_{d+1}\left(T_{i, d+1}, T_{i, d+1}\right) \\
\operatorname{cov}_{d+1}\left(F_{i, d}, Z_{i, d}\right) & =b_{1} \operatorname{cov}_{d}\left(T_{i, d}, T_{i, d}\right)
\end{aligned}
$$

we can use the difference in contemporaneous and lagged covariance to get an estimate of the variance in transitory shocks. 


\section{Additional Empirical Results}

In this appendix, we provide additional results on the empirical analysis that we refer to in the paper for both the SCE and the KM survey. More precisely, we provide (1) additional details on the distributions of elicitations and their correlations, (2) additional details and a series of robustness checks on the predictive power of beliefs and the non-parametric lower bounds, (3) additional details on the biases in beliefs and a detailed robustness analysis of the longitudinal changes in beliefs, (4) evidence on the relationship of beliefs, job search effort and reservation wages in the KM data, and (5) evidence on the relationship between beliefs and indicators of labor market tightness in the SCE.

\section{D.1 Elicited Beliefs about Job Finding}

Figure D1: Histogram of Elicitations of the 12-Month Job Finding Probability in the SCE

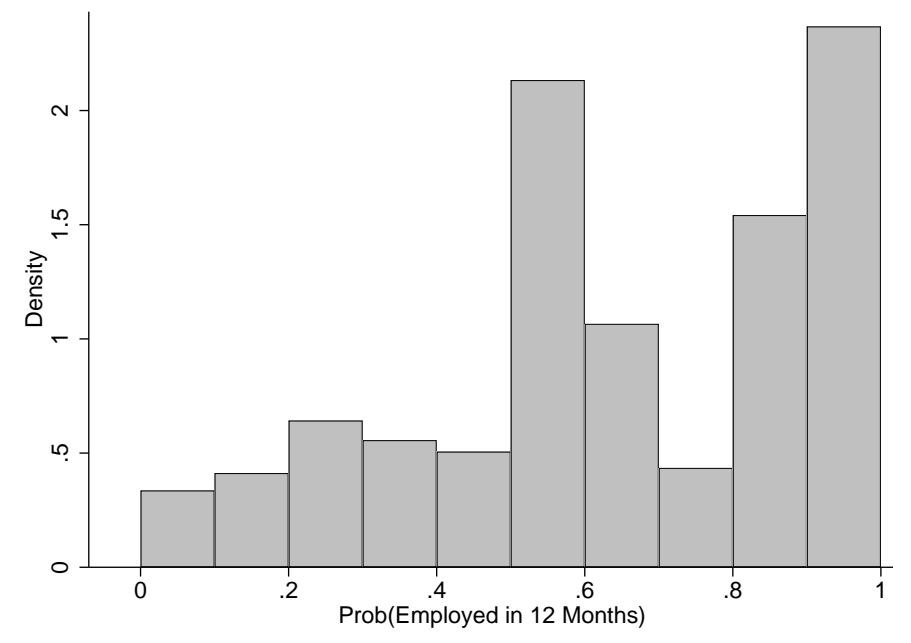

Figure D2: Histogram of Elicitations of the Expected Remaining Duration in the KM survey

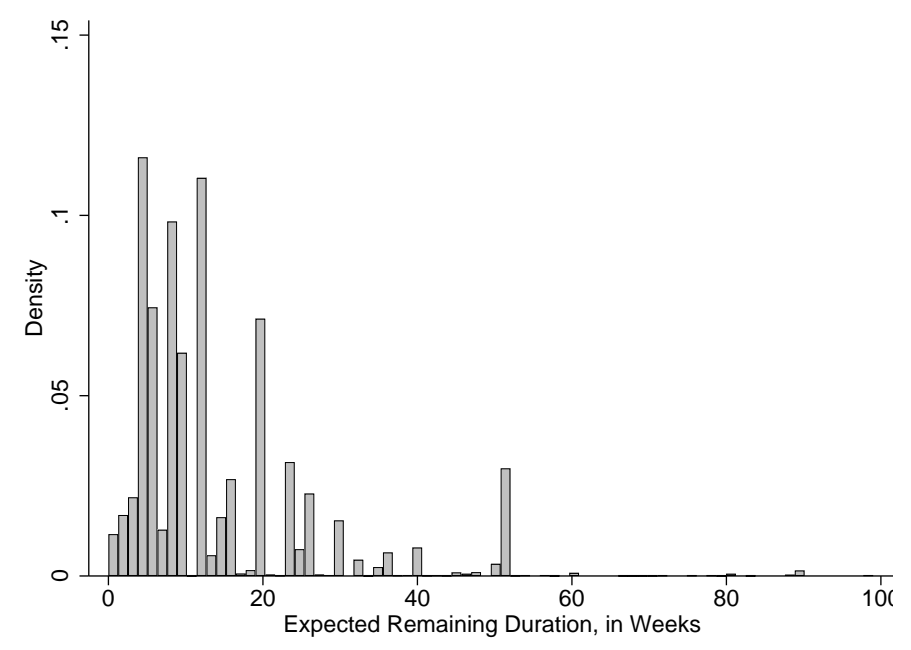


Figure D3: Comparison of Kernel Density Estimates for Alternative Forms of Elicitations
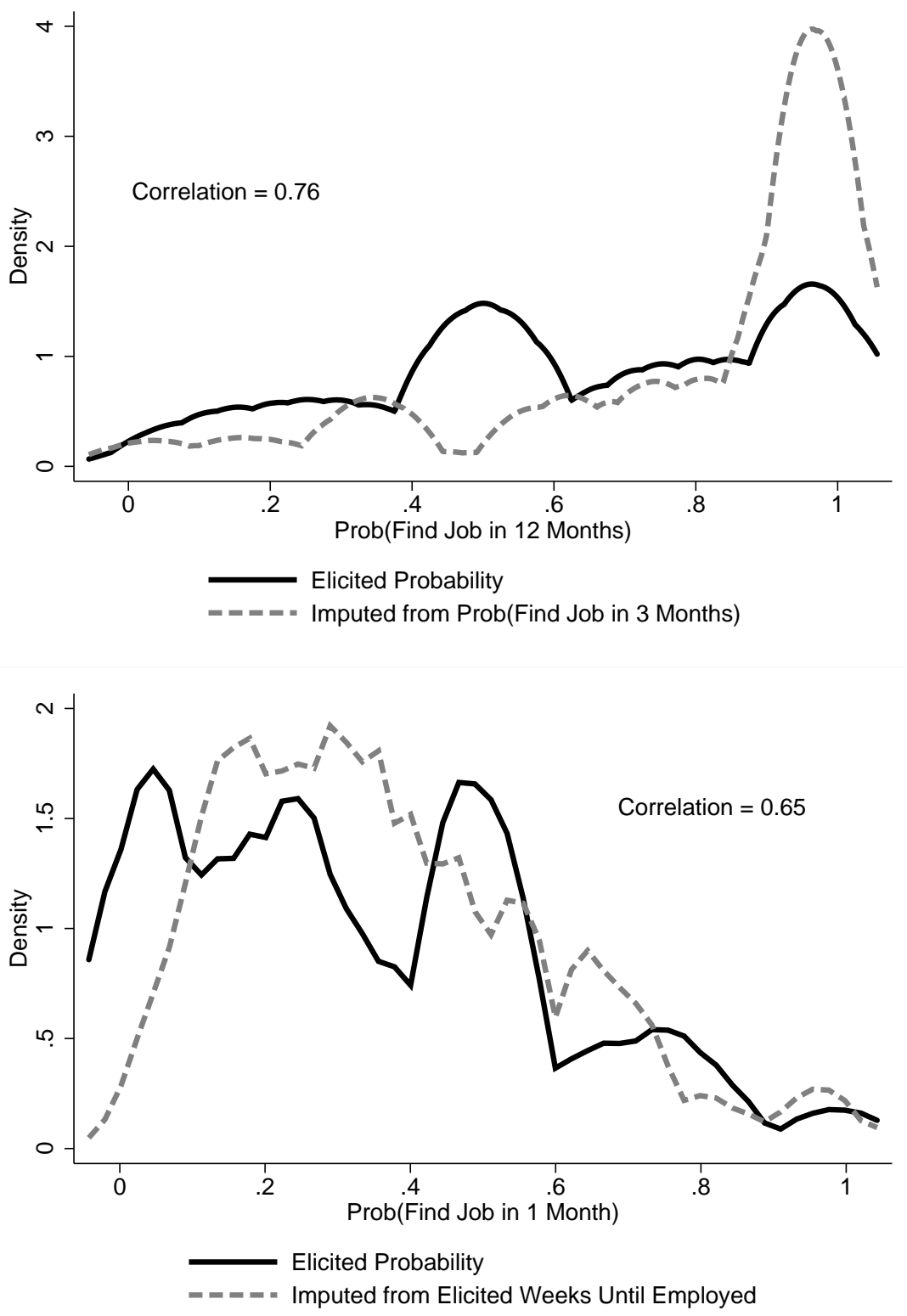
Figure D4: Ratio of Imputed Probabilities and Elicited Probabilities based on Alternative Forms of Elicitations in the SCE (top panel) and KM Survey (bottom panel)
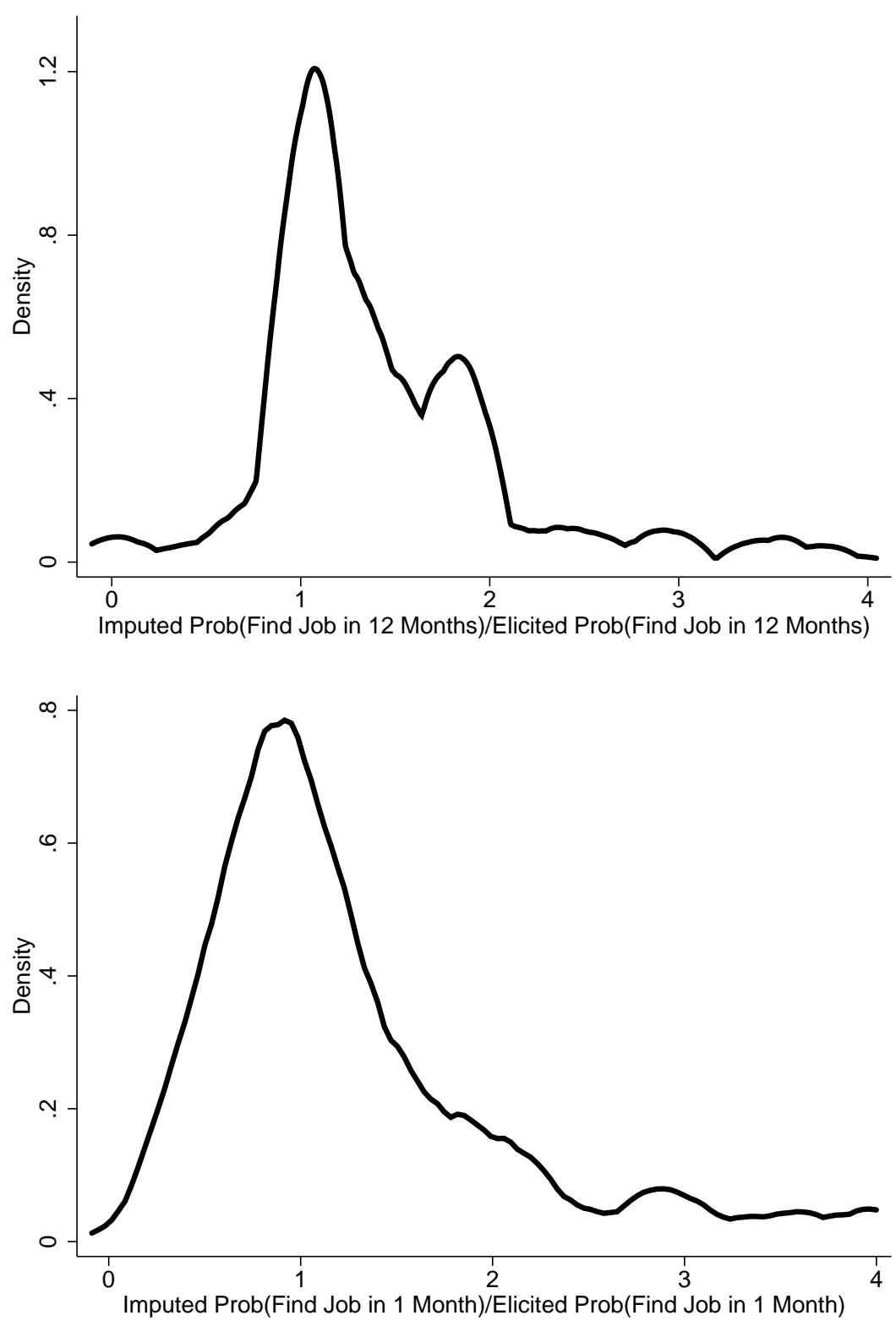

Note: See the main text and Figure D3 for details on the imputed probabilities. 


\section{D.2 Job Finding Beliefs and Outcomes}

In this section, we provide additional details on the analysis of the predictive value of beliefs, a series of robustness checks of the findings in Table 2 in the paper as well as the results for the KM survey. The section also shows additional estimates of the non-parametric lower bounds in the SCE as well as the lower bound estimates for the KM survey.

Table D1: Regressions of Realized Job Finding Probabilities on Elicitations (Showing Controls)

\begin{tabular}{|c|c|c|c|c|}
\hline & (1) & $(2)$ & (3) & (4) \\
\hline Prob(Find Job in 3 Months) & $\begin{array}{c}0.586^{* * * *} \\
(0.073)\end{array}$ & & $\begin{array}{c}0.464^{* * *} \\
(0.069)\end{array}$ & $\begin{array}{c}0.501^{* * *} \\
(0.092)\end{array}$ \\
\hline Prob(Find Job in 3 Months) $x$ LT Unemployed & & & & $\begin{array}{c}-0.258^{*} \\
(0.142)\end{array}$ \\
\hline LT Unemployed & & & & $\begin{array}{l}-0.078 \\
(0.094)\end{array}$ \\
\hline Female & & $\begin{array}{c}-0.134^{* *} \\
(0.055)\end{array}$ & $\begin{array}{c}-0.114^{* *} \\
(0.050)\end{array}$ & $\begin{array}{l}-0.071 \\
(0.046)\end{array}$ \\
\hline Age & & $\begin{array}{c}0.017 \\
(0.017)\end{array}$ & $\begin{array}{c}0.018 \\
(0.015)\end{array}$ & $\begin{array}{c}0.019 \\
(0.013)\end{array}$ \\
\hline Age* Age & & $\begin{array}{c}-0.0003 \\
(0.0002)\end{array}$ & $\begin{array}{c}-0.0003^{*} \\
(0.0002)\end{array}$ & $\begin{array}{c}-0.0003^{*} \\
(0.0001)\end{array}$ \\
\hline High-School Degree & & $\begin{array}{c}0.216^{*} \\
(0.130)\end{array}$ & $\begin{array}{c}0.142 \\
(0.124)\end{array}$ & $\begin{array}{c}0.111 \\
(0.101)\end{array}$ \\
\hline Some College & & $\begin{array}{c}0.136 \\
(0.121)\end{array}$ & $\begin{array}{c}0.098 \\
(0.120)\end{array}$ & $\begin{array}{c}0.075 \\
(0.095)\end{array}$ \\
\hline College Degree & & $\begin{array}{c}0.117 \\
(0.121)\end{array}$ & $\begin{array}{c}0.054 \\
(0.119)\end{array}$ & $\begin{array}{c}0.031 \\
(0.096)\end{array}$ \\
\hline Post-Graduate Education & & $\begin{array}{c}0.139 \\
(0.128)\end{array}$ & $\begin{array}{c}0.059 \\
(0.126)\end{array}$ & $\begin{array}{c}0.034 \\
(0.105)\end{array}$ \\
\hline Other Education & & $\begin{array}{c}0.487^{*} \\
(0.267)\end{array}$ & $\begin{array}{c}0.388 \\
(0.261)\end{array}$ & $\begin{array}{l}0.329^{*} \\
(0.197)\end{array}$ \\
\hline HH income: $\$ 30,000-\$ 59,999$ & & $\begin{array}{c}0.127^{* *} \\
(0.055)\end{array}$ & $\begin{array}{c}0.111^{* *} \\
(0.053)\end{array}$ & $\begin{array}{c}0.095^{* *} \\
(0.048)\end{array}$ \\
\hline HH income: $\$ 60,000-\$ 100,000$ & & $\begin{array}{c}0.182^{* * *} \\
(0.058)\end{array}$ & $\begin{array}{c}0.189^{* * *} \\
(0.057)\end{array}$ & $\begin{array}{c}0.150^{* *} \\
(0.060)\end{array}$ \\
\hline HH income: $\$ 100,000+$ & & $\begin{array}{l}0.151^{*} \\
(0.079)\end{array}$ & $\begin{array}{c}0.156^{* *} \\
(0.072)\end{array}$ & $\begin{array}{c}0.113 \\
(0.082)\end{array}$ \\
\hline Race/Ethnicity: Hispanic & & $\begin{array}{c}-0.022 \\
(0.073)\end{array}$ & $\begin{array}{c}-0.049 \\
(0.067)\end{array}$ & $\begin{array}{c}-0.062 \\
(0.063)\end{array}$ \\
\hline Race/Ethnicity: African-American & & $\begin{array}{c}0.157^{* *} \\
(0.078)\end{array}$ & $\begin{array}{c}0.087 \\
(0.078)\end{array}$ & $\begin{array}{c}0.088 \\
(0.070)\end{array}$ \\
\hline Race/Ethnicity: Asian & & $\begin{array}{c}0.081 \\
(0.100)\end{array}$ & $\begin{array}{c}0.137 \\
(0.084)\end{array}$ & $\begin{array}{l}0.157^{*} \\
(0.092)\end{array}$ \\
\hline Race/Ethnicity: Other & & $\begin{array}{c}-0.145^{*} \\
(0.076)\end{array}$ & $\begin{array}{c}-0.131^{*} \\
(0.073)\end{array}$ & $\begin{array}{c}-0.125^{* *} \\
(0.060)\end{array}$ \\
\hline Constant & $\begin{array}{c}0.121^{* * *} \\
(0.040)\end{array}$ & $\begin{array}{c}0.171 \\
(0.402) \\
\end{array}$ & $\begin{array}{l}-0.104 \\
(0.363)\end{array}$ & $\begin{array}{l}-0.062 \\
(0.329)\end{array}$ \\
\hline Observations & 1,201 & 1,201 & 1,201 & 1,201 \\
\hline$R^{2}$ & 0.131 & 0.148 & 0.218 & 0.259 \\
\hline
\end{tabular}

Notes: The table shows the results in Table 2 in the paper with controls. Robust standard errors (clustered at the individual level) are in parentheses. Asteriks indicate stat. significance at the $*_{0.1}^{*} *^{*} 0.05$ and $* * * 0.01$ level. 


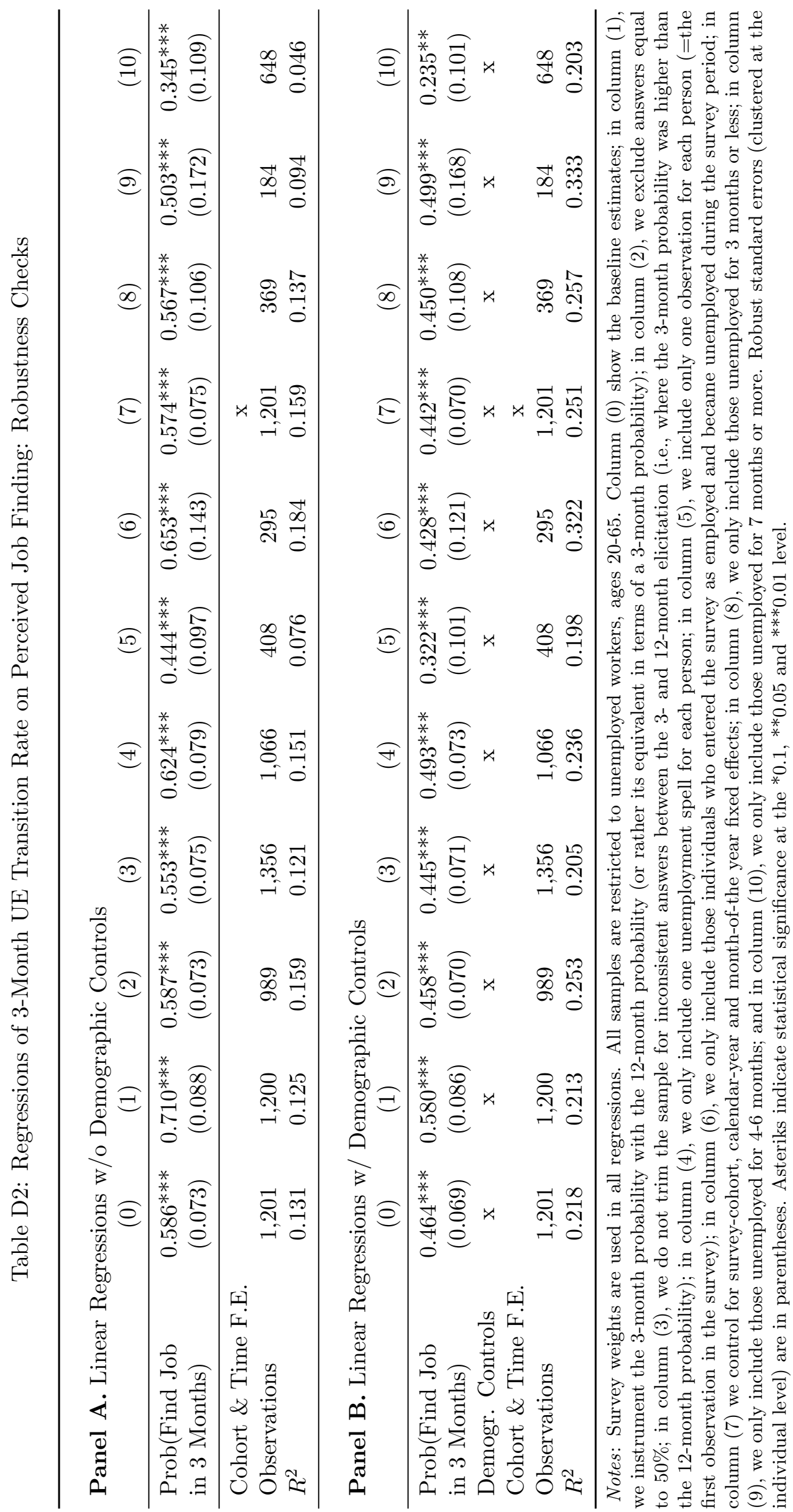


Table D3: Linear Regressions of Realized Job Finding on Elicitations (KM Survey)

Panel A. Dependent Variable: Monthly Job Finding Rate

\begin{tabular}{|c|c|c|c|c|}
\hline Prob(Find Job in 1 Month) & $\begin{array}{c}0.260^{* *} \\
(0.109)\end{array}$ & & $\begin{array}{c}0.266^{* * *} \\
(0.094)\end{array}$ & $\begin{array}{c}0.382^{* * *} \\
(0.131)\end{array}$ \\
\hline Prob(Find Job in 1 Month) x LT Unemployed & & & & $\begin{array}{l}-0.283 \\
(0.180)\end{array}$ \\
\hline LT Unemployed & & & & $\begin{array}{l}0.077^{*} \\
(0.045)\end{array}$ \\
\hline Controls & & & $\mathrm{x}$ & $\mathrm{x}$ \\
\hline Observations & 650 & 650 & 650 & 650 \\
\hline$R^{2}$ & 0.039 & 0.189 & 0.224 & 0.234 \\
\hline
\end{tabular}

Panel B. Dependent Variable: Monthly Job Finding Rate

\begin{tabular}{|c|c|c|c|c|}
\hline Expected Duration (Inverted) & $\begin{array}{c}0.402 \\
(0.178)^{* *}\end{array}$ & & $\begin{array}{c}0.294 \\
(0.090)^{* * *}\end{array}$ & $\begin{array}{c}0.513 \\
(0.140)^{* * *}\end{array}$ \\
\hline Expected Duration (Inverted) x LT Unemployed & & & & $\begin{array}{c}-0.493 \\
(0.157)^{* * *}\end{array}$ \\
\hline LT Unemployed & & & & $\begin{array}{c}0.145 \\
(0.056) * * *\end{array}$ \\
\hline Controls & & & $\mathrm{x}$ & $\mathrm{x}$ \\
\hline Observations & 650 & 650 & 650 & 650 \\
\hline$R^{2}$ & 0.080 & 0.189 & 0.223 & 0.249 \\
\hline
\end{tabular}

Notes: Survey weights are used in all regressions. All samples are restricted to unemployed workers in the KM survey, ages 20-65, with 4 consecutive weekly interviews following the belief question. For the purpose of comparability across the columns in the table, the samples are restricted to the same number of observations, i.e., where all control variables and both elicitations are observed. Expected duration (inverted) is calculated as $1-\left(1-\frac{1}{x}\right)^{4}$, where $x$ is the elicited expected remaining duration of unemployment (in weeks). Controls are dummies for gender, race, ethnicity, household income brackets (4), educational attainment (6), and age and age squared. Robust standard errors (clustered at the individual level) are in parentheses. Asteriks indicate statistical significance at the ${ }^{*} 0.1,{ }^{* *} 0.05$ and $* * * 0.01$ level. 
Figure D5: Averages of Actual Job Finding Probabilities, by Bins of Elicited Probabilities (KM Survey)

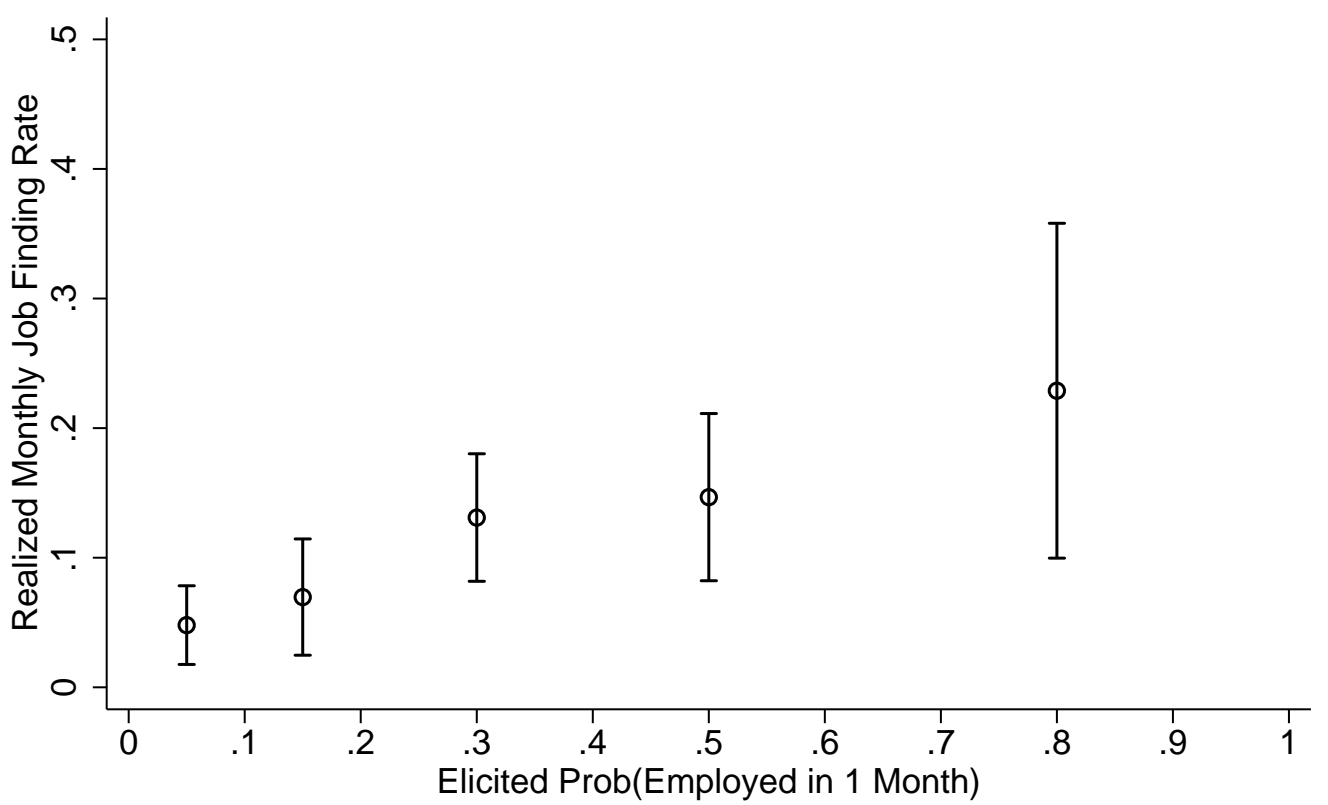

\section{- Mean of Realized Monthly Job Finding Rate 95\% Confidence Interval}

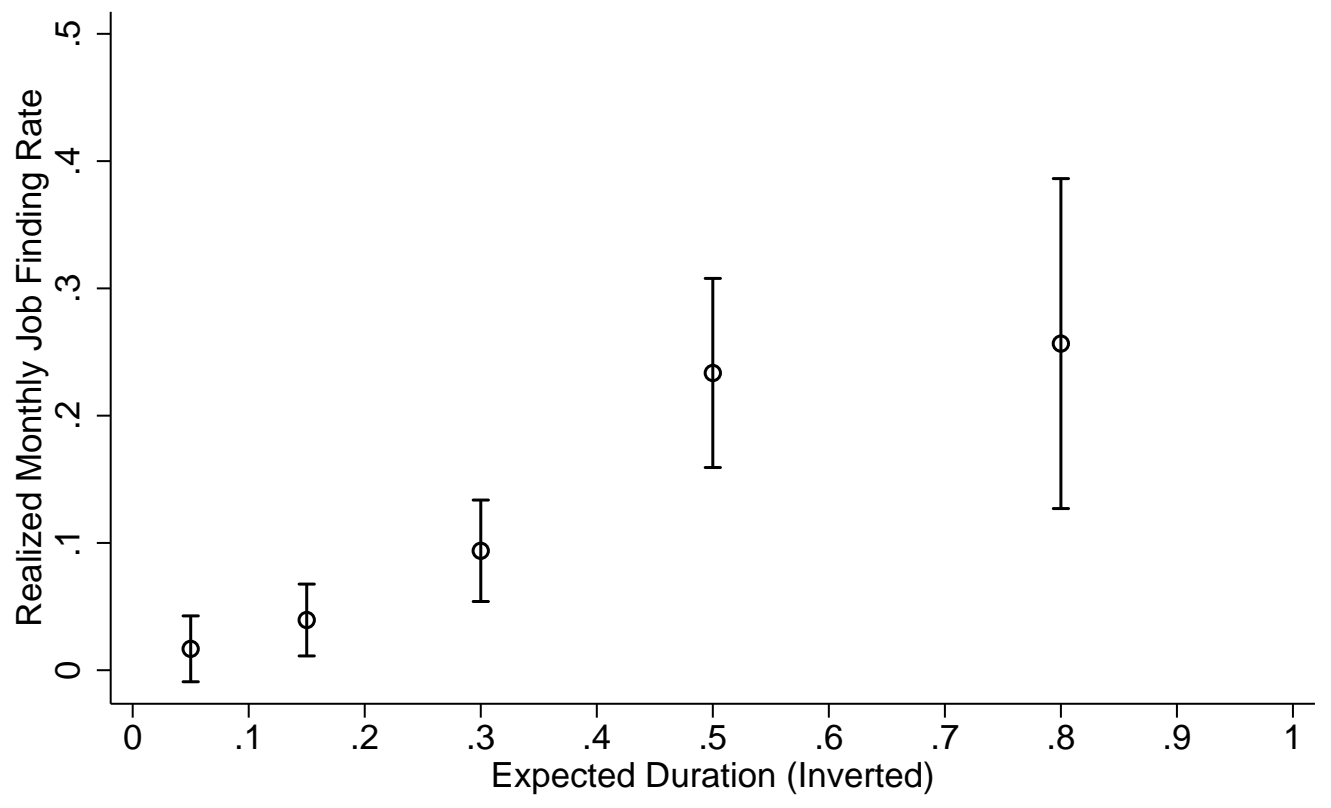

- Mean of Realized Monthly Job Finding Rate 95\% Confidence Interval 
Table D4: Lower Bounds: Additional Estimates (SCE)

\begin{tabular}{lccccccc}
\hline & & & \multicolumn{2}{c}{$\begin{array}{c}\text { Residualized } \\
\text { (full sample) }\end{array}$} & \multicolumn{2}{c}{$\begin{array}{c}\text { Short-term } \\
\text { unemployed }\end{array}$} \\
\cline { 2 - 8 } Lower bound measure based on: & Value & S.e. & Value & S.e. & Value & S.e. \\
\hline ... 3-month elicitations only & 0.032 & $(0.009)$ & 0.016 & $(0.005)$ & 0.031 & $(0.012)$ \\
... 12-month elicitations only & 0.028 & $(0.008)$ & 0.013 & $(0.004)$ & 0.016 & $(0.009)$ \\
$\ldots$ 3- and 12-month elicitations & 0.038 & $(0.010)$ & 0.019 & $(0.006)$ & 0.029 & $(0.013)$ \\
$\ldots$ controls only & 0.036 & $(0.009)$ & 0.020 & $(0.006)$ & 0.043 & $(0.012)$ \\
... controls and 3-month elicitations & 0.053 & $(0.010)$ & 0.030 & $(0.007)$ & 0.059 & $(0.014)$ \\
$\ldots$ controls and both elicitations & 0.054 & $(0.010)$ & 0.031 & $(0.007)$ & 0.060 & $(0.014)$ \\
\hline
\end{tabular}

Notes: Standard errors are bootstrapped with 2,000 replications. For the results in the second column, in a first stage, beliefs (in rows 1 to 3 ) and the predicted values (in rows 4 to 6 ) are regressed on three dummies for unemployment duration (4-6 months, 7-12 months and 13+ months) and then, in a second stage, the residual of the regression is used to compute the lower bounds. The sample in the third column includes only those unemployed with a duration of 3 months or less.

Table D5: Lower Bounds Based on KM Survey

\begin{tabular}{lcc}
\hline Lower bound measure based on: & Value & S.e. \\
\hline .. 1-month elicitation only & 0.0039 & $(0.0035)$ \\
.. elicited duration (inverted) only & 0.0081 & $(0.0086)$ \\
... both elicitations & 0.0085 & $(0.0076)$ \\
... controls only & 0.0192 & $(0.0137)$ \\
... controls and both elicitations & 0.0233 & $(0.0143)$ \\
\hline
\end{tabular}

Notes: Standard errors are bootstrapped with 2,000 replications. 


\section{D.3 Biases in Beliefs}

\section{D.3.1 Average Bias by Duration}

The following table shows the statistics in the SCE underlying the Figure 3 in the paper. It also shows the corresponding statistics in the KM survey.

Table D6: Comparison of Perceived and Realized Job-Finding Probabilities

\begin{tabular}{lccc}
\hline & $\begin{array}{c}\text { Perceived Job- } \\
\text { Finding Probability }\end{array}$ & $\begin{array}{c}\text { Realized Job- } \\
\text { Finding Rate }\end{array}$ & Sample Size \\
\hline Panel A. SCE (3-month horizon) & & & \\
$\quad$ Full Sample & $0.491(0.014)$ & $0.408(0.022)$ & 1,201 \\
$\quad$ Duration 0-3 months & $0.616(0.028)$ & $0.642(0.037)$ & 369 \\
$\quad$ Duration 4-6 months & $0.529(0.031)$ & $0.472(0.050)$ & 184 \\
$\quad$ Duration 7-12 months & $0.530(0.024)$ & $0.333(0.045)$ & 198 \\
$\quad$ Duration 13+ months & $0.354(0.015)$ & $0.221(0.027)$ & 450 \\
Panel B. KM Survey (1-month horizon) & & & \\
Full sample & $0.256(0.019)$ & $0.105(0.022)$ & 734 \\
$\quad$ Duration 0-6 months & $0.256(0.042)$ & $0.135(0.043)$ & 79 \\
$\quad$ Duration 7-12 months & $0.283(0.031)$ & $0.116(0.048)$ & 158 \\
$\quad$ Duration 13+ months & $0.232(0.028)$ & $0.076(0.022)$ & 497
\end{tabular}

Notes: Survey weights are used for all statistics. All samples are restricted to unemployed workers, ages 20-65. The KM sample is further restricted to interviews where the belief questions were administered. Standard errors are in parentheses. Duration refers to self-reported duration in the SCE and duration of weeks of benefit receipt in the KM survey. The SCE sample for this table is restricted to individuals with 4 consecutive interviews. Actual job finding is measured in the SCE as the fraction of individuals who reported being employed in month $t+1$, $t+2$ or $t+3$, where $t$ is the month of the interview where the belief was reported. The KM sample is restricted to those who have not accepted a job in the same or any previous interviews and are not working at the time of the interview. Actual job finding in the KM survey is measured as the fraction accepting a job offer or working in an interview at any point in the 31 days following the interview where the belief was reported. 


\section{D.3.2 Job Finding Beliefs by Duration: Robustness}

In this section, we provide additional details on the robustness analysis of our longitudinal results in Table 4 and Figure 4 in the main paper.

We probe the robustness of the finding that beliefs are not revised downward in several ways and also evaluate potential forces that may underlie the (weakly) increasing beliefs about job finding probabilities. First, we check whether the results in column 4 of Table 4 hold for other measures of perceived job finding. In the KM survey, we find that the expected remaining duration decreases with duration of unemployment when controlling for individual fixed effect. This is obviously consistent with an increasing probability over the spell of unemployment as reported in Table 4. For the purpose of comparison with the probability question, we take the inverse of the expected duration question and convert it into a 4 -week probability, assuming that the probability is constant over the spell of unemployment (see footnote 20 for details). Table D8 reports these results. We find that the coefficient is 0.013 , which is close to the estimate based on the probability question (0.022). Using the 12-month probabilities in the SCE, the coefficient on unemployment duration is negative but insignificant and very close to zero with an estimate of $-0.0027(0.0065)$. The point estimate implies that the 12 -month probability decreases by 3.2 percentage points over a 12 -month period, which is almost trivial.

The first columns in Tables D7 and D8 report results where we exclude answers of 50 percent, results where we exclude answers of 100 percent, results where we do not trim outlier answers as discussed further above, and results where we use self-reported duration of unemployment as the independent variable. While individuals increase their perceived job finding probability as they approach re-employment, the result remains if we exclude individuals who find and accept a job within the next 4 weeks in the KM survey. Neither is the estimate affected when we exclude individuals who reported a job offer in a previous interview but did not accept it (see Table D8). Across all these different specifications, the results are very similar.

We also find that our results are robust to controlling for changes in aggregate labor market conditions during our sample period. For the SCE, which uses a rotating panel, controlling for changes in the national, state unemployment rates or quarterly GDP growth has little effect on our estimate of the duration dependence in perceived job finding rates. More importantly, we also run a specification with individual fixed effects and fixed effects for calendar time, and find that the results are not affected. Even though calendar time and duration are collinear in a given spell, this model is identified in the presence of multiple unemployment spells per person. The results are very similar to our baseline specification, demonstrating that aggregate time trends are unlikely to drive our longitudinal results on perceived job finding. Note that, for the KM survey, the sample period coincides for all job seekers, so calendar time and time spent unemployed are collinear and thus it is problematic to include the state or local unemployment rate into the fixed effect regression. As discussed in Krueger and Mueller [2011], however, the unemployment rate in NJ was nearly constant over the period of the survey (October 2009 through April 2010) between 9.5 and 9.8 and did not drop below 9.4 until August 2011, so it seems unlikely that people perceived the job market to improve over the sample period.

Finally, one may be concerned that the beliefs are not elicited for individuals who get discouraged and drop out of the labor and that as a consequence our longitudinal estimates are upward biased. 
While this is a potential concern in the SCE where individuals were asked the belief questions only when unemployed, we'd like to start by emphasizing that this is not the case for the KM survey, where individuals were followed and their perceptions were elicited independently of whether they indicated searching for a job or not. To further assess this issue in the SCE, we split the sample into those unemployment spells that were interrupted by or ended with a transition into out of the labor force. We find a negligent longitudinal decline for those spells with a UN transition of 0.0022 percentage points per month (or 2.6 percentage points per year). We further assess this issue by imputing the longitudinal decline for the months where the individual was reported to be out of the labor force based on the longitudinal decline in the months unemployed. We then re-estimate our regression with spell fixed effects but now including those survey months where a person was reported out of the labor force as part of the same spell. As the last column in Panel B of Table D7 shows, the resulting coefficient on unemployment duration remains positive and becomes even significant, suggesting that even for the SCE, our longitudinal results are not biased upward. Note that the nature of this exercise is somewhat different from the one further above, as the imputation procedure implies that we give more weight to individuals with more or longer transitions into out of the labor force.

The lack of updating over the spell seems pervasive across different groups of job seekers. When we regress the gradient of perceptions over the spell of unemployment, we find few characteristics that correlate significantly with it. For example, in the KM survey, measures of impatience, risk aversion or available savings do not correlate with the beliefs gradient. ${ }^{59}$ We find a positive within-person correlation between liquidity constraints and the perceived probability - a job seeker reports a higher job finding probability when liquidity constraints become binding - but controlling for liquidity constraints does not attenuate the positive impact of duration on beliefs.

To conclude, we have done extensive robustness checks and find that our results of the lack of negative updating of beliefs over the unemployment spell is a very robust result in both the SCE and the KM survey.

\footnotetext{
${ }^{59}$ Impatience in the KM survey is measured by the choice of a $\$ 20$ incentive payment at the beginning of the survey over the option of a $\$ 40$ incentive payment after the first 12 weeks of the survey. Risk aversion is elicited as the willingness to take risks on a scale from 0 to 10 .
} 


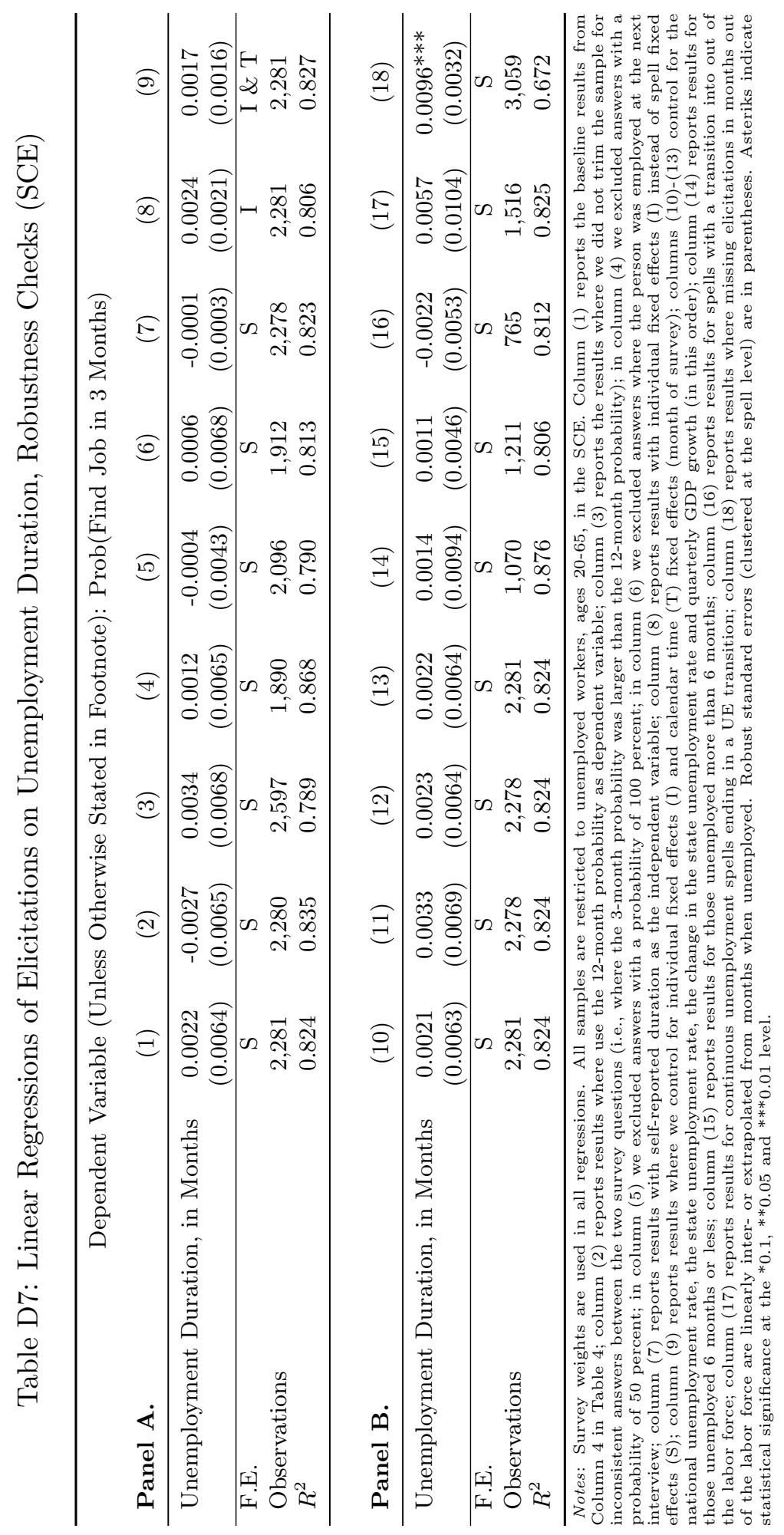




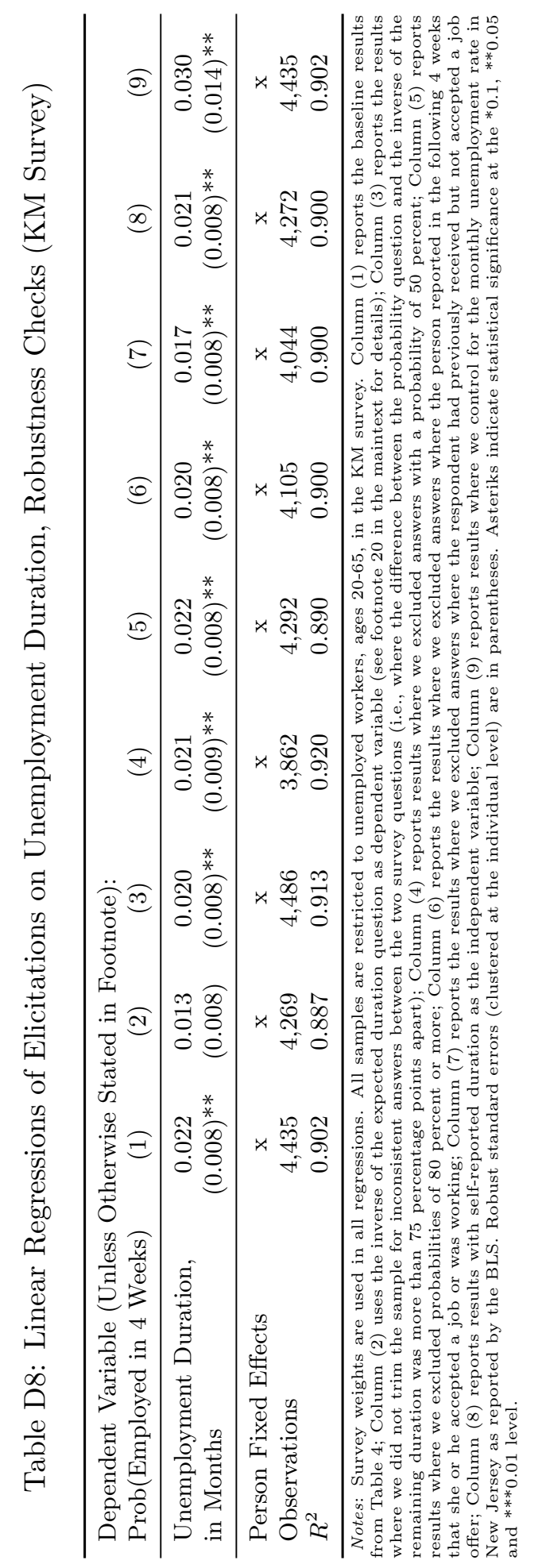


Figure D6: Perceived Job Finding Probabilities, by Time since First Interview

A. Elicitation of 12-Month Probability (SCE)
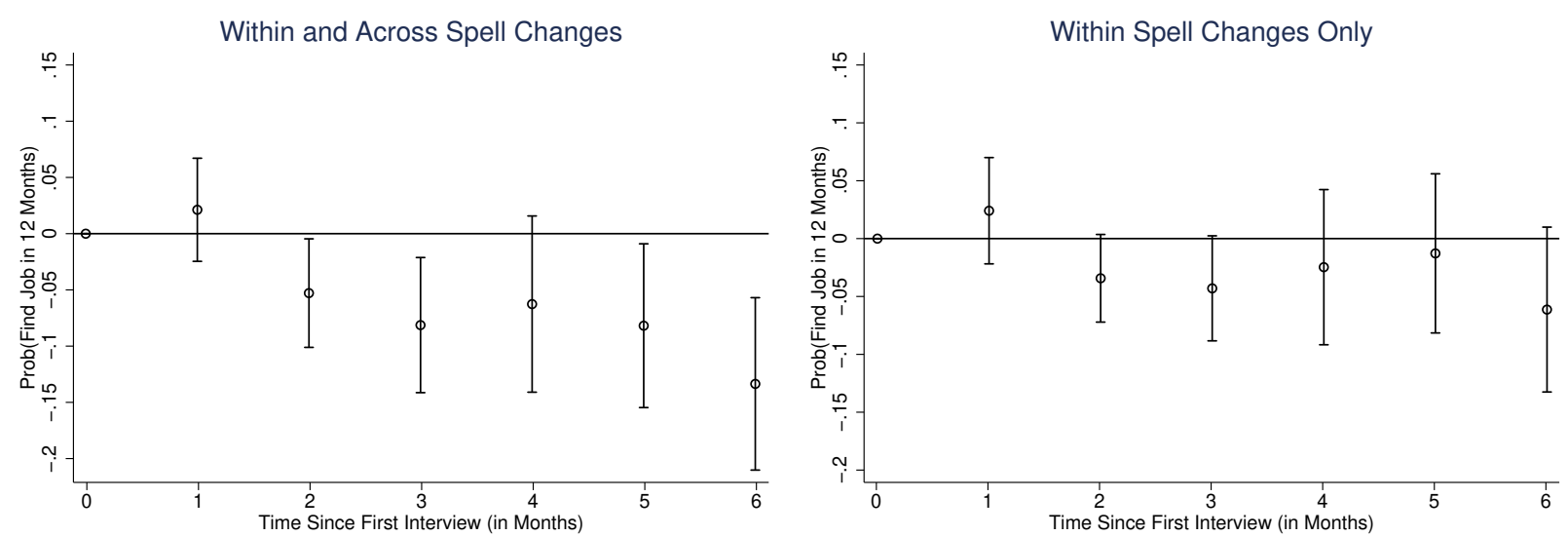

B. Inverse of Elicited Expected Duration (KM Survey)
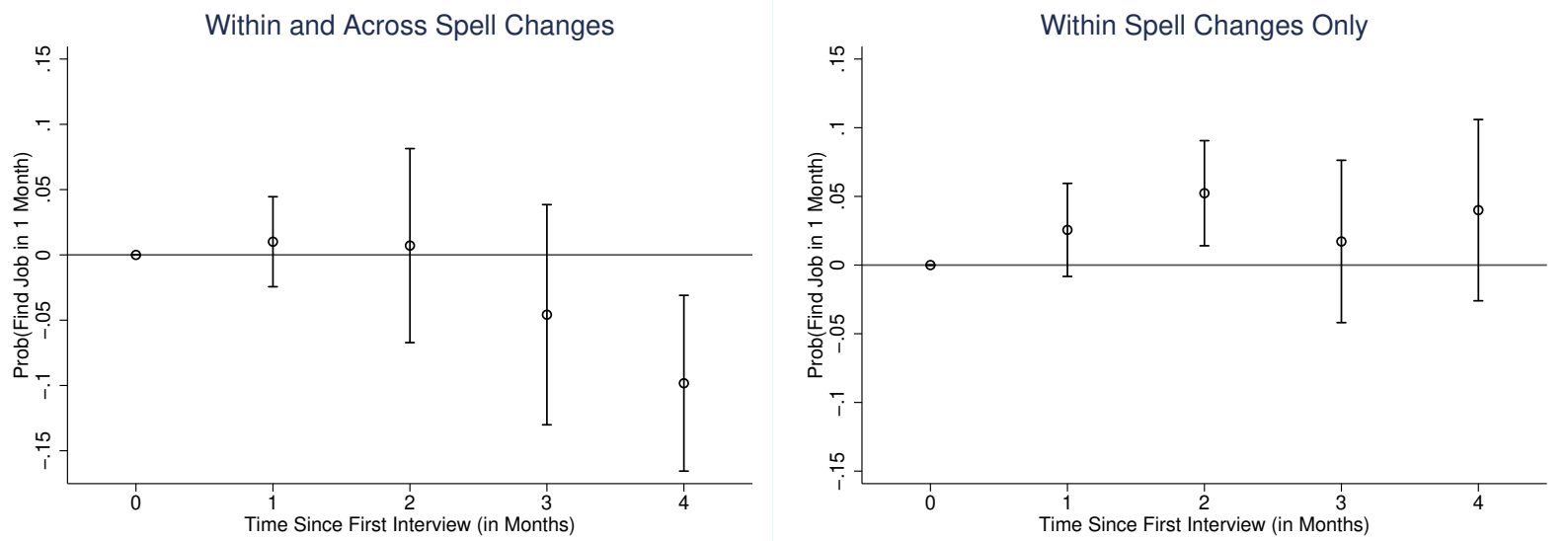
Figure D7: Average Perceived Monthly Job Finding Rate, by Duration of Unemployment and by Cohort (KM Survey)

\section{A. Averages of Elicited Probability (Raw)}
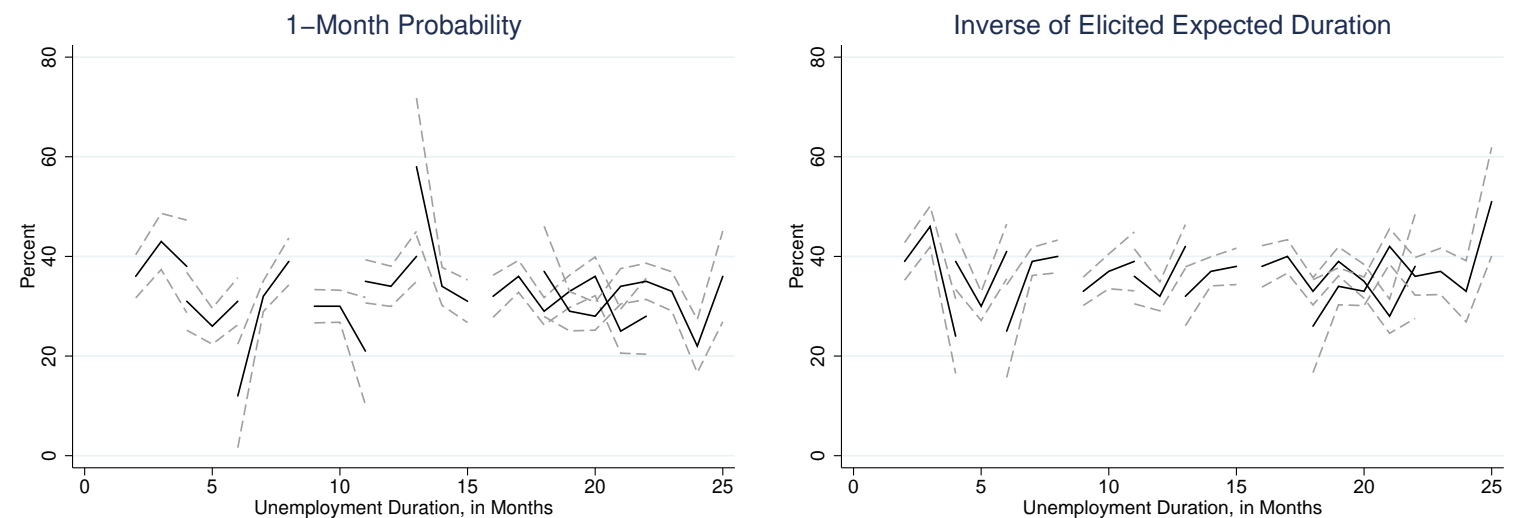

B. Averages of Elicited Probability (Removing Individual Fixed Effects)
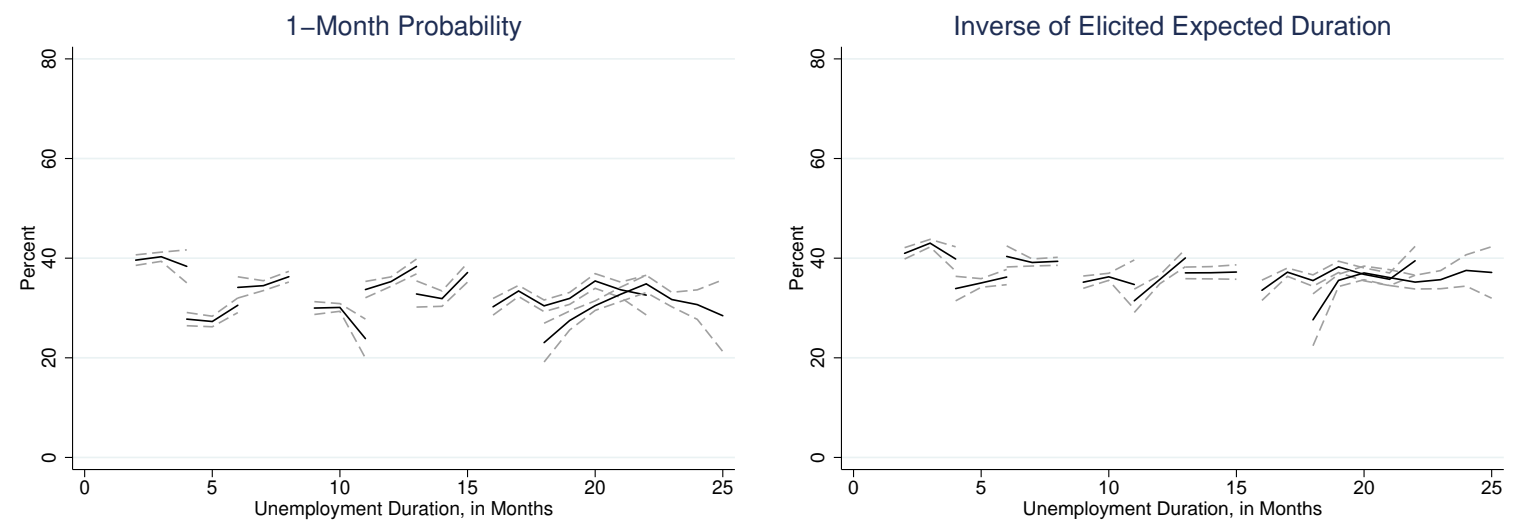

Note: The figure shows averages for each month of unemployment duration and by cohort. The figures in Panel A show raw averages, whereas the figures in Panel B show averages after removing individual fixed effects and adding the average for each cohort. The figures does not show averages for month-cohort bins with less than 10 observations. 


\section{D.3.3 Further Evidence on Elicited Beliefs}

In this section, we provide some evidence on the relationship between eliced beliefs and job search behavior as reported in the KM survey. We also report some evidence on how job-seekers' beliefs respond to aggregate indicators of labor market tightness in the SCE.

Table D9 reports the results of regressions on reported search behavior in the KM data. We find that across job seekers, the self-reported reservation wage bears a negative association with the 1-month probability though statistically insignificant, whereas time spent on job search activities is a positive predictor of the elicited 1-month probability (significant at the 1 percent level). Overall, these results are, at least qualitatively, in line with what one could expect from a simple search model with a reservation wage choice and endogenous search effort: the reservation wage has a negative effect on the probability of accepting and thus finding a job, whereas search effort increases the probability of finding a job. The causality, however, may well run in the opposite direction. Job seekers who update positively on the probability of receiving a job offer are likely to increase their reservation wage. Indeed, we find some evidence for this in column 4: controlling for individual fixed effects, job seekers who decrease their reservation wage, reduce at the same time their expected remaining duration, though for the 1-month probability question the relationship remains small and insignificant. Reverse causality may confound the relationship between job finding beliefs and search effort as well. Controlling for individual fixed effects, the correlation between perceived job finding and search disappears.

When deciding how hard to search, the perceived returns to search are key as well (Spinnewijn [2015]). The survey gauges job seekers' perceived control by asking whether they could increase their job finding chances by spending more time searching for a job. Interestingly, the vast majority of job seekers state that they cannot. Table D9 shows, controlling for search effort, that workers who report a positive return to search at the margin also report higher job finding probabilities.

We revisit the question on the role of beliefs for job search in our structural analysis in Section 5, where we specify a search model allowing for heterogeneous beliefs about the primitives of the job search environment and calibrate this model targeting the true and perceived job finding in our data. Note that our analysis in the statistical model in Section 4 abstracts from job search decisions and does not rely on any assumption about how beliefs affect job search either.

Table D10 shows workers' perceptions respond to aggregate indicators of job finding in the SCE. We find that for unemployed individuals there is no significant relationship between the national or statelevel unemployment rate and the 3-month perception, though standard errors are relatively large. We do find, however, a highly significant positive correlation with the elicited probability that the stock market will rise and a highly significant negative correlation with the elicited probability that the unemployment rate will rise. This suggests that unemployed job seekers take into account their perceptions about aggregate conditions when expressing their perceptions about individual job finding (or vice versa), but their perceptions about aggregate conditions seem ill-informed. Interestingly, when looking at the sample of employed, who were asked the same 3-month perception question for the hypothetical situation where they become unemployed, there is a strongly negative and significant correlation between the 3month perception and the national or state-level unemployment rate. For the state-level results, where the standard errors are lower, we can reject the hypothesis that the unemployed's perceptions respond 
as much as the employed's perceptions to the state-level unemployment rate. At the same time, the correlation between the perceived individual job finding and the perceived aggregate conditions is very similar for the employed and unemployed. Overall, the results seem to suggest that unemployed workers' perceptions under-react to aggregate indicators of their employment prospects. 
Table D9: Linear Regressions of Elicited Perceptions on Time Spent on Job Search and the Reservation Wage (KM Survey)

\begin{tabular}{lcccc}
\hline \multirow{2}{*}{ Dependent variable: } & & & & \\
& Prob(Find Job in 1 Month) & \multicolumn{2}{c}{ Expected Duration (Inverted) } \\
\cline { 2 - 5 } & $(1)$ & $(2)$ & $(3)$ & $(4)$ \\
\hline Dummy for Control Belief & 0.0884 & -0.0109 & 0.1053 & 0.0533 \\
Time Spent on Job Search (Hours per Week) & $0.0253)^{* * *}$ & $(0.0230)$ & $(0.0197)^{* * *}$ & $(0.0307)^{*}$ \\
& $(0.0006)^{* *}$ & -0.0014 & 0.0011 & 0.0008 \\
Log(Hourly Reservation Wage) & -0.0304 & -0.0109 & -0.0477 & 0.1346 \\
& $(0.0346)$ & $(0.0758)$ & $(0.0298)$ & $(0.0812)^{*}$ \\
Reservation Commuting Distance (in min) & -0.0002 & -0.0009 & -0.0008 & -0.0003 \\
& $(0.0006)$ & $(0.0013)$ & $(0.0005)^{*}$ & $(0.0013)$ \\
\hline Controls & $\mathrm{x}$ & & $\mathrm{x}$ & $\mathrm{x}$ \\
Individual F.E. & & $\mathrm{x}$ & & 3,990 \\
N & 3,992 & 4,087 & 3,911 & 0.891 \\
R2 & 0.129 & 0.915 & 0.097 & \\
\hline
\end{tabular}

Notes: Survey weights are used in all regressions. All samples are restricted to unemployed workers, ages 20-65, in the KM survey. Expected duration (inverted) is calculated as $1-\left(1-\frac{1}{x}\right)^{4}$, where $x$ is the elicited expected remaining duration of unemployment (in weeks). The dummy for control belief is set to one for respondents who believe that chances of finding a job increase if they spent more time searching. Robust standard errors (clustered at the individual level) are in parentheses. Asteriks indicate statistical significance at the ${ }^{*} 0.1,{ }^{* *} 0.05$ and ${ }^{* * *} 0.01$ level. 
Table D10: Linear Regressions of Macroeconomic Measures on Elicitations (SCE)

Panel A. Unemployed Individuals:

Elicited 3-Month Probability

(2)

$(3)$

$(4)$

\begin{tabular}{lcccc} 
National Unemployment Rate & 0.812 & & & \\
& $(1.369)$ & & & \\
National Job Openings Rate & 2.597 & & & \\
& $(2.460)$ & & & \\
State Unemployment Rate & & -0.236 & -0.561 & \\
& & $(0.832)$ & $(0.763)$ & \\
Elicited Prob(Rise in US Unemployment) & & & $0.165^{* * *}$ \\
& & & & $(0.039)$ \\
Elicited Prob(Rise in Stock Prices) & & & & $-0.079^{*}$ \\
& \multirow{2}{*}{$\mathrm{x}$} & $\mathrm{x}$ & $\mathrm{x}$ & $\mathrm{x}$ \\
Demographics & & & $\mathrm{x}$ & $\mathrm{x}$ \\
State FE & 2,593 & 2,593 & 2,593 & 2,569 \\
Observations & 0.103 & 0.102 & 0.175 & 0.187 \\
$R^{2}$ & & & &
\end{tabular}

Panel B. Employed Individuals:

Elicited (Conditional) 3-Month Probability

(1)

(2)

(3)

(4)

\begin{tabular}{lcccc} 
National Unemployment Rate & $\begin{array}{c}-2.699^{* * *} \\
(0.366)\end{array}$ & & \\
National Job Openings Rate & $1.528^{* *}$ & & \\
& $(0.637)$ & & \\
State Unemployment Rate & & $-2.789^{* * *}$ & $-2.901^{* * *}$ \\
& & $(0.244)$ & $(0.270)$ & \\
Elicited Prob(Rise in US Unemployment) & & & & $0.217^{* * *}$ \\
& & & & $0.014)$ \\
Elicited Prob(Rise in Stock Prices) & & & & $-0.096^{* * *}$ \\
& \multirow{2}{*}{$\mathrm{x}$} & $\mathrm{x}$ & $\mathrm{x}$ & $\mathrm{x}$ \\
\hline Demographics & & & $\mathrm{x}$ & $\mathrm{x}$ \\
State FE & 58,295 & 58,295 & 58,295 & 57,860 \\
Observations & 0.054 & 0.055 & 0.066 & 0.075 \\
$R^{2}$ & & & \\
\hline
\end{tabular}

Notes: Survey weights are used in all regressions. All samples are restricted to unemployed workers, ages 2065 , in the SCE. Robust standard errors (clustered at the individual level) are in parentheses. Asteriks indicate statistical significance at the ${ }^{*} 0.1,{ }^{* *} 0.05$ and $* * * 0.01$ level. 


\section{E Statistical Framework}

\section{E.1 Model Fit and Estimation Results for Restricted Models}

In this section, we provide additional details regarding the estimation of the statistical model in the paper. Table E1 shows details on the model fit for the baseline model. Table E2 shows additional details on the restricted versions of the model discussed in the paper and shown in Table 6 .

Table E1: Matched Moments

\begin{tabular}{|c|c|c|c|}
\hline \multirow[b]{2}{*}{ Moment } & \multirow[b]{2}{*}{ Symbol } & \multicolumn{2}{|c|}{ Value in } \\
\hline & & Data & Model \\
\hline Mean of 3-Month Job Finding Rates: & & & \\
\hline$\ldots$ at $0-3$ Months of Unemployment & $m_{F_{03}}$ & 0.642 & 0.646 \\
\hline ... at 4-6 Months of Unemployment & $m_{F_{46}}$ & 0.472 & 0.456 \\
\hline$\ldots$ at 7 Months of Unemployment or More & $m_{F_{7+}}$ & 0.256 & 0.262 \\
\hline Mean of 3-Month Elicitations (Deviation from Actual): & & & \\
\hline$\ldots$ at $0-3$ Months of Unemployment & $m_{Z_{03}}-m_{F_{03}}$ & -0.026 & -0.027 \\
\hline ... at 4-6 Months of Unemployment & $m_{Z_{46}}-m_{F_{46}}$ & 0.057 & 0.058 \\
\hline ... at 7 Months of Unemployment or More & $m_{Z_{7+}}-m_{F_{7+}}$ & 0.153 & 0.147 \\
\hline Mean of Monthly Innovations in Elicitations & $m_{d Z}$ & 0.008 & 0.006 \\
\hline Variance of Elicitations & $s_{Z}^{2}$ & 0.093 & 0.093 \\
\hline Covariance of Elicitations and Job Finding & $c_{Z, F}$ & 0.054 & 0.056 \\
\hline Covariance of Elicitations and Job Finding in 3 Months & $c_{Z_{d}, F_{d+3}}$ & 0.025 & 0.024 \\
\hline
\end{tabular}


Table E2: Parameter Estimates and Model Fit for Restricted Versions of the Model

\begin{tabular}{|c|c|c|c|c|c|c|c|}
\hline \multicolumn{2}{|c|}{$\begin{array}{l}\text { A. Parameter Estimates } \\
\text { and Selected Moments: }\end{array}$} & $\begin{array}{c}(1) \\
\text { Baseline }\end{array}$ & $\begin{array}{c}(2) \\
\theta=0\end{array}$ & $\begin{array}{c}(3) \\
\text { No heterog. } \\
\text { in } T_{i, d}\end{array}$ & $\stackrel{(4)}{\sigma_{\tau}=0}$ & $\begin{array}{c}(5) \\
b_{1}=1\end{array}$ & $\begin{array}{c}(6) \\
b_{0}=0 \\
b_{1}=1\end{array}$ \\
\hline & 0.403 & 0.405 & 0.318 & 0.419 & 0.294 & 0.332 \\
\hline \multicolumn{2}{|l|}{$\operatorname{Var}\left(T_{i}\right)$} & 0.044 & 0.051 & 0.000 & 0.070 & 0.019 & 0.019 \\
\hline \multicolumn{2}{|l|}{$\sigma_{\tau}$} & 0.334 & -0.275 & 0.000 & 0.000 & 0.201 & 0.245 \\
\hline \multicolumn{2}{|l|}{$\theta$} & 0.017 & 0.000 & 0.106 & -0.044 & 0.012 & 0.015 \\
\hline \multicolumn{2}{|l|}{$b_{0}$} & 0.265 & 0.269 & 0.341 & 0.27 & 0.065 & 0.000 \\
\hline \multicolumn{2}{|l|}{$b_{1}$} & 0.55 & 0.538 & 0.349 & 0.543 & 1.000 & 1.000 \\
\hline \multicolumn{2}{|l|}{$\sigma_{\varepsilon}$} & 0.453 & 0.453 & 0.442 & 0.454 & 0.374 & 0.38 \\
\hline \multicolumn{2}{|l|}{$\operatorname{Var}_{0}\left(T_{i, 0}^{3}\right)$} & 0.076 & 0.079 & 0.000 & 0.085 & 0.051 & 0.047 \\
\hline \multicolumn{2}{|l|}{$\operatorname{Var}_{0}\left(T_{i}^{3}\right)$} & 0.057 & 0.065 & 0.000 & 0.085 & 0.040 & 0.033 \\
\hline \multicolumn{2}{|l|}{$\operatorname{Var}_{0}\left(Z_{i, 0}^{3}\right)$} & 0.081 & 0.082 & 0.066 & 0.083 & 0.087 & 0.085 \\
\hline \multicolumn{2}{|l|}{$\mathrm{TD}$} & 0.459 & 0.454 & 0.430 & 0.452 & 0.301 & 0.315 \\
\hline & 0.070 & 0.000 & 0.430 & -0.116 & 0.054 & 0.071 \\
\hline \multicolumn{2}{|l|}{$1-L D / T D($ in $\%)$} & 84.71 & 100.00 & 0.000 & 125.67 & 82.20 & 77.53 \\
\hline B. Model Fit: & Data & $(1)$ & $(2)$ & $(3)$ & $(4)$ & $(5)$ & $(6)$ \\
\hline \multicolumn{8}{|l|}{ Targeted Moments: } \\
\hline$m_{F_{03}}$ & 0.642 & 0.646 & 0.640 & 0.598 & 0.63 & 0.571 & 0.627 \\
\hline$m_{F_{46}}$ & 0.472 & 0.456 & 0.446 & 0.460 & 0.418 & 0.464 & 0.520 \\
\hline$m_{F_{7+}}$ & 0.256 & 0.262 & 0.263 & 0.218 & 0.262 & 0.321 & 0.373 \\
\hline$m_{Z_{03}}-m_{F_{03}}$ & -0.026 & -0.027 & -0.027 & -0.049 & -0.018 & 0.064 & 0.000 \\
\hline$m_{Z_{46}}-m_{F_{46}}$ & 0.057 & 0.058 & 0.062 & 0.041 & 0.078 & 0.066 & -0.001 \\
\hline$m_{Z_{7+}}-m_{F_{7+}}$ & 0.153 & 0.147 & 0.148 & 0.199 & 0.151 & 0.066 & 0.00 \\
\hline$m_{d Z}$ & 0.008 & 0.006 & 0.007 & -0.013 & 0.006 & 0.004 & 0.006 \\
\hline$s_{Z}^{2}$ & 0.093 & 0.093 & 0.092 & 0.069 & 0.092 & 0.098 & 0.099 \\
\hline$c_{Z, F}$ & 0.054 & 0.056 & 0.056 & 0.012 & 0.054 & 0.059 & 0.058 \\
\hline$c_{Z_{d}, F_{d+3}}$ & 0.025 & 0.024 & 0.025 & 0.010 & 0.029 & 0.034 & 0.034 \\
\hline Weighted SSR & & 0.470 & 0.695 & 49.198 & 2.514 & 12.251 & 21.613 \\
\hline
\end{tabular}




\section{E.2 Robustness}

In this section, we study the robustness of our results when using alternative specifications, alternative moments, and alternative functional forms and distributions. Tables E3 and E4 show results for various robustness checks discussed briefly in the paper.

First, we assess the estimated heterogeneity in our statistical model using the heterogeneity that is not predictable using observable characteristics. The robustness check we perform is to estimate the model on a set of residualized moments, i.e., the moments obtained from the residuals of a set of linear regressions of the 3-month belief question and of the 3-month job finding rate on the same set of demographic controls as in Table 2. The estimation results are shown in Table E4 and the moments in Table E5 . Overall, the estimation results are very similar to the baseline, with the role played by true duration dependence being again close to zero. Of course, the extent of ex-ante heterogeneity is estimated to be smaller in this robustness check, as the effects of observables are parsed out from all moments. We also obtain a comparable estimate for the slope coefficient $b_{1}$ of 0.559 , which suggests that the relationship between observed heterogeneity in job finding and beliefs is similar as the relationship between unobserved heterogeneity in job finding and beliefs.

Second, we probe the robustness of our findings to alternative assumptions about the functional form and distributions as well as extensions of the model, as reported in Tables E3 and E4. Without discussing these estimates in detail, the table shows that the parameter estimates are very stable across all of the results reported in the table. In particular, our results are robust to assuming that $T_{i}$ follows the Gamma distribution (2), and to assuming that $\varepsilon$ follows a bounded normal distribution, which no longer satisfies mean-independence of the error term (3). Our results are also robust to assuming piecewise linear duration dependence instead of geometric depreciation (4), extending the horizon of the model to 5 years (5), and doing both (6). We also extend the model to allow for completely persistent elicitation errors (i.e., $\varepsilon_{i, d}=\varepsilon_{i}$ ) and find that it has no impact on our estimation results (7). This is also true when we extend the model to allow for bunching at $0,0.5$ and 1 of the elicited beliefs, by imposing on the baseline model that any belief in the intervals $(0,0.1],[0.4,0.6]$ resp. $[0.9,1)$ are reset to the bunching points $0,0.5$ resp. 1. Despite these relatively strong assumptions about the nature of bunching, the results of the estimation appear not to be affected (8). This suggests that the variations in elicitations across (rather than within) these intervals is the dominant source of variation that is relevant for identification of the key parameters in the model. We also report the results for a model (9), where a share $\alpha$ of individuals has random elicitations $\left(Z_{i, d}^{3}=b_{0}+\varepsilon\right)$ and a share $1-\alpha$ correctly perceives their job finding prospects $\left(Z_{i, d}^{3}=T_{i, d}^{3}\right)$. The model results are very similar to our baseline, and the value of $1-\alpha$ is close to the value of $b_{1}$, suggesting that $b_{1}$ in our baseline may instead capture the share of individuals who perceive their job finding prospects correctly. Our results are also very similar when using the residualized data moments as discussed before (10), or when excluding individuals with recall expectations when generating the data moments (11). Furthermore, the results do not change either when restricting the set of moments by using only 0-6 and 7+ months for the time intervals and dropping the mean of monthly innovations, so that the model is exactly identified (12), or when using the inverse of the bootstrapped variances on the diagonal of the weighting matrix (and zero otherwise) instead of the full variance-covariance matrix as the weighting matrix (13). 
Finally, in (14) we show the results for the extended model, where $\hat{\theta} \neq \theta$, as discussed in detail in the paper. The targeted moments and the model fit are reported in Table E6. Figures E1 and E2 show the estimated duration dependence in actual and perceived job finding for both the baseline model and the extended model. Overall, the duration depdencence in both actual job finding and the bias looks very similar across the two models. For this reason, not surprisingly, the fit of the restricted model in column 15 of Table E4 where $\hat{\theta}=\theta$ is close to the fit of the unrestricted version of the extended model in column 14 .

To sumarize, we find that our results for the baseline model are very robust to alternative assumptions about functional form and distributional assumptions as well as to extensions of our baseline model. 


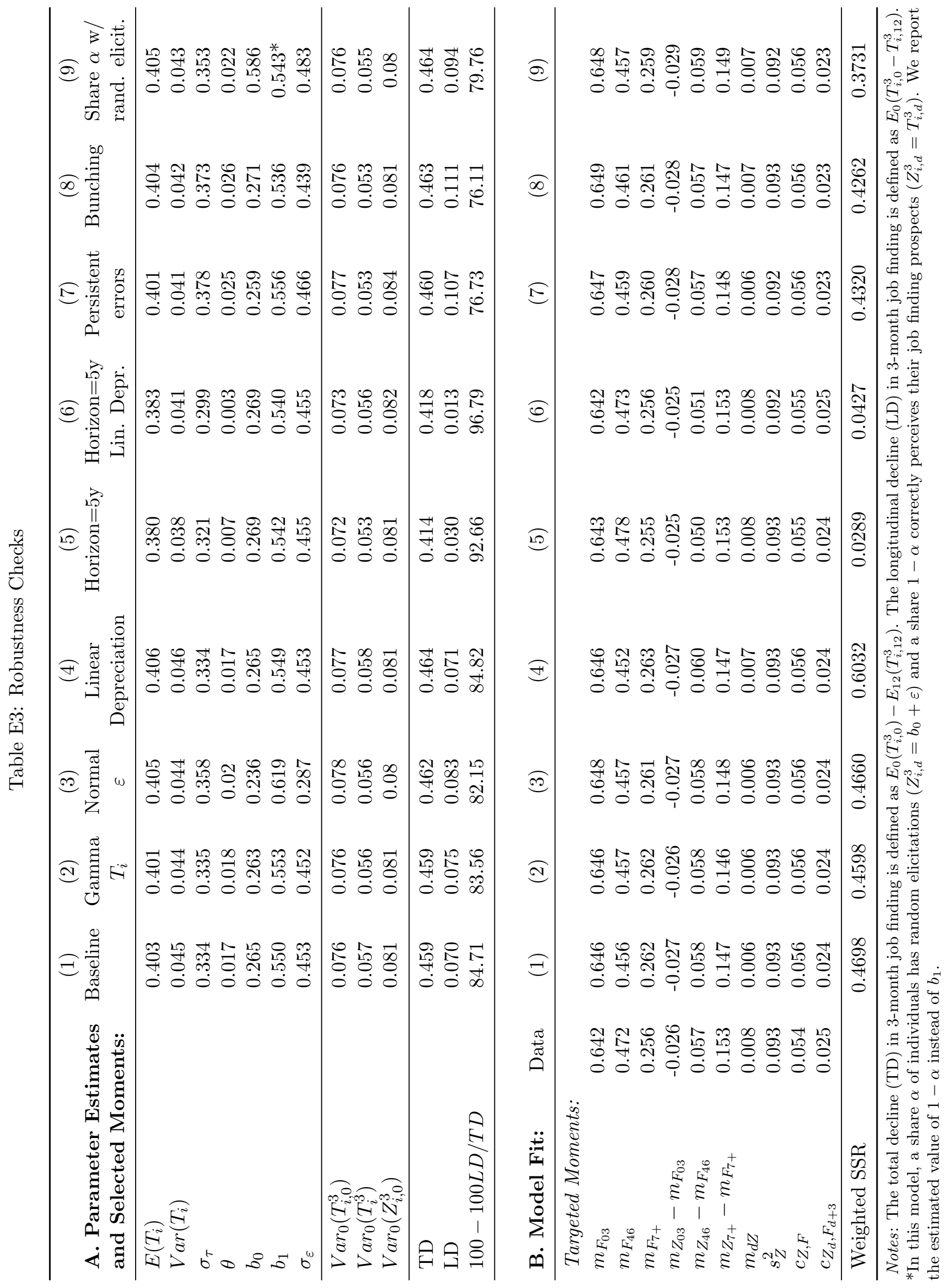




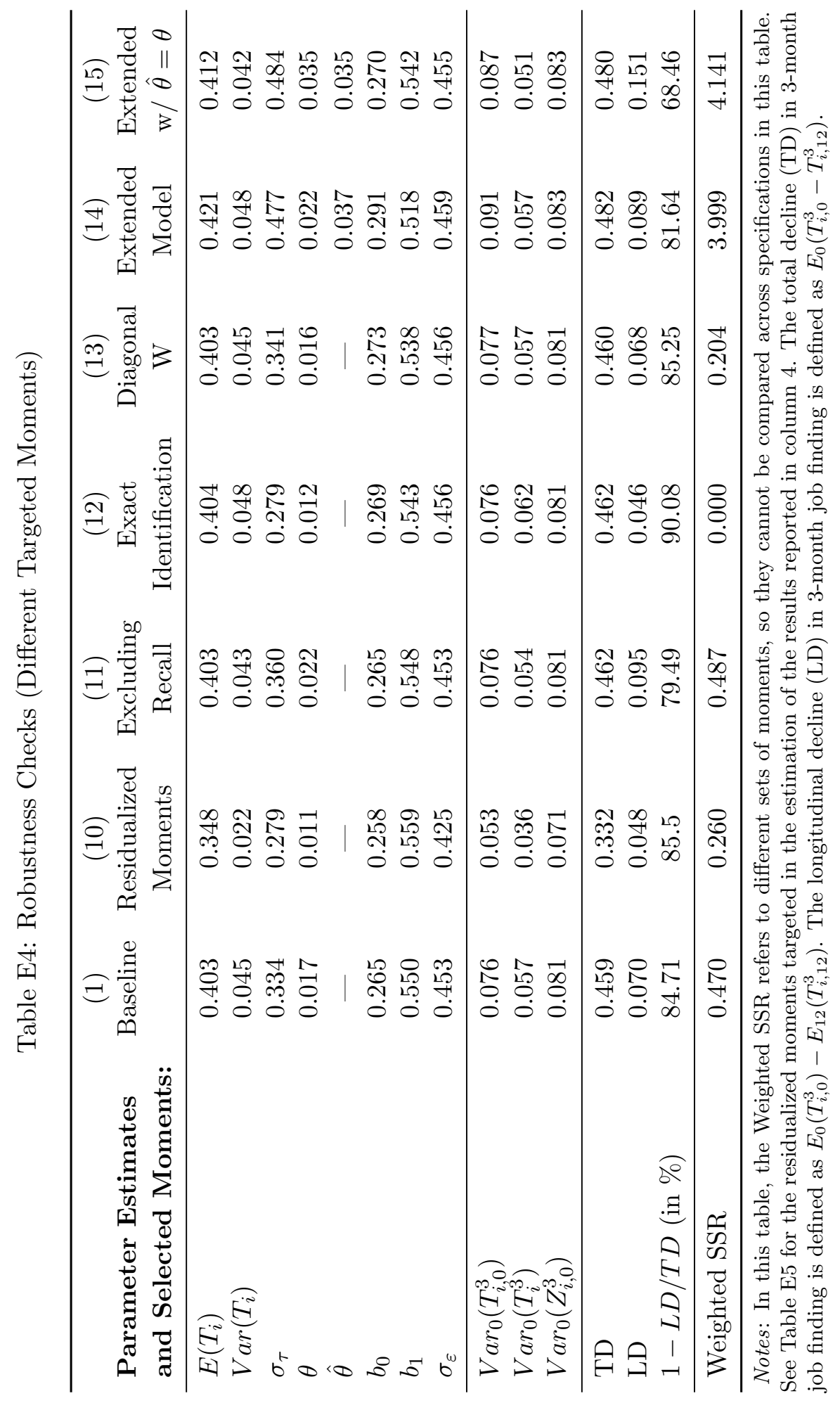


Table E5: Matched Moments (Residualized)

\begin{tabular}{lcrr}
\hline & & \multicolumn{2}{c}{ Value in } \\
Moment & Symbol & Data & Model \\
\hline Mean of 3-Month Job Finding Rates: & $m_{F_{03}}$ & 0.642 & 0.641 \\
$\ldots$ at $0-3$ Months of Unemployment & $m_{F_{4}}$ & 0.513 & 0.525 \\
$\ldots$ at 4 -6 Months of Unemployment & $m_{F_{7+}}$ & 0.369 & 0.373 \\
$\ldots$ at 7 Months of Unemployment or More & & & \\
Mean of 3-Month Elicitations (Deviation from Actual): & $m_{Z_{03}}-m_{F_{03}}$ & -0.026 & -0.025 \\
$\ldots$ at 0 -3 Months of Unemployment & $m_{Z_{46}}-m_{F_{46}}$ & 0.042 & 0.026 \\
$\ldots$ at 4-6 Months of Unemployment & $m_{Z_{7+}}-m_{F_{7+}}$ & 0.098 & 0.094 \\
$\ldots$ at 7 Months of Unemployment or More & $m_{d Z}$ & 0.009 & 0.006 \\
Mean of Monthly Innovations in Elicitations & $s_{Z}^{2}$ & 0.078 & 0.078 \\
Variance of Elicitations & $c_{Z, F}$ & 0.036 & 0.038 \\
Covariance of Elicitations and Job Finding & $c_{Z_{d}, F_{d+3}}$ & 0.020 & 0.020 \\
Covariance of Elicitations and Job Finding in 3 Months & & \\
\hline
\end{tabular}

Notes: The sample is restricted to unemployed workers, ages 20-65, in the SCE. Moments are computed based on residuals from a regression on dummies for gender, race, ethnicity, household income, educational attainment, and age and age squared. Note that the raw mean of the variables in the full sample is added to the residual. 
Table E6: Matched Moments (Extended Model)

\begin{tabular}{|c|c|c|c|}
\hline \multirow[b]{2}{*}{ Moment } & \multirow[b]{2}{*}{ Symbol } & \multicolumn{2}{|c|}{ Value in } \\
\hline & & Data & Model \\
\hline \multicolumn{4}{|l|}{ Mean of 3-Month Job Finding Rates: } \\
\hline$\ldots$ at $0-3$ Months of Unemployment & $m_{F_{03}}$ & 0.642 & 0.656 \\
\hline ... at 4-6 Months of Unemployment & $m_{F_{46}}$ & 0.472 & 0.452 \\
\hline ... at 7 Months of Unemployment or More & $m_{F_{7+}}$ & 0.256 & 0.250 \\
\hline \multicolumn{4}{|l|}{ Mean of 3-Month Elicitations (Deviation from Actual): } \\
\hline ... at $0-3$ Months of Unemployment & $m_{Z_{03}}-m_{F_{03}}$ & -0.026 & -0.030 \\
\hline ... at 4-6 Months of Unemployment & $m_{Z_{46}}-m_{F_{46}}$ & 0.057 & 0.060 \\
\hline ... at 7 Months of Unemployment or More & $m_{Z_{7+}}-m_{F_{7+}}$ & 0.153 & 0.157 \\
\hline Mean of Monthly Innovations in Elicitations & $m_{d Z}$ & 0.008 & 0.009 \\
\hline \multicolumn{4}{|l|}{ Variance of Elicitations: } \\
\hline ... at $0-6$ Months of Unemployment & $s_{Z_{06}}^{2}$ & 0.098 & 0.091 \\
\hline ... at 7 Months of Unemployment or More & $s_{Z_{7+}}^{2}$ & 0.073 & 0.079 \\
\hline \multicolumn{4}{|l|}{ Covariance of Elicitations and Job Finding: } \\
\hline$\ldots$ at $0-6$ Months of Unemployment & $c_{Z_{06}, F_{06}}$ & 0.056 & 0.055 \\
\hline$\ldots$ at 7 Months of Unemployment or More & $c_{Z_{7+}, F_{7+}}$ & 0.025 & 0.029 \\
\hline Covariance of Elicitations and Job Finding in 3 Months & $c_{Z_{d}, F_{d+3}}$ & 0.025 & 0.021 \\
\hline
\end{tabular}

Notes: The sample is restricted to unemployed workers, ages 20-65, in the SCE. 
Figure E1: Duration Dependence in Job Finding in Baseline and Extended Model

(a) Baseline Model

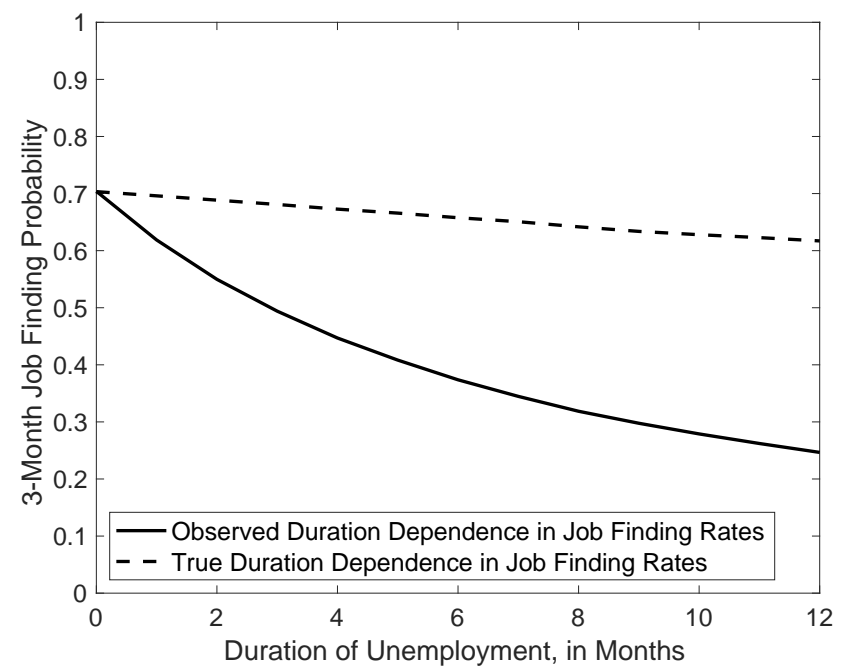

(b) Extended Model

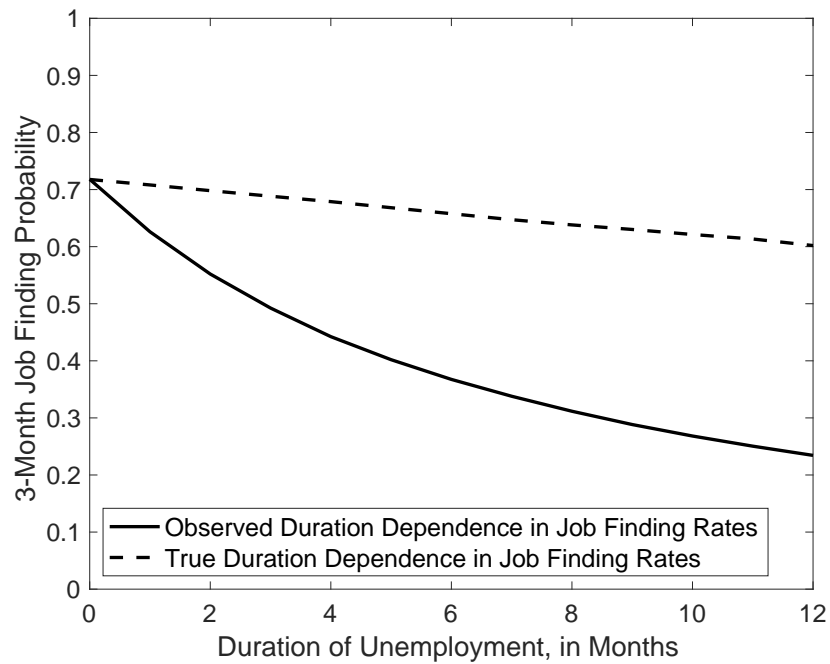

Figure E2: Duration Dependence in Biases in Perceptions in Baseline and Extended Model

(a) Baseline Model

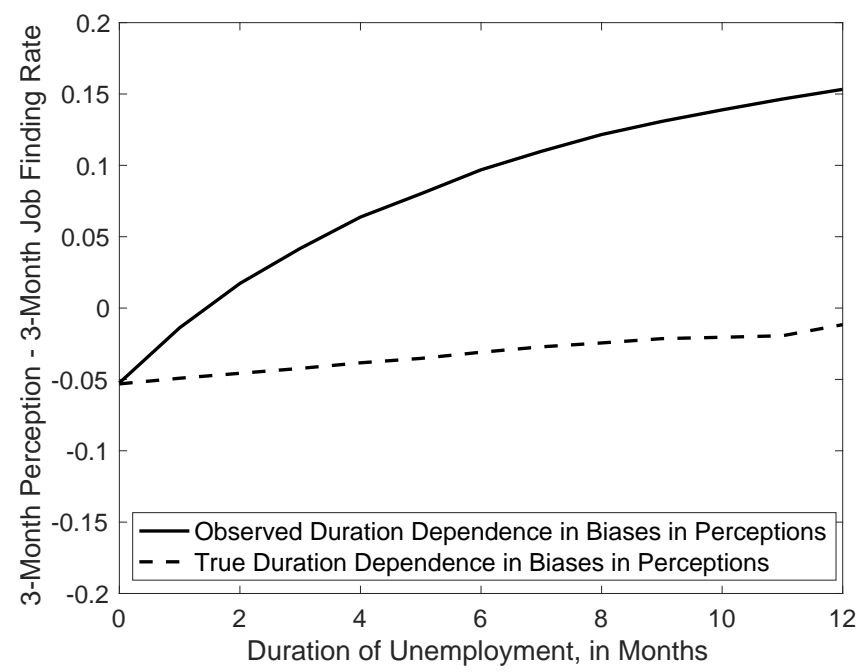

(b) Extended Model

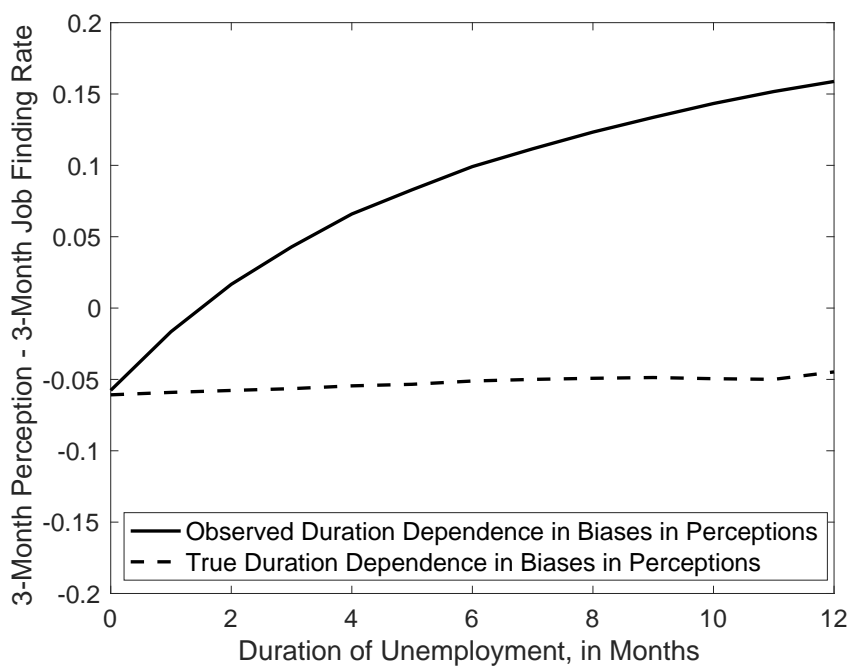




\section{E.3 Identification}

In this section, we provide further details on the identification of the parameters in the statistical model. We proceed in two steps:

First, we prove that in a two-period version of the statistical model, where $\sigma_{\tau}=0$, all other parameters are a function of moments with an empirical counterpart in the data and thus are identified.

Second, we provide a formal identification argument in the two-period model where $\sigma_{\tau}>0$, and then show that in the full model a monotone relationship exists between $\sigma_{\tau}$ and the moment $c_{Z_{d}, F_{d+3}}$, conditional on having identified all other parameters of the model.

Third, we extend the two-period model to allow for $\hat{\theta} \neq \theta$ and prove that in the version of this model, where $\sigma_{\tau}=0$, all other parameters are a function of moments with an empirical counterpart in the data and thus are identified. We then show in the full model that a monotonic relationship exists between $\hat{\theta}$ and the moments $c_{F_{7+}, Z_{7+}}$ and $s_{Z_{7+}}^{2}$, conditional on having identified all other parameters of the model.

\section{E.3.1 Identification in two-period model with $\sigma_{\tau}=0$}

Proposition 2. In a two-period version of the statistical model with measurement error, var $(\varepsilon)$, that is independent of $T_{i, d}$ and with $\sigma_{\tau}=0$, the parameters $b_{0}, b_{1}$, and $\theta$ as well as the mean and the variance of the persistent component of job finding rates, $E\left(T_{i}\right)$ and $\operatorname{var}\left(T_{i}\right)$, and the variance of the elicitation error, $\operatorname{var}(\varepsilon)$, are identified by the moment conditions for: (1) the means of the elicitations in period 1 and 2, $m_{Z_{1}}$ and $m_{Z_{2}}$, (2) the means of the job finding rates in period 1 and 2, $m_{F_{1}}$ and $m_{F_{2}}$, (3) the covariance of job finding and elicitations in period $1, c_{F_{1}, Z_{1}}$, and (4) the variance of elicitations in period $1, s_{Z_{1}}^{2}$.

Proof. We start by assuming that there are only two periods, and that $\sigma_{\tau}=0$. In this case, we can write down the moment conditions for the moments mentioned in the proposition above as:

$$
\begin{aligned}
m_{Z_{1}} & =b_{0}+b_{1} E_{1}\left(T_{i}\right) \\
m_{Z_{2}} & =b_{0}+b_{1}(1-\theta) E_{2}\left(T_{i}\right) \\
m_{F_{1}} & =E_{1}\left(T_{i}\right) \\
m_{F_{2}} & =(1-\theta) E_{2}\left(T_{i}\right) \\
c_{F_{1}, Z_{1}} & =\operatorname{cov}_{1}\left(F_{i, 1}, b_{1} T_{i}\right) \\
s_{Z_{1}}^{2} & =b_{1}^{2} \operatorname{var}_{1}\left(T_{i}\right)+\operatorname{var}(\varepsilon)
\end{aligned}
$$

where sub-indices 1 and 2 on the moments stands for the sample of survivors. Note that $E_{1}\left(T_{i}\right)=E\left(T_{i}\right)$ and $\operatorname{var}_{1}\left(T_{i}\right)=\operatorname{var}\left(T_{i}\right)$, i.e. the moments for the sample of survivors in period 1 correspond to the population moments. The first two moments directly pin down $b_{0}$ and $b_{1}$ :

$$
\begin{aligned}
b_{1} & =\frac{m_{Z_{2}}-m_{Z_{1}}}{m_{F_{2}}-m_{F_{1}}} \\
b_{0} & =m_{Z_{1}}-\frac{m_{Z_{2}}-m_{Z_{1}}}{m_{F_{2}}-m_{F_{1}}} m_{F_{1}}
\end{aligned}
$$


Then, we can write:

$$
\begin{aligned}
c_{F_{1}, Z_{1}} & =\operatorname{cov}_{1}\left(F_{i, 1}, b_{1} T_{i}\right) \\
& =b_{1}\left[E_{1}\left(F_{i, 1} T_{i}\right)-E_{1}\left(F_{i, 1}\right) E_{1}\left(T_{i}\right)\right] \\
& =b_{1}\left[E_{1}\left(E_{1}\left(F_{i, 1} T_{i} \mid T_{i}\right)\right)-E_{1}\left(T_{i}\right)^{2}\right] \\
& =b_{1}\left[E_{1}\left(T_{i}^{2}\right)-E\left(T_{i}\right)^{2}\right] \\
& =b_{1} \operatorname{var}_{1}\left(T_{i}\right)=b_{1} \operatorname{var}\left(T_{i}\right)
\end{aligned}
$$

Hence, we can pin down the mean and the variance of $T_{i}$ from moment conditions (23) and (29):

$$
\begin{aligned}
E\left(T_{i}\right) & =m_{F_{1}} \\
\operatorname{var}\left(T_{i}\right) & =\frac{m_{F_{2}}-m_{F_{1}}}{m_{Z_{2}}-m_{Z_{1}}} c_{F_{1}, Z_{1}}
\end{aligned}
$$

We next note that we can re-write the expected value of $T_{i}$, conditional on survival to period 2 as:

$$
\begin{aligned}
E_{2}\left(T_{i}\right) & =\frac{E_{1}\left[T_{i}\left(1-T_{i}\right)\right]}{1-E\left(T_{i}\right)} \\
& =\frac{E_{1}\left(T_{i}\right)-E_{1}\left(T_{i}^{2}\right)}{1-E_{1}\left(T_{i}\right)} \\
& =\frac{E_{1}\left(T_{i}\right)\left(1-E_{1}\left(T_{i}\right)\right)-\operatorname{var}_{1}\left(T_{i}\right)}{1-E_{1}\left(T_{i}\right)}
\end{aligned}
$$

Substituting this into the moment condition for $m_{F_{2}}$, we get:

$$
m_{F_{2}}=(1-\theta) \frac{E_{1}\left(T_{i}\right)\left(1-E_{1}\left(T_{i}\right)\right)-\operatorname{var}_{1}\left(T_{i}\right)}{1-E\left(T_{i}\right)}
$$

Rearranging and using equation (30), we get:

$$
\begin{aligned}
\theta & =1-\frac{m_{F_{2}}\left(1-m_{F_{1}}\right)}{m_{F_{1}}\left(1-m_{F_{1}}\right)-\operatorname{var}_{1}\left(T_{i}\right)} \\
& =1-\frac{m_{F_{2}}\left(1-m_{F_{1}}\right)}{m_{F_{1}}\left(1-m_{F_{1}}\right)-\frac{m_{F_{2}}-m_{F_{1}}}{m_{Z_{2}}-m_{Z_{1}}} c_{F_{1}, Z_{1}}} \\
& =1-\frac{\left(m_{Z_{2}}-m_{Z_{1}}\right)\left(m_{F_{2}}\left(1-m_{F_{1}}\right)\right)}{m_{F_{1}}\left(1-m_{F_{1}}\right)-\left(m_{F_{2}}-m_{F_{1}}\right) c_{F_{1}, Z_{1}}}
\end{aligned}
$$

Finally, given $b_{1}$, we can solve for $\operatorname{var}(\varepsilon)$ by using the moment condition for $s_{Z_{1}}^{2}$ :

$$
\operatorname{var}(\varepsilon)=s_{Z_{1}}^{2}-\frac{m_{Z_{2}}-m_{Z_{1}}}{m_{F_{2}}-m_{F_{1}}} c_{F_{1}, Z_{1}}
$$

Since $\operatorname{var}(\varepsilon)$ is increasing in $\sigma_{\varepsilon}$, the equation implies a value for $\sigma_{\varepsilon}$.

In conclusion, equations $27,28,30,31,34$ and 35 solve parameters $b_{0}, b_{1}, \theta$ and moments $E\left(T_{i}\right)$, $\operatorname{var}\left(T_{i}\right)$ and $\operatorname{var}(\varepsilon)$ for any distribution of these variables as function of moments that we observe in 
the data $\left(m_{Z_{1}}, m_{Z_{2}}, m_{F_{1}}, m_{F_{2}}, c_{F_{1}, Z_{1}}\right.$ and $\left.s_{Z_{1}}^{2}\right)$. The two-period model with $\sigma_{\tau}=0$ is thus identified.

Proposition 3. In a two-period version of the statistical model with both a measurement error, $\varepsilon$, that is independent of $T_{i, d}$, as well as a non-classical measurement error of the form $\eta=c_{0}+c_{1} T_{i, d}$, and with $\sigma_{\tau}=0$, the parameters $\tilde{b}_{0}=b_{0}, \tilde{b}_{1}=b_{1}+c_{1}$, and $\theta$ as well as the mean and the variance of the persistent component of job finding rates, $E\left(T_{i}\right)$ and $\operatorname{var}\left(T_{i}\right)$, and the variance of the classical elicitation error, $\operatorname{var}(\varepsilon)$, are identified by the moment conditions for: (1) the means of the elicitations in period 1 and $2, m_{Z_{1}}$ and $m_{Z_{2}}$, (2) the means of the job finding rates in period 1 and $2, m_{F_{1}}$ and $m_{F_{2}}$, (3) the covariance of job finding and elicitations in period $1, c_{F_{1}, Z_{1}}$, and (4) the variance of elicitations in period $1, s_{Z_{1}}^{2}$.

Proof. As argued in the main text of the paper, the model continues to be identified exactly in the presence of non-classical measurement error, as long as it is a linear in $T_{i}$. The proof is almost trivial, as we can re-express equations $21,22,25$ and 26 from above as:

$$
\begin{aligned}
m_{Z_{1}} & =\left(b_{0}+c_{0}\right)+\left(b_{1}+c_{1}\right) E_{1}\left(T_{i}\right) \\
m_{Z_{2}} & =\left(b_{0}+c_{0}\right)+\left(b_{1}+c_{1}\right)(1-\theta) E_{2}\left(T_{i}\right) \\
c_{F_{1}, Z_{1}} & =\operatorname{cov}_{1}\left(F_{i},\left(b_{1}+c_{1}\right) T_{i}\right) \\
s_{Z_{1}}^{2} & =\left(b_{1}+c_{1}\right)^{2} \operatorname{var}_{1}\left(T_{i}\right)+\operatorname{var}(\varepsilon)
\end{aligned}
$$

or:

$$
\begin{aligned}
m_{Z_{1}} & =\tilde{b}_{0}+\tilde{b}_{1} E_{1}\left(T_{i}\right) \\
m_{Z_{2}} & =\tilde{b}_{0}+\tilde{b}_{1}(1-\theta) E_{2}\left(T_{i}\right) \\
c_{F_{1}, Z_{1}} & =\operatorname{cov}_{1}\left(F_{i}, \tilde{b}_{1} T_{i}\right) \\
s_{Z_{1}}^{2} & =\left(\tilde{b}_{1}\right)^{2} \operatorname{var}_{1}\left(T_{i}\right)+\operatorname{var}(\varepsilon)
\end{aligned}
$$

These moment conditions are identical to the ones in the model without non-classical measurement error, except that we replaced $b_{0}$ and $b_{1}$ with $\tilde{b}_{0}$ and $\tilde{b}_{1}$. It follows from the proof for Proposition 2 that the parameters $\tilde{b}_{0}, \tilde{b}_{1}, \theta$ and moments $E\left(T_{i}\right), \operatorname{var}\left(T_{i}\right)$ and $\operatorname{var}(\varepsilon)$ are functions of moments that we observe in the data $\left(m_{Z_{1}}, m_{Z_{2}}, m_{F_{1}}, m_{F_{2}}, c_{F_{1}, Z_{1}}\right.$ and $\left.s_{Z_{1}}^{2}\right)$. The two-period model with $\sigma_{\tau}=0$ and non-classical measurement error of the form $\eta=c_{0}+c_{1} T_{i}$ is thus identified.

\section{E.3.2 Identification of $\sigma_{\tau}$}

Our conjecture is that in a two-period version of the statistical model with measurement error, $\varepsilon$, that is independent of $T_{i, d}$, with transitory shocks to job finding, $\tau_{i, d}$, that are independent of $T_{i}$, and with $G\left(T_{i}\right)$ following a two-parameter distribution, the parameters $b_{0}, b_{1}, \theta$, and $\sigma_{\tau}$ as well as the mean and the variance of the persistent component of job finding rates, $E\left(T_{i}\right)$ and $\operatorname{var}\left(T_{i}\right)$, and the variance of the elicitation error, $\operatorname{var}(\varepsilon)$, are identified by the moment conditions for: (1) the means of the elicitations in period 1 and $2, m_{Z_{1}}$ and $m_{Z_{2}}$, (2) the means of the job finding rates in period 1 and $2, m_{F_{1}}$ and $m_{F_{2}}$, 
(3) the covariance of job finding and elicitations in period $1, c_{F_{1}, Z_{1}},(4)$ the covariance of job finding in period 2 and elicitations in period $1, c_{F_{2}, Z_{1}}$, and (5) the variance of elicitations in period $1, s_{Z_{1}}^{2}$.

We again consider a model with only two periods, period 1 and 2 . In this case, we can write down the moment conditions for the moments mentioned in the proposition above as:

$$
\begin{aligned}
m_{Z_{1}} & =b_{0}+b_{1} E_{1}\left(T_{i}+\tau_{i, 1}\right) \\
m_{Z_{2}} & =b_{0}+b_{1}(1-\theta) E_{2}\left(T_{i}+\tau_{i, 2}\right) \\
m_{F_{1}} & =E_{1}\left(T_{i}+\tau_{i, 1}\right) \\
m_{F_{2}} & =(1-\theta) E_{2}\left(T_{i}+\tau_{i, 2}\right) \\
c_{F_{1}, Z_{1}} & =\operatorname{cov}_{1}\left(F_{i}, b_{1}\left(T_{i}+\tau_{i, 1}\right)\right) \\
c_{F_{2}, Z_{1}} & =\operatorname{cov}_{2}\left(F_{i}, b_{1}\left(T_{i}+\tau_{i, 1}\right)\right) \\
s_{Z_{1}}^{2} & =b_{1}^{2} \operatorname{var}_{1}\left(T_{i}+\tau_{i, 1}\right)+\operatorname{var}(\varepsilon)
\end{aligned}
$$

The first two moments again directly pin down $b_{0}$ and $b_{1}$ :

$$
\begin{aligned}
b_{1} & =\frac{m_{Z_{2}}-m_{Z_{1}}}{m_{F_{2}}-m_{F_{1}}} \\
b_{0} & =m_{Z_{1}}-\frac{m_{Z_{2}}-m_{Z_{1}}}{m_{F_{2}}-m_{F_{1}}} m_{F_{1}}
\end{aligned}
$$

We can again re-write the expectation conditional on survival to period 2 , now of $T_{i}+\tau_{i, 1}$, as:

$$
\begin{aligned}
E_{2}\left(T_{i}+\tau_{i, 1}\right) & =\frac{E_{1}\left[\left(T_{i}+\tau_{i, 1}\right)\left(1-T_{i}-\tau_{i, 1}\right)\right]}{1-E_{1}\left(T_{i}+\tau_{i, 1}\right)} \\
& =\frac{E_{1}\left(T_{i}\right)-E_{1}\left(T_{i}^{2}\right)-E_{1}\left(\tau_{i, 1}^{2}\right)}{1-E_{1}\left(T_{i}\right)} \\
& =\frac{E_{1}\left(T_{i}\right)\left(1-E_{1}\left(T_{i}\right)\right)-\operatorname{var}_{1}\left(T_{i}\right)-\operatorname{var}_{1}\left(\tau_{i, 1}\right)}{1-E_{1}\left(T_{i}\right)}
\end{aligned}
$$

because $E_{1}\left(\tau_{i, 1}\right)=E_{1}\left(T_{i} \tau_{i, 1}\right)=0$. Similarly, we obtain

$$
E_{2}\left(T_{i}+\tau_{i, 2}\right)=\frac{E_{1}\left(T_{i}\right)\left(1-E_{1}\left(T_{i}\right)\right)-\operatorname{var}_{1}\left(T_{i}\right)}{1-E_{1}\left(T_{i}\right)}
$$


because $E_{1}\left(\tau_{i, 1}\right)=E_{1}\left(T_{i} \tau_{i, 2}\right)=E_{1}\left(T_{i} \tau_{i, 1}\right)=E_{1}\left(\tau_{i, 1} \tau_{i, 2}\right)=0$. Hence, we can re-write:

$$
\begin{aligned}
c_{F_{1}, Z_{1}} & =\operatorname{cov}_{1}\left(F_{i, 1}, b_{1}\left(T_{i}+\tau_{i, 1}\right)\right) \\
& =b_{1}\left[E_{1}\left(F_{i, 1}\left(T_{i}+\tau_{i, 1}\right)\right)-E_{1}\left(F_{i}\right) E_{1}\left(T_{i}+\tau_{i, 1}\right)\right] \\
& =b_{1}\left[E_{1}\left(E_{1}\left(F_{i, 1}\left(T_{i}+\tau_{i, 1}\right) \mid T_{i}, \tau_{i, 1}\right)\right)-E_{1}\left(T_{i}+\tau_{i, 1}\right) E_{1}\left(T_{i}+\tau_{i, 1}\right)\right] \\
& =b_{1}\left[E_{1}\left(E_{1}\left(\left(T_{i}+\tau_{i, 1}\right)\left(T_{i}+\tau_{i, 1}\right) \mid T_{i}, \tau_{i, 1}\right)\right)-E_{1}\left(T_{i}+\tau_{i, 1}\right) E_{1}\left(T_{i}+\tau_{i, 1}\right)\right] \\
& =b_{1}\left[E_{1}\left(\left(T_{i}+\tau_{i, 1}\right)^{2}\right)-E_{1}\left(T_{i}+\tau_{i, 1}\right) E_{1}\left(T_{i}+\tau_{i, 1}\right)\right] \\
& =b_{1}\left[E_{1}\left(\left(T_{i}^{2}+2 T_{i} \tau_{i, 1}+\tau_{i, 1}^{2}\right)-E_{1}\left(T_{i}\right) E_{1}\left(T_{i}\right)\right]\right. \\
& =b_{1}\left[E_{1}\left(\left(T_{i}^{2}\right)+E_{1}\left(\tau_{i, 1}^{2}\right)-E_{1}\left(T_{i}\right) E_{1}\left(T_{i}\right)\right]\right. \\
& =b_{1}\left[\operatorname{var}_{1}\left(T_{i}\right)+\operatorname{var}_{1}\left(\tau_{i, 1}\right)\right]
\end{aligned}
$$

because $E_{1}\left(T_{i} \tau_{i, 1}\right)=0$. Similarly, we obtain:

$$
\begin{aligned}
c_{F_{2}, Z_{1}} & =\operatorname{cov}_{2}\left(F_{i, 2}, b_{1}\left(T_{i}+\tau_{i, 1}\right)\right) \\
& =b_{1}\left[E_{2}\left(F_{i, 2}\left(T_{i}+\tau_{i, 1}\right)\right)-E_{2}\left(F_{i, 2}\right) E_{2}\left(T_{i}+\tau_{i, 1}\right)\right] \\
& =b_{1}\left[E_{2}\left(E_{2}\left(F_{i, 2}\left(T_{i}+\tau_{i, 1}\right) \mid T_{i}, \tau_{i, 1}\right)\right)-(1-\theta) E_{2}\left(T_{i}+\tau_{i, 2}\right) E_{2}\left(T_{i}+\tau_{i, 1}\right)\right] \\
& =b_{1}\left[E_{2}\left((1-\theta)\left(T_{i}+\tau_{i, 2}\right)\left(T_{i}+\tau_{i, 1}\right)\right)-(1-\theta) E_{2}\left(T_{i}+\tau_{i, 2}\right) E_{2}\left(T_{i}+\tau_{i, 1}\right)\right] \\
& =b_{1}(1-\theta)\left[E_{2}\left(\left(T_{i}+\tau_{i, 2}\right)\left(T_{i}+\tau_{i, 1}\right)\right)-E_{2}\left(T_{i}+\tau_{i, 2}\right) E_{2}\left(T_{i}+\tau_{i, 1}\right)\right] \\
& =b_{1}(1-\theta)\left[\frac{E_{1}\left(T_{i}^{2}\right)-E_{1}\left(T_{i}^{3}\right)-E_{1}\left(T_{i} \tau_{i, 1}^{2}\right)}{1-E_{1}\left(T_{i}\right)}-\left(E_{1}\left(T_{i}\right)-\frac{\operatorname{var}_{1}\left(T_{i}\right)}{1-E_{1}\left(T_{i}\right)}\right)\left(E_{1}\left(T_{i}\right)-\frac{\operatorname{var}_{1}\left(\tau_{i, 1}\right)}{1-E_{1}\left(T_{i}\right)}\right)\right]
\end{aligned}
$$

where the last equality uses the same steps as before to re-write the conditional expectation. Rearranging terms and using $m_{F_{1}}=E_{1}\left(T_{i}\right), m_{F_{2}}=(1-\theta)\left[m_{F_{1}}-\frac{v a r_{1}\left(T_{i}\right)}{1-m_{F_{1}}}\right]$ and $b_{1}=\frac{m_{Z_{2}}-m_{Z_{1}}}{m_{F_{2}}-m_{F_{1}}}$, we get:

$$
\begin{aligned}
c_{F_{2}, Z_{1}}= & b_{1}(1-\theta)\left[\frac{\operatorname{var}_{1}\left(T_{i}\right)+m_{F_{1}}^{2}-E_{1}\left(T_{i}^{3}\right)-E_{1}\left(T_{i} \tau_{i, 1}^{2}\right)}{1-m_{F_{1}}}\right]-b_{1} m_{F_{2}}\left(m_{F_{1}}-\frac{1}{b_{1}} \frac{c_{F_{1}, Z_{1}}}{1-m_{F_{1}}}\right) \\
= & \frac{m_{Z_{2}}-m_{Z_{1}}}{m_{F_{2}}-m_{F_{1}}} \frac{m_{F_{2}}\left(1-m_{F_{1}}\right)}{m_{F_{1}}\left(1-m_{F_{1}}\right)-\operatorname{var}\left(T_{i}\right)}\left[\frac{\operatorname{var}_{1}\left(T_{i}\right)+m_{F_{1}}^{2}-E_{1}\left(T_{i}^{3}\right)-E_{1}\left(T_{i} \tau_{i, 1}^{2}\right)}{1-m_{F_{1}}}\right] \\
& -\frac{m_{Z_{2}}-m_{Z_{1}}}{m_{F_{2}}-m_{F_{1}}} m_{F_{2}} m_{F_{1}}+m_{F_{2}} \frac{c_{F_{1}, Z_{1}}}{1-m_{F_{1}}} \\
= & \frac{m_{Z_{2}}-m_{Z_{1}}}{m_{F_{2}}-m_{F_{1}}} \frac{m_{F_{2}}\left(1-m_{F_{1}}\right)}{m_{F_{1}}\left(1-m_{F_{1}}\right)-\operatorname{var}\left(T_{i}\right)}\left[\frac{\operatorname{var}_{1}\left(T_{i}\right)+m_{F_{1}}^{2}-E_{1}\left(T_{i}^{3}\right)}{1-m_{F_{1}}}\right] \\
& -\frac{m_{Z_{2}}-m_{Z_{1}}}{m_{F_{2}}-m_{F_{1}}} m_{F_{2}} m_{F_{1}}+m_{F_{2}} \frac{c_{F_{1}, Z_{1}}}{1-m_{F_{1}}}
\end{aligned}
$$


Using equation (55) to get $\operatorname{var}_{1}\left(T_{i}\right)=\frac{c_{F_{1}, Z_{1}}}{b_{1}}-\operatorname{var}_{1}\left(\tau_{i, 1}\right)$, we can rearrange the equation above, to get:

$$
\begin{aligned}
c_{F_{2}, Z_{1}}= & \frac{m_{Z_{2}}-m_{Z_{1}}}{m_{F_{2}}-m_{F_{1}}} \frac{m_{F_{2}}\left(1-m_{F_{1}}\right)}{m_{F_{1}}\left(1-m_{F_{1}}\right)-\frac{m_{F_{2}}-m_{F_{1}}}{m_{Z_{2}}-m_{Z_{1}}} c_{F_{1}, Z_{1}}+\operatorname{var}_{1}\left(\tau_{i, 1}\right)} \\
& {\left[\frac{\frac{m_{F_{2}}-m_{F_{1}}}{m_{Z_{2}}-m_{Z_{1}}} c_{F_{1}, Z_{1}}-\operatorname{var}_{1}\left(\tau_{i, 1}\right)+m_{F_{1}}^{2}-E_{1}\left(T_{i}^{3}\right)}{1-m_{F_{1}}}\right] } \\
& -\frac{m_{Z_{2}}-m_{Z_{1}}}{m_{F_{2}}-m_{F_{1}}} m_{F_{2}} m_{F_{1}}+m_{F_{2}} \frac{c_{F_{1}, Z_{1}}}{1-m_{F_{1}}}
\end{aligned}
$$

For two-parameter distributions of $T_{i}$ where $E_{1}\left(T_{i}^{3}\right)$ is either implicitly or explicitly defined by the first two moments of the distribution, we can define a function $h(.,$.$) , such that E_{1}\left(T_{i}^{3}\right)=h\left(E_{1}\left(T_{i}\right), \operatorname{var}_{1}\left(T_{i}\right)\right)$, and thus:

$$
\begin{aligned}
c_{F_{2}, Z_{1}}= & \left.\frac{m_{Z_{2}}-m_{Z_{1}}}{m_{F_{2}}-m_{F_{1}}} \frac{m_{F_{2}}\left(1-m_{F_{1}}\right)}{m_{F_{1}}\left(1-m_{F_{1}}\right)-\frac{m_{F_{2}}-m_{F_{1}}}{m_{Z_{2}}-m_{Z_{1}}} c_{F_{1}, Z_{1}}+\operatorname{var}_{1}\left(\tau_{i, 1}\right)}\right] \\
& {\left[\frac{\frac{m_{F_{2}}-m_{F_{1}}}{m_{Z_{2}}-m_{Z_{1}}} c_{F_{1}, Z_{1}}-\operatorname{var}_{1}\left(\tau_{i, 1}\right)+m_{F_{1}}^{2}-h\left(m_{F_{1}}, \frac{m_{F_{2}}-m_{F_{1}}}{m_{Z_{2}}-m_{Z_{1}}} c_{F_{1}, Z_{1}}-\operatorname{var}_{1}\left(\tau_{i, 1}\right)\right)}{1-m_{F_{1}}}\right] } \\
& -\frac{m_{Z_{2}}-m_{Z_{1}}}{m_{F_{2}}-m_{F_{1}}} m_{F_{2}} m_{F_{1}}+m_{F_{2}} \frac{c_{F_{1}, Z_{1}}}{1-m_{F_{1}}}
\end{aligned}
$$

While it is not possible to solve explicitly for $\sigma_{\tau}$, we note that for $h_{2} \leq 0$, the right-hand side of the equation (56) above depends negatively on $\sigma_{\tau}$, and thus a solution for $\sigma_{\tau}$ exists. ${ }^{60}$ A solution also exists for $h_{2} \leq \tilde{h}$, where $\tilde{h}$ is some positive number, as long as $\tilde{h}$ is smaller than some upper bound $\bar{h}$.

Having solved for $\operatorname{var}_{1}\left(\tau_{i, 1}\right)$, when a solution to equation (56) exists, we can then find a solution for the mean and variance of $T_{i}$ :

$$
\begin{aligned}
E_{1}\left(T_{i}\right) & =m_{F_{1}} \\
\operatorname{var}_{1}\left(T_{i}\right) & =\frac{m_{F_{2}}-m_{F_{1}}}{m_{Z_{2}}-m_{Z_{1}}} c_{F_{1}, Z_{1}}-\operatorname{var}_{1}\left(\tau_{i, 1}\right)
\end{aligned}
$$

Rearranging and using equation (47), we also get:

$$
\theta=1-\frac{m_{F_{2}}\left(1-m_{F_{1}}\right)}{m_{F_{1}}\left(1-m_{F_{1}}\right)-\frac{m_{F_{2}}-m_{F_{1}}}{m_{Z_{2}}-m_{Z_{1}}} c_{F_{1}, Z_{1}}+\operatorname{var}_{1}\left(\tau_{i, 1}\right)}
$$

As before, given $b_{1}$, we can also solve for $\operatorname{var}(\varepsilon)$ by using the moment condition for $s_{Z_{1}}^{2}$ :

$$
\operatorname{var}(\varepsilon)=s_{Z_{1}}^{2}-\frac{m_{Z_{2}}-m_{Z_{1}}}{m_{F_{2}}-m_{F_{1}}} c_{F_{1}, Z_{1}}
$$

In conclusion, if a solution exists to equation (56), implicitly defining $\sigma_{\tau}$, we can solve for parameters $b_{0}, b_{1}, \sigma_{\varepsilon}$, and $\theta$ as well as the mean and variance of the persistent component of job finding rates, $E\left(T_{i}\right)=E_{1}\left(T_{i}\right)$ and $\operatorname{var}\left(T_{i}\right)=\operatorname{var}_{1}\left(T_{i}\right)$, as a function of the moments $m_{Z_{1}}, m_{Z_{2}}, m_{F_{1}}, m_{F_{2}}, c_{F_{1}, Z_{1}}$,

\footnotetext{
${ }^{60}$ Note $\sigma_{\tau}$ is monotonically increasing in but not equal to $\operatorname{var}_{1}\left(\tau_{i, 1}\right)$, because of the boundary conditions.
} 
Figure E3: The relationship between $\sigma_{\tau}$ and the moment $c_{Z_{d}, F_{d+3}}$ in the estimated sub-model

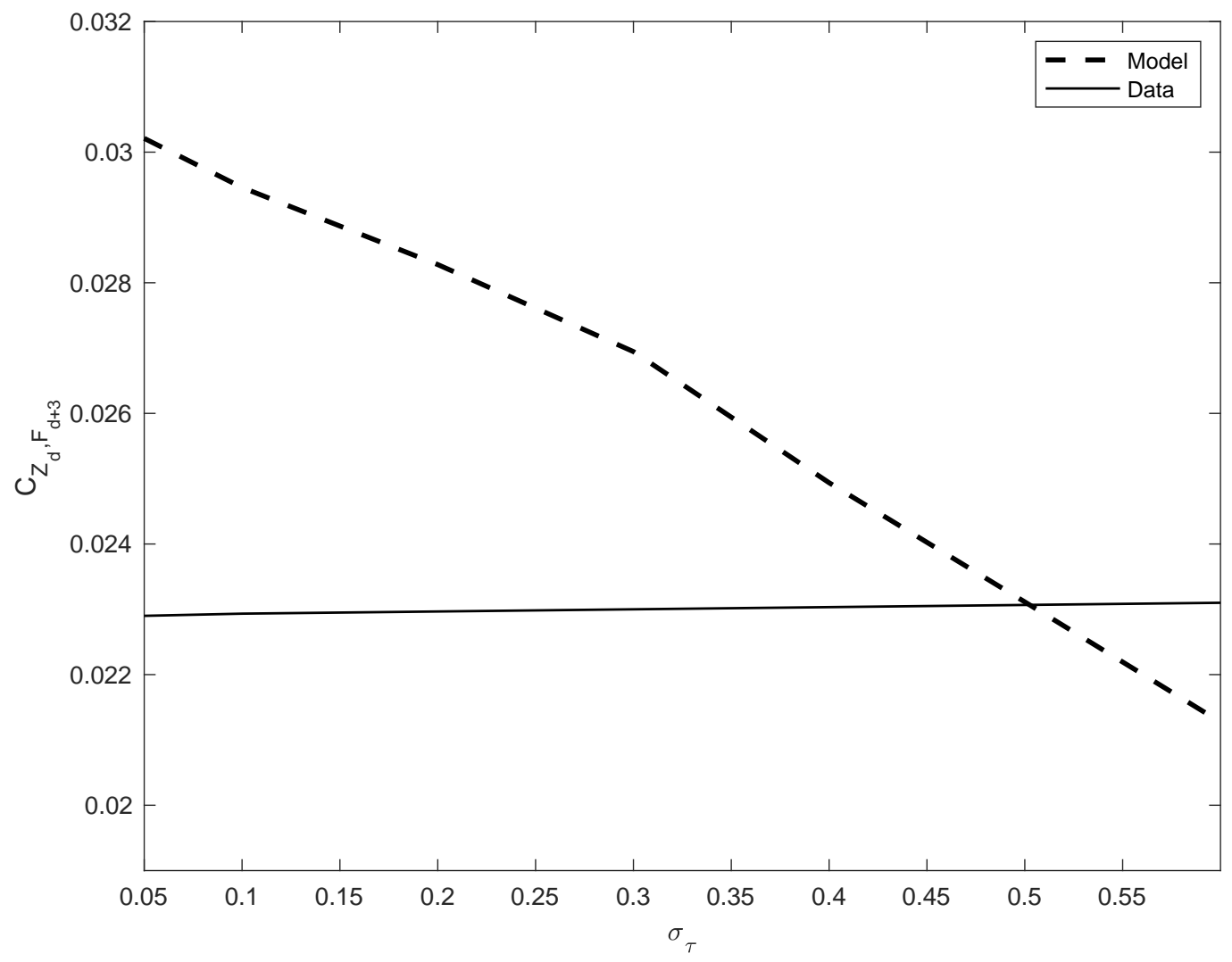

$c_{F_{2}, Z_{1}}, s_{Z_{1}}^{2}$, as shown in equations $51,52,57,58,59$ and 60 .

To provide further evidence on identification of the parameter $\sigma_{\tau}$, we now proceed by showing that in the context of our estimated model (i.e., with more than two periods), there is a monotone mapping between the parameter $\sigma_{\tau}$ and the moment $C_{Z_{d}, F_{d+3}}$. More precisely, we estimate a sub-model of the baseline version of our statistical model for different levels of $\sigma_{\tau}$, by targeting all of the same moments except $C_{Z_{d}, F_{d+3}}$. Figure E3 shows that there is a monotone relationship between the level of $\sigma_{\tau}$ and the covariance of elicitations and the 3 -month forward job finding rates in this estimated sub-model, which shows that our parameter $\sigma_{\tau}$ is identified by the moment $C_{Z_{d}, F_{d+3}}$ in the full (baseline) model.

\section{E.3.3 Identification in extended model with $\hat{\theta} \neq \theta$}

Proposition 4. In a two-period version of the extended version of the statistical model with $\hat{\theta} \neq \theta$ and with measurement error, $\varepsilon$, that is independent of $T_{i, d}$, but with $\sigma_{\tau}=0$, the parameters $b_{0}, b_{1}, \theta, \hat{\theta}$ as well as the mean and the variance of the persistent component of job finding rates, $E\left(T_{i}\right)$ and $\operatorname{var}\left(T_{i}\right)$, and the variance of the elicitation error, $\operatorname{var}(\varepsilon)$, are identified by the moment conditions for: (1) the means of the elicitations in period 1 and $2, m_{Z_{1}}$ and $m_{Z_{2}}$, (2) the means of the job finding rates in period 1 and 2, $m_{F_{1}}$ and $m_{F_{2}}$, (3) the covariance of job finding and elicitations in period 1, $c_{F_{1}, Z_{1}}$, (4) the variance of elicitations in period $1, s_{Z_{1}}^{2}$, and (5) a statistic that depends on all these moments as well as the variance of eliciations in period $2, s_{Z_{2}}^{2}$, and the covariance with job finding in period 2 , 
$c_{F_{2}, Z_{2}}$.

Proof. We assume that there are only two periods, and that $\sigma_{\tau}=0$. In this case, we can write down the moment conditions for the moments mentioned in the proposition above as:

$$
\begin{aligned}
m_{Z_{1}} & =b_{0}+b_{1} E_{1}\left(T_{i}\right) \\
m_{Z_{2}} & =b_{0}+b_{1}(1-\hat{\theta}) E_{2}\left(T_{i}\right) \\
m_{F_{1}} & =E_{1}\left(T_{i}\right) \\
m_{F_{2}} & =(1-\theta) E_{2}\left(T_{i}\right) \\
c_{F_{1}, Z_{1}} & =\operatorname{cov}_{1}\left(F_{i, 1}, b_{1} T_{i}\right) \\
c_{F_{2}, Z_{2}} & =\operatorname{cov}_{2}\left(F_{i, 2}, b_{1} T_{i}\right) \\
s_{Z_{1}}^{2} & =b_{1}^{2} \operatorname{var}_{1}\left(T_{i}\right)+\operatorname{var}(\varepsilon) \\
s_{Z_{2}}^{2} & =b_{1}^{2}(1-\hat{\theta})^{2} \operatorname{var}_{2}\left(T_{i}\right)+\operatorname{var}(\varepsilon)
\end{aligned}
$$

where sub-indices 1 and 2 on the moments stands for the sample of survivors. Note that $E_{1}\left(T_{i}\right)=E\left(T_{i}\right)$ and $\operatorname{var}_{1}\left(T_{i}\right)=\operatorname{var}\left(T_{i}\right)$, i.e. the moments for the sample of survivors in period 1 correspond to the population moments. One can express the additional moment condition (66) as follows:

$$
\begin{aligned}
c_{F_{2}, Z_{2}} & =\operatorname{cov}_{2}\left(F_{i, 2}, b_{1}(1-\hat{\theta}) T_{i}\right) \\
& =b_{1}(1-\hat{\theta})\left[E_{2}\left(F_{i, 2} T_{i}\right)-E_{2}\left(F_{i, 2}\right) E\left(T_{i}\right)\right] \\
& =b_{1}(1-\hat{\theta})\left[E_{2}\left(E_{2}\left(F_{i, 2} T_{i} \mid T_{i}\right)\right)-(1-\theta) E_{2}\left(T_{i}\right)^{2}\right] \\
& =b_{1}(1-\hat{\theta})(1-\theta)\left[E_{2}\left(T_{i}^{2}\right)-E_{2}\left(T_{i}\right)^{2}\right] \\
& =b_{1}(1-\hat{\theta})(1-\theta) \operatorname{var}_{2}\left(T_{i}\right)
\end{aligned}
$$

Re-arranging the moment conditions 61-67 and using equations (29) and (32), we thus get:

$$
\begin{aligned}
m_{Z_{1}} & =b_{0}+b_{1} m_{F_{1}} \\
m_{Z_{2}} & =b_{0}+b_{1} \frac{1-\hat{\theta}}{1-\theta} m_{F_{2}} \\
m_{F_{1}} & =E_{1}\left(T_{i}\right) \\
m_{F_{2}} & =(1-\theta)\left[m_{F_{1}}-\frac{\operatorname{var}_{1}\left(T_{i}\right)}{1-m_{F_{1}}}\right] \\
c_{F_{1}, Z_{1}} & =b_{1} \operatorname{var}_{1}\left(T_{i}\right) \\
c_{F_{2}, Z_{2}} & =b_{1}(1-\hat{\theta})(1-\theta) \operatorname{var}_{2}\left(T_{i}\right) \\
s_{Z_{1}}^{2} & =b_{1}^{2} \operatorname{var}_{1}\left(T_{i}\right)+\operatorname{var}_{(\varepsilon)} \\
s_{Z_{2}}^{2} & =b_{1}^{2}(1-\hat{\theta})^{2} \operatorname{var}_{2}\left(T_{i}\right)+\operatorname{var}(\varepsilon)
\end{aligned}
$$

The mean of the job finding rate, $E\left(T_{i}\right)=E_{1}\left(T_{i}\right)$, is directly identified by moment condition in equation 
(71).We then take the difference of the first two moment conditions:

$$
m_{Z_{1}}-m_{Z_{2}}=b_{1}\left(m_{F_{1}}-\frac{1-\hat{\theta}}{1-\theta} m_{F_{2}}\right)
$$

which gives $b_{1}$ as a function of moments, $\theta$ and $\hat{\theta}$. Next combine equations 73 and 75 and equations 74 and 76 , to get:

$$
\begin{aligned}
& s_{Z_{1}}^{2}=b_{1} c_{F_{1}, Z_{1}}+\operatorname{var}(\varepsilon) \\
& s_{Z_{2}}^{2}=b_{1} \frac{1-\hat{\theta}}{1-\theta} c_{F_{2}, Z_{2}}+\operatorname{var}(\varepsilon)
\end{aligned}
$$

and taking the difference, we get:

$$
s_{Z_{1}}^{2}-s_{Z_{2}}^{2}=b_{1}\left(c_{F_{1}, Z_{1}}-\frac{1-\hat{\theta}}{1-\theta} c_{F_{2}, Z_{2}}\right)
$$

Taking the ratio of equation 77 and 80 , we get:

$$
\frac{m_{Z_{1}}-m_{Z_{2}}}{s_{Z_{1}}^{2}-s_{Z_{2}}^{2}}=\frac{m_{F_{1}}-\frac{1-\hat{\theta}}{1-\theta} m_{F_{2}}}{c_{F_{1}, Z_{1}}-\frac{1-\hat{\theta}}{1-\theta} c_{F_{2}, Z_{2}}}
$$

Rearranging:

$$
\frac{m_{Z_{1}}-m_{Z_{2}}}{s_{Z_{1}}^{2}-s_{Z_{2}}^{2}}\left(c_{F_{1}, Z_{1}}-\frac{1-\hat{\theta}}{1-\theta} c_{F_{2}, Z_{2}}\right)=m_{F_{1}}-\frac{1-\hat{\theta}}{1-\theta} m_{F_{2}}
$$

Rearranging further:

$$
\frac{m_{Z_{1}}-m_{Z_{2}}}{s_{Z_{1}}^{2}-s_{Z_{2}}^{2}} c_{F_{1}, Z_{1}}-m_{F_{1}}=-\frac{1-\hat{\theta}}{1-\theta} m_{F_{2}}+\frac{m_{Z_{1}}-m_{Z_{2}}}{s_{Z_{1}}^{2}-s_{Z_{2}}^{2}} \frac{1-\hat{\theta}}{1-\theta} c_{F_{2}, Z_{2}}
$$

Rearranging further:

$$
\frac{1-\hat{\theta}}{1-\theta}=\frac{\frac{m_{Z_{1}}-m_{Z_{2}}}{s_{Z_{1}}^{2}-s_{Z_{2}}^{2}} c_{F_{1}, Z_{1}}-m_{F_{1}}}{\frac{m_{Z_{1}}-m_{Z_{2}}}{s_{Z_{1}}^{2}-s_{Z_{2}}^{2}} c_{F_{2}, Z_{2}}-m_{F_{2}}}
$$

Equation 84 defines the ratio of $\frac{1-\hat{\theta}}{1-\theta}$ as a function of moments only. Using the ratio, one can rearrange equation 77 to get $b_{1}$ as a function of moments only:

$$
b_{1}=\frac{m_{Z_{1}}-m_{Z_{2}}}{m_{F_{1}}-\frac{1-\hat{\theta}}{1-\theta} m_{F_{2}}}
$$


Using $b_{1}$, one can use equation 61 to get $b_{0}$ as a function of moments only:

$$
b_{0}=m_{Z_{1}}-b_{1} m_{F_{2}}
$$

Using $b_{1}$, one can use equation 73 to get $\operatorname{var}\left(T_{i}\right)=\operatorname{var}_{1}\left(T_{i}\right)$ as a function of moments only:

$$
\operatorname{var}\left(T_{i}\right)=\frac{c_{F_{1}, Z_{1}}}{b_{1}}
$$

Using $b_{1}$ and $\operatorname{var}\left(T_{i}\right)$, one can use equation 75 to get $\operatorname{var}(\varepsilon)$ as a function of moments only:

$$
\operatorname{var}(\varepsilon)=s_{Z_{1}}^{2}-b_{1}^{2} \operatorname{var}\left(T_{i}\right)
$$

Using $\operatorname{var}\left(T_{i}\right)$, one can use equation 64 to get $\theta$ as a function of moments only:

$$
\theta=\frac{\left(m_{F_{1}}-m_{F_{2}}\right)\left(1-m_{F_{1}}\right)-\operatorname{var}\left(T_{i}\right)}{m_{F_{1}}\left(1-m_{F_{1}}\right)-\operatorname{var}\left(T_{i}\right)}
$$

Using $\theta$ and equation 84 , we get $\hat{\theta}$ as a function of moments only:

$$
\hat{\theta}=1-(1-\theta) \frac{\frac{m_{Z_{1}}-m_{Z_{2}}}{s_{Z_{1}}^{2}-s_{Z_{2}}^{2}} c_{F_{1}, Z_{1}}-m_{F_{1}}}{\frac{m_{Z_{1}}-m_{Z_{2}}}{s_{Z_{1}}^{2}-s_{Z_{2}}^{2}} c_{F_{2}, Z_{2}}-m_{F_{2}}}
$$

In conclusion, equations 85 (together with equation 84), 86, 63, 87, 88, 89 and 90 solve parameters $b_{0}, b_{1}, \theta, \hat{\theta}$ and population moments $E\left(T_{i}\right), \operatorname{var}\left(T_{i}\right)$ and $\operatorname{var}(\varepsilon)$ for any distribution of these variables as function of moments that we observe in the data $\left(m_{Z_{1}}, m_{Z_{2}}, m_{F_{1}}, m_{F_{2}}, c_{F_{1}, Z_{1}}, s_{Z_{1}}^{2}\right.$ and the ratio in equation 84). The two-period model with $\sigma_{\tau}=0$ and $\hat{\theta} \neq \theta$ is thus identified.

To provide evidence on the identification of the parameter $\hat{\theta}$ in the full version of the model that we estimate with the data, we proceed by showing that in the context of our estimated model (i.e., with more than two periods and $\sigma_{\tau}>0$ ), there is a monotone mapping between $\hat{\theta}$ and the covariance in duration interval $7+, c_{F_{7+}, Z_{7+}}$ as well as a monotone mapping between $\hat{\theta}$ and the variance of elicitations in duration interval $7+, s_{Z_{7+}}^{2}$. More precisely, we estimate a sub-model of the extended version of our statistical model, where $\hat{\theta} \neq \theta$, for different levels of $\hat{\theta}$, targeting all the same moments except $c_{F_{7+}, Z_{7+}}$ and $s_{Z_{7+}}^{2}$. Figure E4 shows that there is a monotone relationship between the level of $\hat{\theta}$ and the covariance of elicitations and job finding rates in duration interval $7+$ as well as a monotone relationship between level of $\hat{\theta}$ and the variance of elicitations in duration interval $7+$. This shows that both of these moments provide variation that identifies the parameter $\hat{\theta}$ in the full (extended) model. 
Figure E4: The relationship between $\hat{\theta}$ and moments $c_{F_{7+}, Z_{7+}}$ and $s_{Z_{7+}}^{2}$ in the estimated sub-model
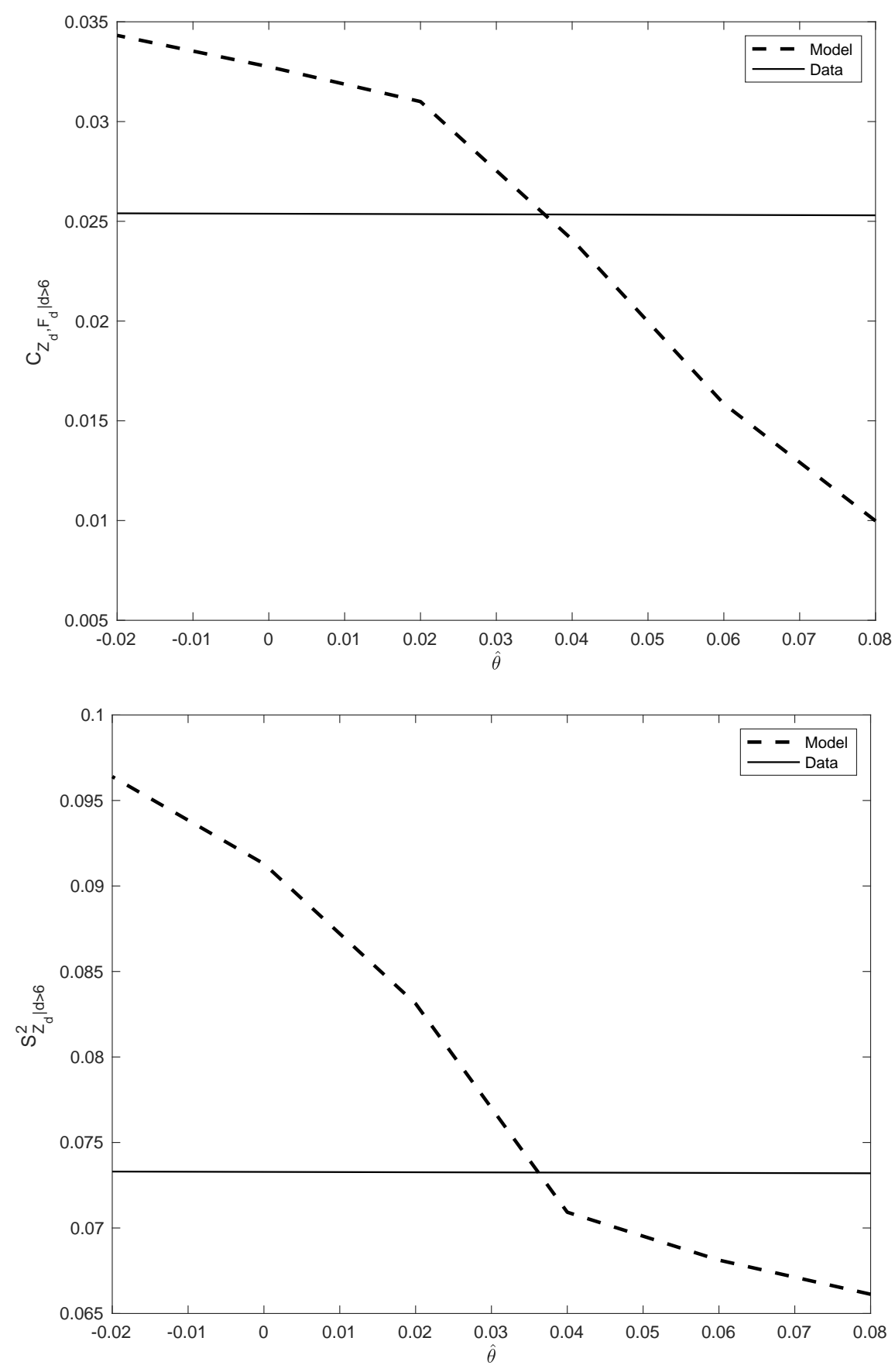


\section{F Structural Model}

This section provides further details on the derivations and Proposition in the theoretical analysis and the calibration and counterfactual analysis in the numerical analysis in Section 5.

\section{F.1 Theoretical Analysis}

In a stationary setting (with $\theta=0$ ), we have for any individual

$$
T_{i, d}=\lambda_{i}\left[1-F\left(R_{i}\right)\right]
$$

Now dropping subindices, we can consider the impact on the job finding rate $T$ of infinitesimal changes in $\lambda$ and $\hat{\lambda}$,

$$
d T=[1-F(R)] d \lambda-\lambda f(R) \frac{d R}{d \hat{\lambda}} d \hat{\lambda},
$$

A change in $\lambda$ does not trigger a change in the reservation wage $R$ since it is only the perceived arrival rate that informs the agent's reservation wage. Rearranging this equation we get,

$$
\frac{d T}{d \lambda} \frac{\lambda}{T}=1-\lambda \frac{f(R)}{1-F(R)} \frac{d R}{d \hat{\lambda}} \frac{d \hat{\lambda}}{d \lambda} .
$$

To unpack the $\frac{d R}{d \hat{\lambda}}$ term we consider the determination of the reservation wage. The reservation wage is defined by $U=V(R)$, where

$$
\begin{aligned}
U & \left.=u\left(b_{u}\right)+\frac{1}{1+\delta} \max _{R}\left\{U+\hat{\lambda} \int_{R}[V(w)-U] d F(w)\right]\right\} \\
V(w) & =u(w)+\frac{1}{1+\delta}\left\{(1-\sigma)\left(V(w)+\lambda^{e} \int_{w}(V(x)-V(w)) d F(w)\right)+\sigma U\right\} .
\end{aligned}
$$

Assuming $\sigma=\lambda^{e}=0$, we can write,

$$
V(R)=\frac{1+\delta}{\delta} u(R)
$$

and thus

$$
\frac{1+\delta}{\delta} u(R)=u+\frac{1}{1+\delta} \max _{R}\left\{\frac{1+\delta}{\delta} u(R)+\hat{\lambda} \int_{R}\left[V(w)-\frac{1+\delta}{\delta} u(R)\right] d F(w)\right\}
$$

We can totally differentiate this condition with respect to $R$ and $\hat{\lambda}$, applying the envelope theorem to the right hand side (i.e., $d U / d R=0$ ) and assuming no job separation risk and no on-the-job search such that $V(w)=(1+\delta) u(w) / \delta$,

$$
\frac{u^{\prime}(R)}{1-\frac{1}{1+\delta}} d R=\frac{1}{1+\delta}\left\{\int_{R}\left[\frac{u(w)}{1-\frac{1}{1+\delta}}-\frac{u(R)}{1-\frac{1}{1+\delta}}\right] d F(w)\right\} d \hat{\lambda}
$$

So, we can conclude

$$
\frac{d R}{d \hat{\lambda}}=\frac{1}{1+\delta}\left\{\int_{R}\left[\frac{u(w)-u(R)}{u^{\prime}(R)}\right] d F(w)\right\}
$$


Combining this with our earlier result, we find

$$
\begin{aligned}
\frac{d T}{d \lambda} \frac{\lambda}{T} & =1-\frac{1}{1+\delta} \lambda f(R) \frac{\int_{R}\left[\frac{u(w)-u(R)}{u^{\prime}(R)}\right] d F(w)}{1-F(R)} \frac{d \hat{\lambda}}{d \lambda} \\
& =1-\frac{1}{1+\delta} T \frac{f(R)}{1-F(R)} E\left[\frac{u(w)-u(R)}{u^{\prime}(R)} \mid w \geq R\right] \frac{d \hat{\lambda}}{d \lambda} \\
& \equiv 1-\kappa \frac{d \hat{\lambda}}{d \lambda}
\end{aligned}
$$

This corresponds to equation (17) in the main text.

\section{F.1.1 Proof of Proposition 1}

First, we consider the introduction of heterogeneity. That is, we assume $\lambda^{j}=\bar{\lambda}+d \lambda^{j}$ for $j=h, l$ with $d \lambda^{h}=-d \lambda^{l} \approx 0$, but we keep $\theta=0$. We also assume an equal share of high and low types, $\phi=1 / 2$. Now for small differences in actual and perceived arrival rates, we can approximate

$$
\begin{aligned}
T_{i} & \approx T+\frac{d T}{d \lambda_{i}} d \lambda_{i}+\frac{d T}{d \hat{\lambda}_{i}} d \hat{\lambda}_{i}, \\
& =\bar{\lambda}[1-F(R)]+[1-F(R)] d \lambda_{i}-\bar{\lambda} f(R) \frac{d R}{d \hat{\lambda}_{i}} d \hat{\lambda}_{i} \\
& =\bar{\lambda}[1-F(R)]+[1-F(R)]\left[d \lambda_{i}-\kappa d \hat{\lambda}_{i}\right] .
\end{aligned}
$$

Following the derivations in the conceptual framework (see Appendix C), we can write

$$
\frac{E_{d+1}\left(T_{i}\right)}{E_{d}\left(T_{i}\right)}=1-\frac{\operatorname{var}_{d}\left(T_{i}\right)}{E_{d}\left(T_{i}\right)\left[1-E_{d}\left(T_{i}\right)\right]}
$$

Given the mean-preserving spread in the arrival rates, we have

$$
E_{0}\left(T_{i}\right) \approx \bar{\lambda}[1-F(R)]
$$

We also have

$$
\begin{aligned}
\operatorname{var}_{0}\left(T_{i}\right) & \approx \operatorname{var}_{0}\left([1-F(R)]\left[d \lambda_{i}-\kappa d \hat{\lambda}_{i}\right]\right) \\
& =[1-F(R)]^{2} \operatorname{var}_{0}\left[d \lambda_{i}-\kappa d \hat{\lambda}_{i}\right] \\
& =[1-F(R)]^{2}\left[\operatorname{var}_{0}(d \lambda)+\kappa^{2} \operatorname{var}_{0}(d \hat{\lambda})-2 \kappa \operatorname{cov}_{0}(d \lambda, d \hat{\lambda})\right]
\end{aligned}
$$

where

$$
\begin{aligned}
\operatorname{cov}_{0}(d \lambda, d \hat{\lambda}) & =B_{1} \phi\left(\lambda^{h}\right)^{2}+B_{1}(1-\phi)\left(\lambda^{l}\right)^{2}+(1-B) \phi \lambda^{h} \lambda^{l}+\left(1-B_{1}\right)(1-\phi) \lambda^{h} \lambda^{l}-\bar{\lambda}^{2} \\
& =B_{1} \operatorname{var}_{0}(d \lambda)+\left(1-B_{1}\right)\left[\lambda^{h} \lambda^{l}-\bar{\lambda}^{2}\right] \\
& =\left[2 B_{1}-1\right] \operatorname{var}_{0}(d \lambda) .
\end{aligned}
$$


The last equality follows since $\operatorname{var}_{0}(d \lambda)=\bar{\lambda}^{2}-\lambda^{h} \lambda^{l}$ for $\phi=1 / 2$.

Hence,

$$
\operatorname{var}_{0}\left(T_{i}\right)=[1-F(R)]^{2}\left[1+\kappa^{2}-2 \kappa\left[2 B_{1}-1\right]\right] \operatorname{var}_{0}(d \lambda) .
$$

Small changes in the dispersion leave the expected job finding rate unaffected to a first-order, but do increase the variance in job finding rates. However, the increase in the dispersion is scaled and has a smaller impact on the variance in job finding rates, the higher $B_{1}$. The first part of the Proposition immediately follows.

Second, we consider the introduction of geometric depreciation of the true and perceived arrival rates,

$$
\begin{aligned}
& \lambda_{d+1}=(1-\theta) \lambda_{d}, \\
& \hat{\lambda}_{d+1}=\left(1-B_{\theta} \theta\right) \hat{\lambda}_{d} .
\end{aligned}
$$

We can write,

$$
\begin{gathered}
\frac{T_{d+1}}{T_{d}}=(1-\theta) \frac{1-F\left(R_{d+1}\right)}{1-F\left(R_{d}\right)} \\
\frac{d\left[\frac{T_{d+1}}{T_{d}}\right]}{d \theta}=-\frac{1-F\left(R_{d+1}\right)}{1-F\left(R_{d}\right)}+(1-\theta) \frac{d\left[\frac{1-F\left(R_{d+1}\right)}{1-F\left(R_{d}\right)}\right]}{d \theta}
\end{gathered}
$$

Unpacking the last term, we find

$$
\begin{aligned}
& \frac{d\left[\frac{1-F\left(R_{d+1}\right)}{1-F\left(R_{d}\right)}\right]}{d \theta}=\frac{f\left(R_{d}\right)\left[1-F\left(R_{d+1}\right)\right] \frac{d R_{d}}{d \theta}-f\left(R_{d+1}\right)\left[1-F\left(R_{d}\right)\right] \frac{d R_{d+1}}{d \theta}}{\left[1-F\left(R_{d}\right)\right]^{2}}, \\
& =\frac{f\left(R_{d}\right) \frac{1-F\left(R_{d+1}\right)}{1-F\left(R_{d}\right)} \frac{d R_{d}}{d \theta}-f\left(R_{d+1}\right) \frac{d R_{d+1}}{d \theta}}{1-F\left(R_{d}\right)}, \\
& =\frac{f\left(R_{d+1}\right) \frac{d R_{d+1}}{d \theta}}{1-F\left(R_{d}\right)}\left[\frac{f\left(R_{d}\right)}{f\left(R_{d+1}\right)} \frac{1-F\left(R_{d+1}\right)}{1-F\left(R_{d}\right)} \frac{\frac{d R_{d}}{d \theta}}{\frac{d R_{d+1}}{d \theta}}-1\right] \text {. }
\end{aligned}
$$

We now look at the reaction of the respective reservations wage to the depreciation parameter. The reservation wage is characterized by $V\left(R_{d}\right)=U_{d}$ where,

$$
\begin{aligned}
V\left(R_{d}\right) & =\frac{1+\delta}{\delta} u\left(R_{d}\right) \\
U_{d} & =u\left(b_{u}\right)+\frac{1}{1+\delta} \max _{R_{d}}\left\{U_{d+1}+\left(1-B_{\theta} \theta\right)^{d} \lambda_{0} \int_{R_{d}}\left[V(w)-U_{d+1}\right] d F(w)\right\},
\end{aligned}
$$

so substituting the former into the latter for $U_{d}, U_{d+1}$, and $V(w)$ gives,

$$
\frac{1+\delta}{\delta} u\left(R_{d}\right)=u\left(b_{u}\right)+\frac{1}{\delta} \max _{R_{d}}\left\{u\left(R_{d+1}\right)+\left(1-B_{\theta} \theta\right)^{d} \lambda_{0} \int_{R_{d}}\left[u(w)-u\left(R_{d+1}\right)\right] d F(w)\right\} .
$$


Total differentiation yields,

$$
\begin{aligned}
\frac{1+\delta}{\delta} u^{\prime}\left(R_{d}\right) d R_{d}= & -\frac{1}{\delta} d B_{\theta}\left(1-B_{\theta} \theta\right)^{d-1} \lambda_{0} \int_{R_{d}}\left[u(w)-u\left(R_{d+1}\right)\right] d F(w) d \theta \ldots \\
& \ldots+\frac{1}{\delta} u^{\prime}\left(R_{d+1}\right) \frac{d R_{d+1}}{d \theta} d \theta-\frac{1}{\delta}\left(1-B_{\theta} \theta\right)^{t} \lambda_{0} u^{\prime}\left(R_{d+1}\right) \frac{d R_{d+1}}{d \theta} d \theta
\end{aligned}
$$

Hence, we find

$$
\frac{d R_{d}}{d \theta}=\frac{1}{1+\delta}\left\{-d \frac{B_{\theta}}{1-B_{\theta} \theta}\left(\frac{1-B_{\theta} \theta}{1-\theta}\right)^{d} T_{d} E\left[\frac{u(w)-u\left(R_{d+1}\right)}{u^{\prime}\left(R_{d}\right)} \mid w>R_{d}\right]+\frac{u^{\prime}\left(R_{d+1}\right)}{u^{\prime}\left(R_{d}\right)}\left(1-\hat{\lambda}_{d}\right) \frac{d R_{d+1}}{d \theta}\right\}
$$

and, then by iterating, we get

$$
\frac{d R_{d}}{d \theta}=-\frac{1}{1+\delta} \frac{B_{\theta}}{1-B_{\theta} \theta} \sum_{s=d}^{\infty}\left\{\left(\frac{\prod_{k=d}^{s}\left[1-\hat{\lambda}_{k}\right]}{1-\hat{\lambda}_{s}}\right) \frac{u^{\prime}\left(R_{s+1}\right)}{u^{\prime}\left(R_{d}\right)} s\left(\frac{1-B_{\theta} \theta}{1-\theta}\right)^{s} T_{s} E\left[\frac{u(w)-u\left(R_{s+1}\right)}{u^{\prime}\left(R_{s}\right)} \mid w>R_{s}\right]\right\} .
$$

Starting from $\theta \approx 0$, the reservation wage, arrival rate, and job finding rate are approximate constant and the perceived arrival rate equals the actual arrival rate. Denoting by $R$ and $T=\lambda[1-F(R)]$ the reservation wage and the job finding for the stationary type, where we have dropped the subindex 0 in the notation, we can write

$$
\left.\frac{d R_{d+1}}{d \theta}\right|_{\theta=0}=-\frac{1}{1+\delta} B_{\theta} T E\left[\frac{u(w)-u(R)}{u^{\prime}(R)} \mid w>R\right] \sum_{s=d+1}^{\infty}\left\{(1-\lambda)^{s-d-1} s\right\},
$$

and thus

$$
\begin{aligned}
\frac{\frac{d R_{d}}{d \theta}}{\left.\frac{d R_{d+1}}{d \theta}\right|_{\theta=0}} & =\frac{\sum_{s=d-}^{\infty}(1-\lambda)^{s-d} s}{\sum_{s=d+1}^{\infty}(1-\lambda)^{s-d-1} s}=\frac{d+(1-\lambda) \sum_{s=d+1}^{\infty}(1-\lambda)^{s-d-1} s}{\sum_{s=d+1}^{\infty}(1-\lambda)^{s-d-1} s} \\
& =\frac{d+(1-\lambda)\left[\frac{d+1}{\lambda}+\frac{1-\lambda}{\lambda^{2}}\right]}{\frac{d+1}{\lambda}+\frac{1-\lambda}{\lambda^{2}}}<1
\end{aligned}
$$

which proves that the reservation wage responds more at longer durations. The last equality above 
follows from expanding the power series as follows:

$$
\begin{aligned}
\sum_{s=d+1}^{\infty}(1-\lambda)^{s-d-1} s & =d+1+(1-\lambda)(d+2)+(1-\lambda)^{2}(d+3)+(1-\lambda)^{3}(d+4)+\ldots \\
& =(d+1)\left(1+(1-\lambda)+(1-\lambda)^{2}+(1-\lambda)^{3}+\ldots\right)+(1-\lambda)+2(1-\lambda)^{2}+\ldots \\
& =\frac{d+1}{\lambda}+(1-\lambda)\left(1+(1-\lambda)+(1-\lambda)^{2}+(1-\lambda)^{3}+\ldots\right)+(1-\lambda)^{2}+2(1-\lambda)^{3}+\ldots \\
& =\frac{d+1}{\lambda}+\frac{1-\lambda}{\lambda}+(1-\lambda)^{2}\left(1+(1-\lambda)+(1-\lambda)^{3}+\ldots\right)+(1-\lambda)^{3}+2(1-\lambda)^{4}+\ldots \\
& =\frac{d+1}{\lambda}+\frac{1-\lambda}{\lambda}+\frac{(1-\lambda)^{2}}{\lambda}+\frac{(1-\lambda)^{3}}{\lambda}+\frac{(1-\lambda)^{4}}{\lambda}+\ldots \\
& =\frac{d+1}{\lambda}+\frac{1-\lambda}{\lambda}\left(1+(1-\lambda)+(1-\lambda)^{2}+(1-\lambda)^{3}+\ldots\right) \\
& =\frac{d+1}{\lambda}+\frac{1-\lambda}{\lambda^{2}}
\end{aligned}
$$

Hence, putting things together and starting from $\theta \approx 0$, we have

$$
\begin{aligned}
\left.\frac{d\left[\frac{T_{d+1}}{T_{d}}\right]}{d \theta}\right|_{\theta=0}= & -1+\frac{\left.f(R) \frac{d R_{d+1}}{d \theta}\right|_{\theta=0}}{1-F(R)}\left[\frac{\frac{d R_{d}}{d \theta}}{\left.\left.\frac{d R_{d+1}}{d \theta}\right|_{\theta=0}-1\right],}\right. \\
= & -1+\frac{f(R)}{1-F(R)} \frac{1}{1+\delta} B_{\theta} T E\left[\frac{u(w)-u(R)}{u^{\prime}(R)} \mid w>R\right]\left\{\frac{d+1}{\lambda}+\frac{1-\lambda}{\lambda^{2}}\right\} \ldots \\
& \ldots\left[1-\frac{d+(1-\lambda)\left[\frac{d+1}{\lambda}+\frac{1-\lambda}{\lambda^{2}}\right]}{\frac{d+1}{\lambda}+\frac{1-\lambda}{\lambda^{2}}}\right], \\
= & -1+\frac{f(R)}{1-F(R)}\left[1+\frac{1-\lambda}{\lambda}\right] \frac{1}{1+\delta} B_{\theta} T E\left[\frac{u(w)-u(R)}{u^{\prime}(R)} \mid w>R\right], \\
= & \frac{1}{1+\delta} B_{\theta} E\left[\frac{u(w)-u(R)}{u^{\prime}(R)} \mid w>R\right] f(R)-1, \\
= & B_{\theta} \times \frac{\kappa}{\lambda}-1 .
\end{aligned}
$$

Moreover, since $\frac{d R}{d B_{\theta}}=0$ for $\theta=0$, we also have

$$
\left.\frac{d^{2}\left[\frac{T_{d+1}}{T_{d}}\right]}{d \theta d B_{\theta}}\right|_{\theta=0}=\frac{\kappa}{\lambda}>0 .
$$

This proves the second part of the Proposition. 


\section{F.2 Numerical Analysis}

Table F1 shows the 8 moments that we target in the calibration of our structural model. As in the statistical model, the targeted moments include the actual and perceived job finding rates for the short, medium and long-term unemployed. We additionally target an average job acceptance rate underlying the job finding rates of 0.71 , as estimated by Hall and Mueller [2018] using the KM survey. As we already estimated the true duration dependence in our statistical model using elicited beliefs moments, instead of targeting these again, we directly target a moment capturing the depreciation in job finding, i.e., the average of the ratio of true job finding when long-term vs. short-term unemployed within a spell (i.e., $E_{7+}\left(T_{i, d}\right) / E_{06}\left(T_{i, d}\right)$ for a given spell). We simulate this moment using the baseline estimation of our statistical model, obtaining a value of .895. We also gauge the robustness of our results to the rate of depreciation and recalibrate the model targeting a ratio .75 , which is below any estimate we obtain in the statistical model (excluding the specification in which we do not allow for heterogeneity). We set the perceived duration dependence $B_{\theta}$ equal to 0 in both specifications.

Table F2 Panel A shows the set parameter values. We set the separation rate at 0.02 per month, corresponding the average separation rate in the SCE. We set arrival rate of job offers for employed workers at 0.15, in line with recent evidence in Faberman et al. [2017] also using the SCE. We assume that wages are log-normally distributed, with a standard deviation of the logged distribution of $\sigma_{w}=0.24$ as estimated by Hall and Mueller [2018] with the KM survey data. We normalize the median of the wage offer distribution to 1 . We also assume an annual discount factor 0.996 and CRRA preferences with relative risk aversion equal to 2. Panel B of Table F2 shows the remaining 7 parameters of our model $\left\{B_{0}, B_{1}, \lambda_{l}, \lambda_{h}, \phi, \theta, b_{u}\right\}$ that are estimated by targeting the vector of 8 moments. We find that the uniform bias parameter $B_{0}$ is negative, but the average bias is still positive. This is due to the share of low types perceiving themselves as high, who remain unemployed for the longest. The probability that high (low) types perceive themselves as high (low) types equals $B_{1}=0.84$ in the baseline specification. As we assume that no duration dependence is perceived $\left(B_{\theta}=0\right)$, the corresponding cross-sectional bias becomes smaller in the model where we target high true duration dependence $\left(B_{1}=0.89\right) .{ }^{61}$ The estimated parameters minimize the sum of squared differences between data moments and simulated moments from the model. Table F1 shows that we closely match our targeted moments. We also obtain plausible values for standard labor market statistics; the elasticity of the unemployment duration with respect to unemployment benefits is 0.62 , which is within the range of estimates in the literature (see Schmieder and von Wachter [2016]). The elasticity of the reservation wage equals .44, which corresponds to estimates in Feldstein and Poterba [1984] and Fishe [1982]. The elasticity of the equilibrium wage equals .04, which is arguably low, but still higher than recent estimates in Jaeger et al. [2020]. The monthly rate of job-to-job transitions equals 0.024 , which is within the range considered by Hornstein et al. [2011]. ${ }^{62}$

\footnotetext{
${ }^{61}$ We have also extended our model with a type-specific bias in the perceived arrival rates. This relaxes the restrictions of our stylized model that on average the low-type job seekers are more optimistic than the high-type job seekers. However, the estimated type-specific biases are very close, suggesting that this restriction is not binding.

${ }^{62}$ We also performed sensitivity checks when changing incidental parameters, including the arrival rate of job offers for the employed, the dispersion of the wage distribution and the level of risk aversion, which all change the relative value of unemployment to employment. For the baseline model, it is mainly the parameter $b_{u}$ affecting the flow value of unemployment that adjusts, while the other parameter estimates remain very similar. The other parameter estimates
} 
Table F3 shows the impact of eliminating the biases in beliefs on the average unemployment durations and the share of long-term unemployed. The intermediate columns consider the elimination of one bias at a time, the last column the elimination of all biases simultaneously. From Panel A, which shows the results for the baseline model, we see that eliminating all biases lowers the average unemployment duration, but this effect is numerically very small. Despite the small impact on the overall duration, the impact on the share of LT unemployed is substantial, which decreases by 8.2 percent (2.4 percentage points) when all biases are eliminated. Panel B shows the results for the model calibrated with high depreciation rate. The effect on the average unemployment duration is somewhat larger, at around 0.15 months. However, eliminating the biases reduces the share of LT unemployed by 2.6 percentage points, which is slightly higher than in the baseline model. Overall, the model's prediction that biased beliefs contribute substantially to the high incidence of LT unemployment is robust to the relative importance of heterogeneity vs. depreciation in the arrival rates. ${ }^{63}$

become more sensitive in the model with high depreciation.

${ }^{63}$ We note that these counterfactual results remain very similar when changing incidental parameters (i.e., wage offer distribution, arrival rates, risk aversion) in the baseline calibration, but are somewhat sensitive in the calibration with high depreciation. 
Table F1: Targeted Data Moments and Corresponding Moments in Structural Model

\begin{tabular}{lccc}
\hline Moments & Data & $\begin{array}{c}\text { Baseline } \\
\text { Model }\end{array}$ & $\begin{array}{c}\text { High Depreciation } \\
\text { Model }\end{array}$ \\
\hline Mean of 3-Month Job Finding Rates: & & & \\
$\ldots$ at 0-3 Months of Unemployment & 0.642 & 0.642 & 0.640 \\
$\ldots$ at 4-6 Months of Unemployment & 0.472 & 0.470 & 0.474 \\
$\ldots$ at 7 Months of Unemployment or more & 0.256 & 0.259 & 0.255 \\
Mean of 3-Month Elicitations: & & & \\
$\ldots$ at 0-3 Months of Unemployment & 0.616 & 0.614 & 0.615 \\
$\ldots$ at 4-6 Months of Unemployment & 0.529 & 0.537 & 0.535 \\
$\ldots$ at 7 Months of Unemployment or more & 0.409 & 0.404 & 0.405 \\
Acceptance Rate: & 0.710 & 0.716 & 0.715 \\
True Duration Dependence: & & & \\
$\ldots$ Baseline Depreciation & 0.895 & 0.895 & - \\
$\ldots$ High Depreciation & 0.75 & - & 0.751 \\
\hline
\end{tabular}


Table F2: Calibrated Parameters

\begin{tabular}{lccc}
\hline Parameters & Symbol & $\begin{array}{c}\text { Baseline } \\
\text { Model }\end{array}$ & $\begin{array}{c}\text { High Depreciation } \\
\text { Model }\end{array}$ \\
\hline A. Set Parameters & & & \\
Median of wage offer distribution & $\mu_{w}$ & 1 & 1 \\
Std. dev. of logged wage offer distribution & $\sigma_{w}$ & 0.24 & 0.24 \\
Exogeneous job loss probability & $\sigma$ & 0.02 & 0.02 \\
Arrival rate when employed & $\lambda^{e}$ & 0.15 & 0.15 \\
Discount rate & $\delta$ & 0.004 & 0.004 \\
Coefficient of relative risk aversion & $\gamma$ & 2 & 2 \\
Longitudinal bias & $B_{\theta}$ & 0 & 0 \\
B. Estimated Parameters & & & \\
Uniform bias & $B_{0}$ & -0.014 & -0.050 \\
Cross-sectional bias & $B_{1}$ & 0.84 & 0.89 \\
Low-type arrival rate & $\lambda_{l}$ & 0.12 & 0.16 \\
High-type arrival rate & $\lambda_{h}$ & 0.63 & 0.67 \\
Share of high-types & $\phi$ & 0.78 & 0.74 \\
Depreciation in arrival rate & $\theta$ & 0.019 & 0.046 \\
Unemployed consumption & $b_{u}$ & 0.52 & 0.52 \\
\hline
\end{tabular}

Table F3: Comparative Statics in Structural Model

\begin{tabular}{lccccc}
\hline & & \multicolumn{4}{c}{ Eliminating Biases } \\
\cline { 3 - 6 } & Calibrated & & & & $B_{0}=0$ \\
& Model & $B_{0}=0$ & $B_{1}=1$ & $B_{\theta}=1$ & $B_{1}=1$ \\
& & & & & $B_{\theta}=1$ \\
\hline A. Baseline Model & 4.01 & 4.07 & 4.01 & 3.90 & 3.95 \\
Unemployment duration & 0.295 & 0.297 & 0.275 & 0.289 & 0.271 \\
Share of LT unemployed & & & & & \\
B. High Depreciation Model & & & & & \\
Average unemployment duration & 3.99 & 4.15 & 3.99 & 3.75 & 3.85 \\
Share of LT unemployed & 0.294 & 0.299 & 0.278 & 0.278 & 0.267 \\
\hline
\end{tabular}


Figure F1: Comparative Statics: True vs. Perceived Changes in Arrival Rates

\section{A. Impact of Arrival Rates on Duration}

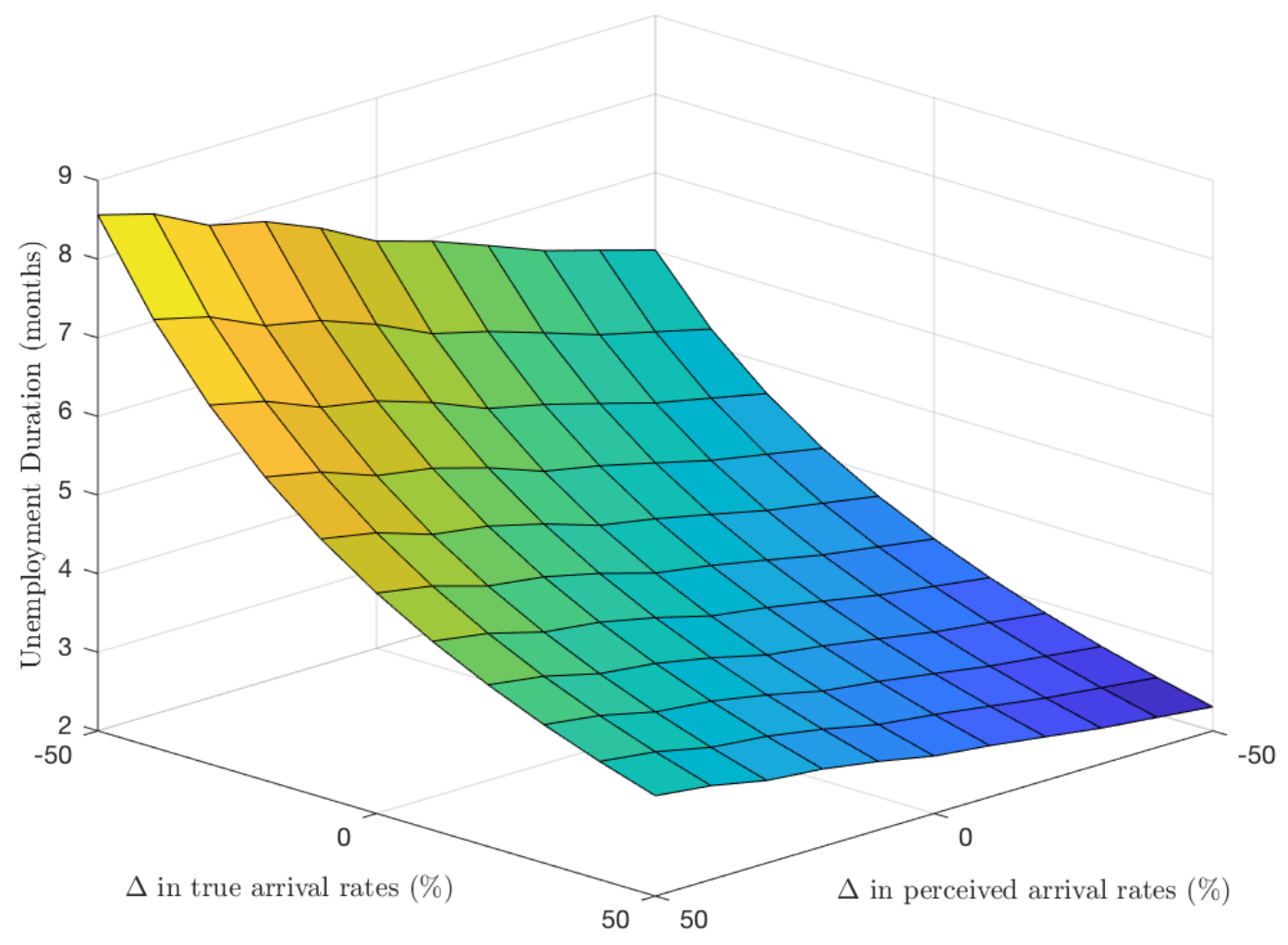

B. Impact of Heterogeneity on LT Incidence

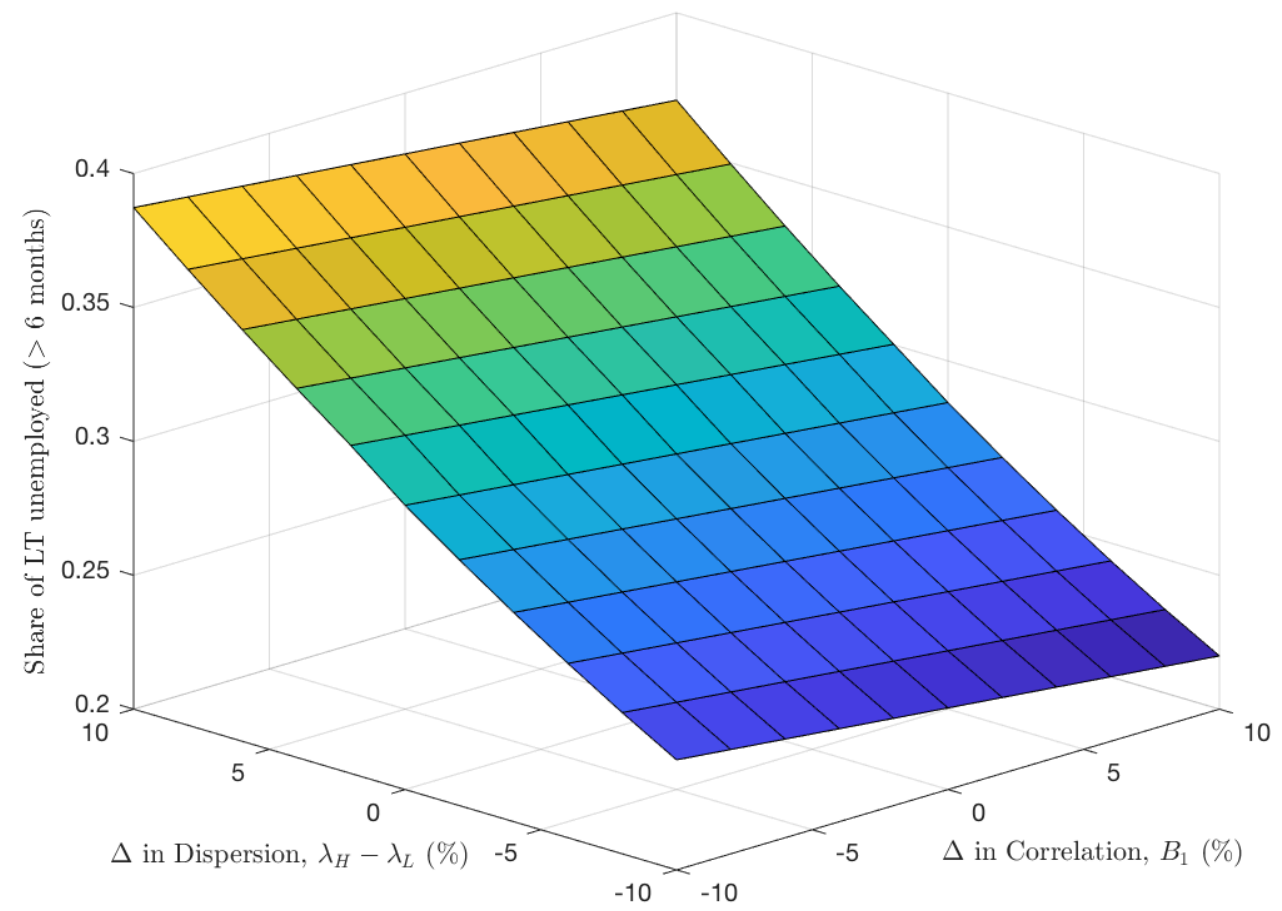


Figure F1: Comparative Statics: True vs. Perceived Changes in Arrival Rates (continued)

\section{Impact of Depreciation on LT Incidence}

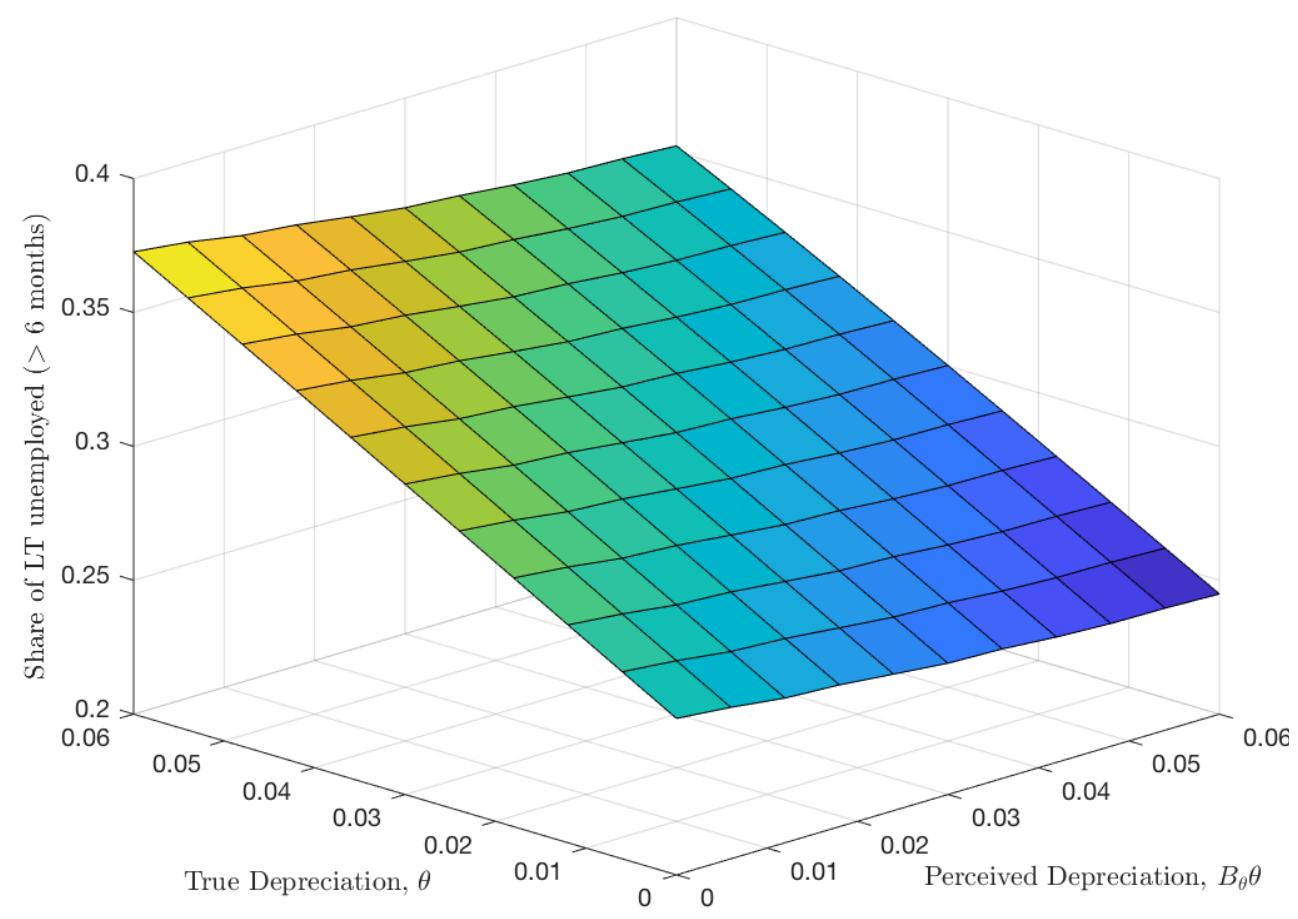

Notes: Panel A plots the average unemployment duration as a function of actual and perceived arrival rates, changing them in the same way for all types relative to the baseline model. Panel B plots the share of long-term unemployment (i.e., the share of unemployed workers who are unemployed for longer than 6 months) as a function of the spread of true arrival rates (while preserving the mean arrival rate) and the correlation between the perceived and true arrival rates. Panel $\mathrm{C}$ plots the share of long-term unemployment as a function of the true and perceived depreciation rate. The output in the last two panels corresponds to results (i) and (ii) in Proposition 1. 